NASA Technical Memorandum 105636

AIAA-92-3516

Corrected Copy

\title{
Development and Flight History of SERT II Spacecraft
}

William R. Kerslake

Sverdrup Technology, Inc.

Lewis Research Center Group

Brook Park, Ohio

and

Louis R. Ignaczak

National Aeronautics and Space Administration

Lewis Research Center

Cleveland, Ohio

Prepared for the

28th Joint Propulsion Conference and Exhibit cosponsored by AIAA, SAE, ASME, and ASEE

Nashville, Tennessee, July 6-8, 1992 
Trade names or manufacturers' names are used in this report for identification only. This usage does not constitute an official endorsement, either expressed or implied, by the National Aeronautics and Space Administration. 


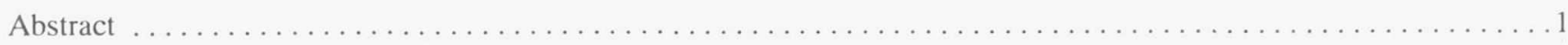

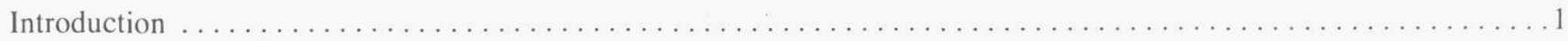

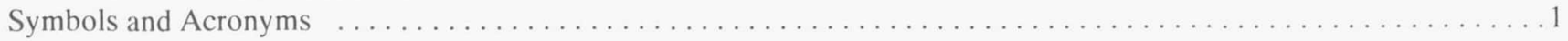

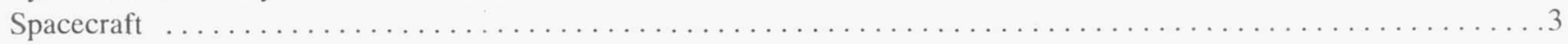

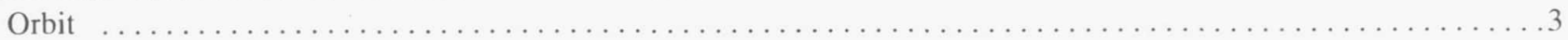

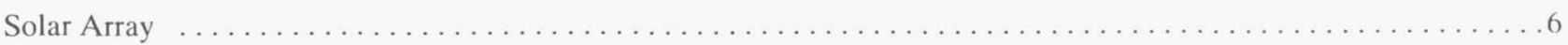

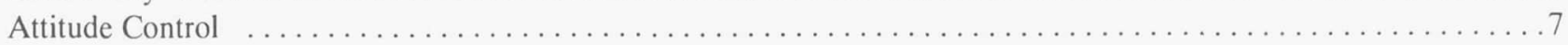

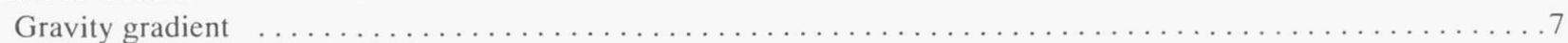

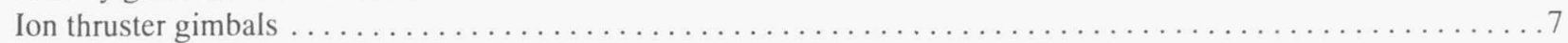

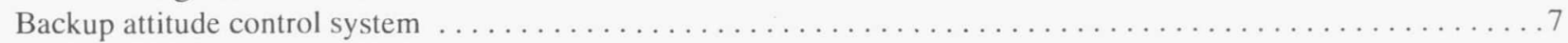

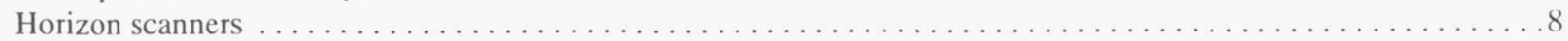

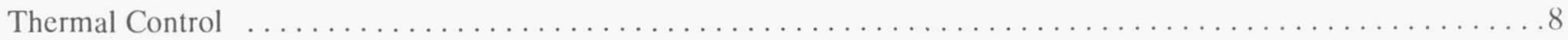

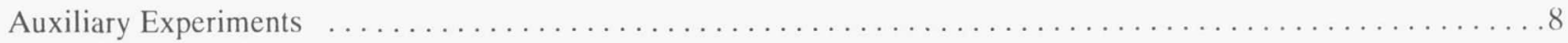

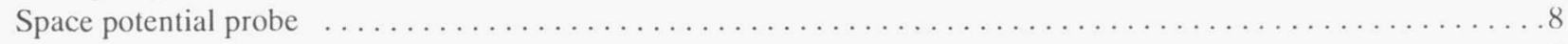

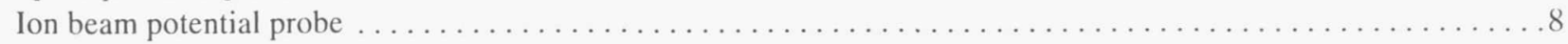

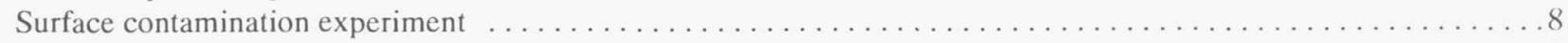

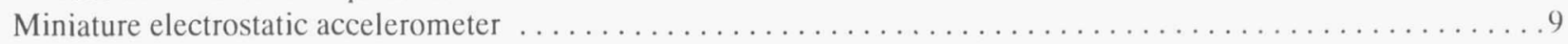

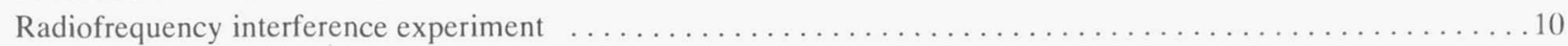

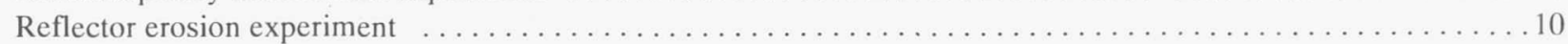

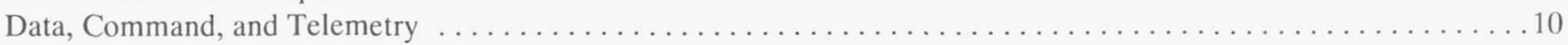

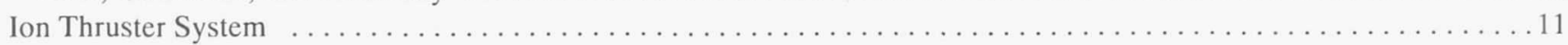

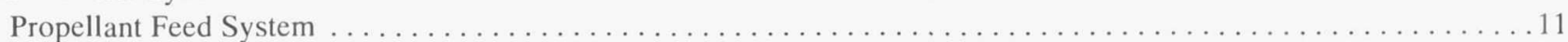

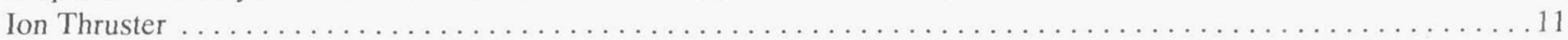

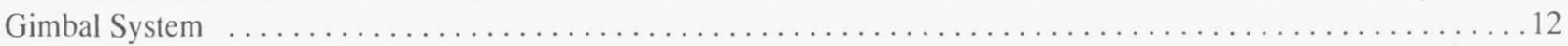

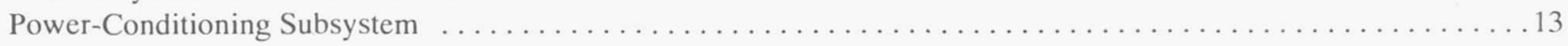

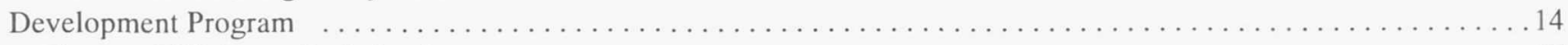

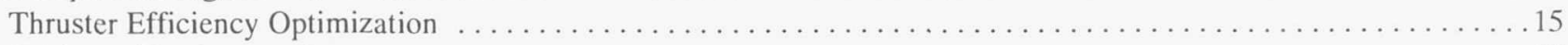

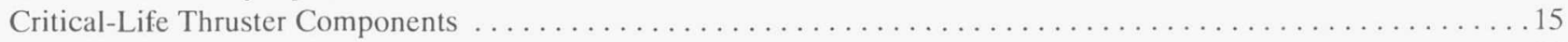

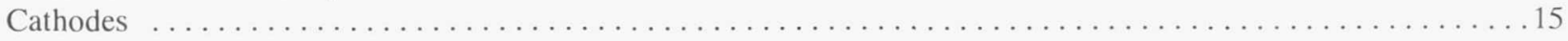

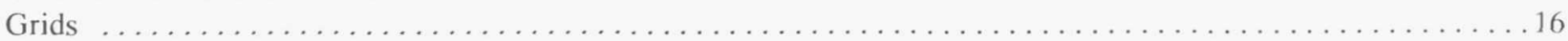

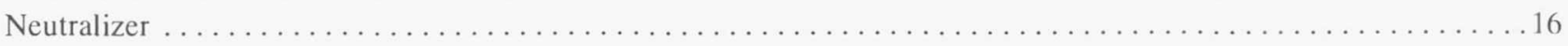

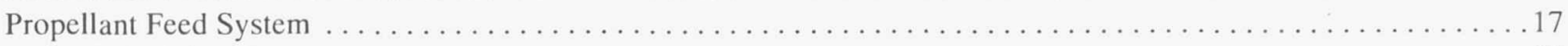

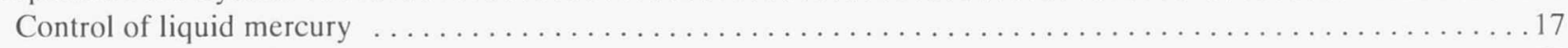

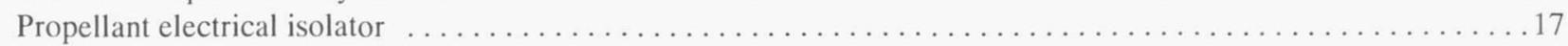

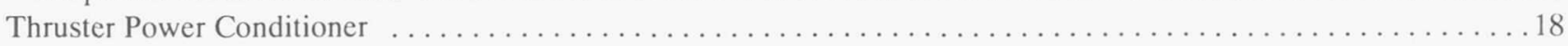

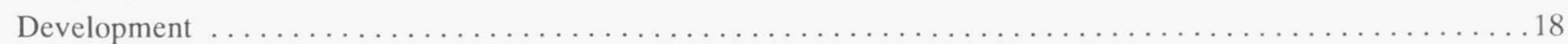

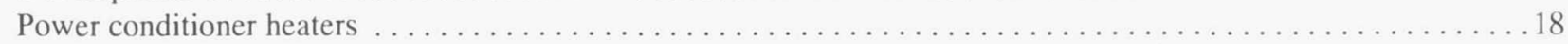

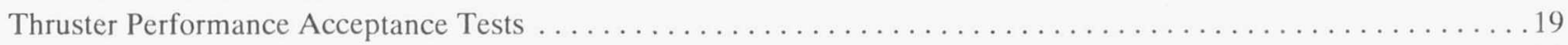

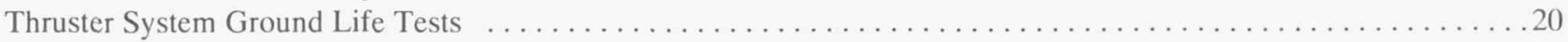

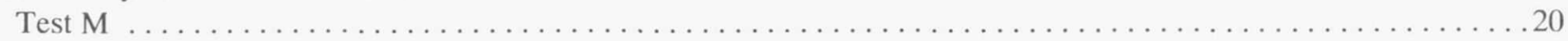

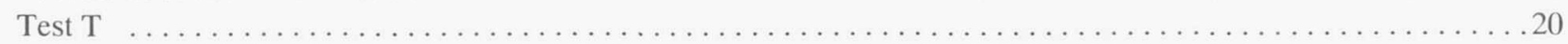

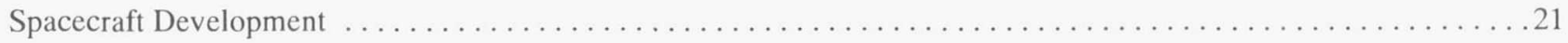

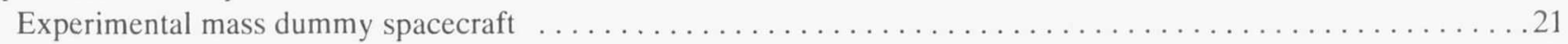

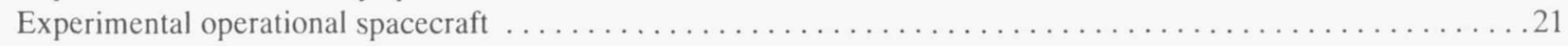

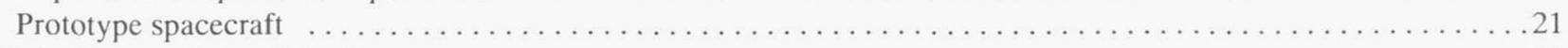

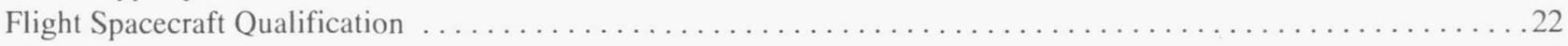

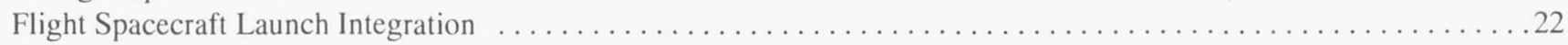

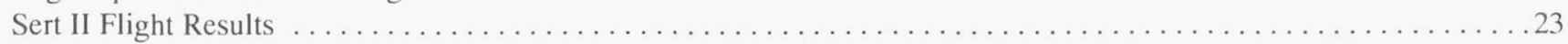

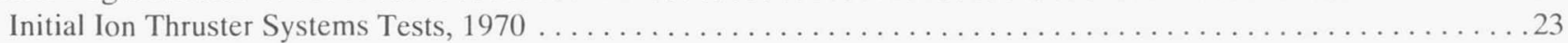

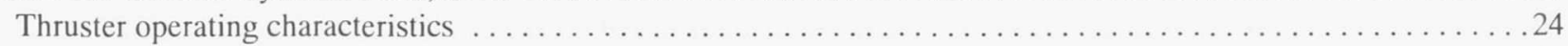

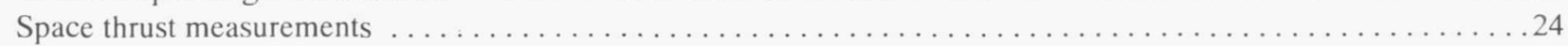

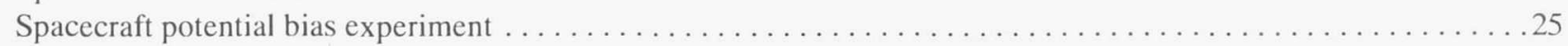

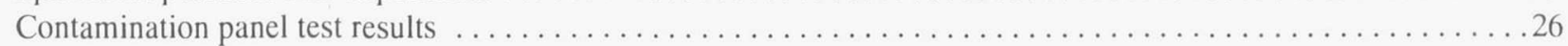

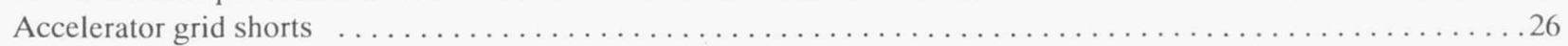




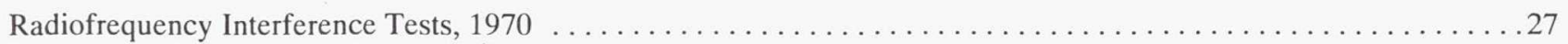

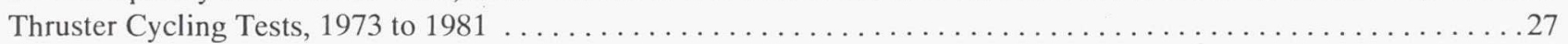

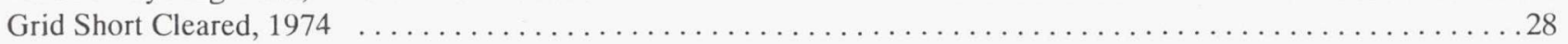

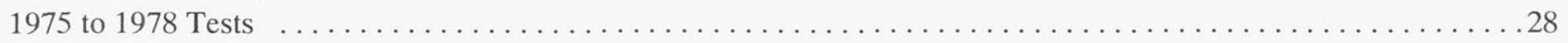

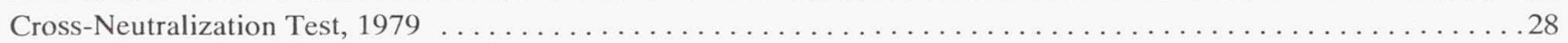

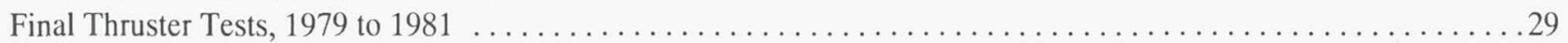

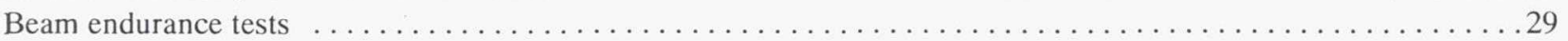

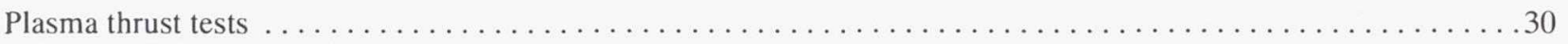

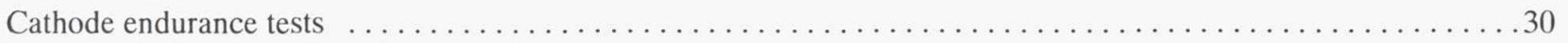

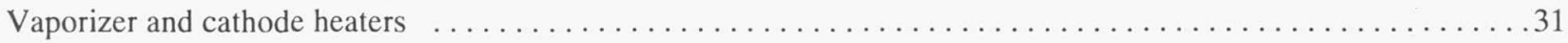

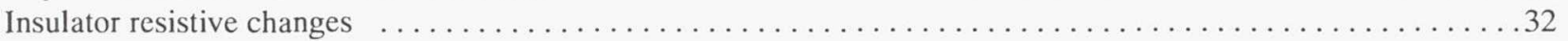

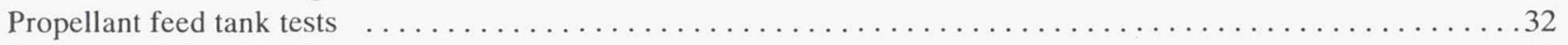

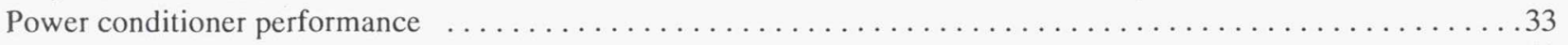

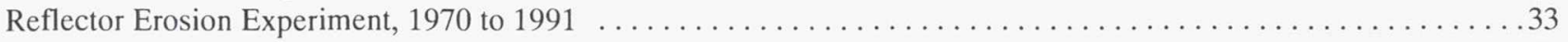

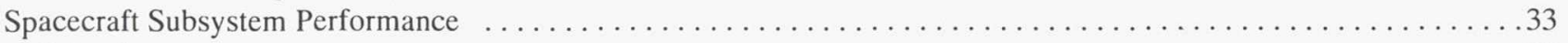

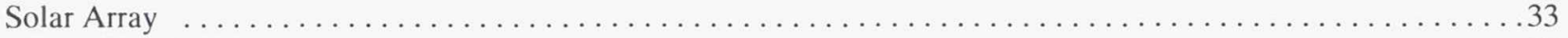

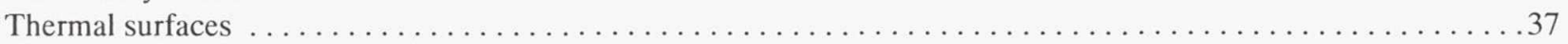

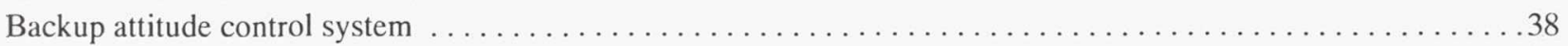

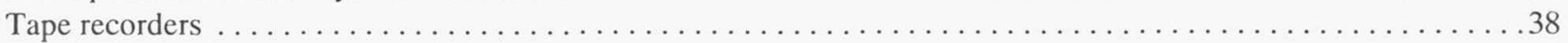

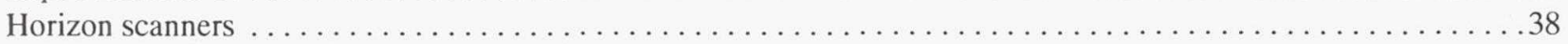

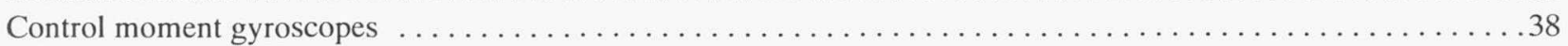

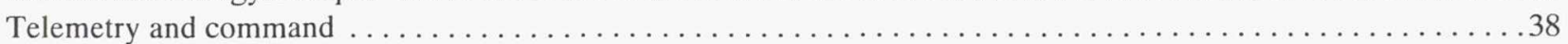

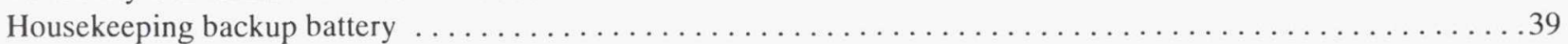

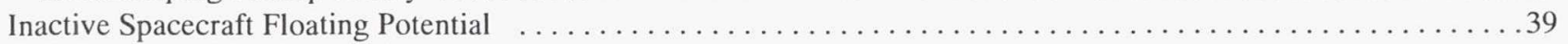

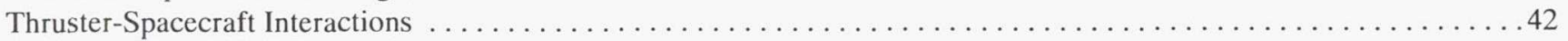

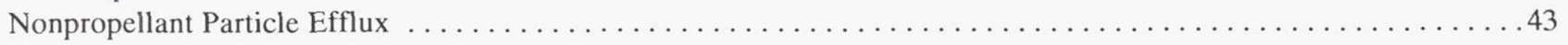

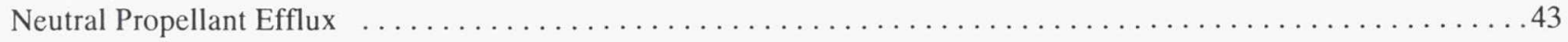

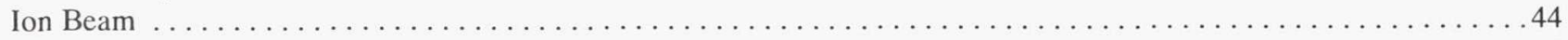

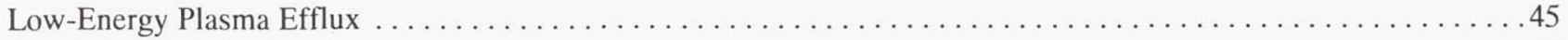

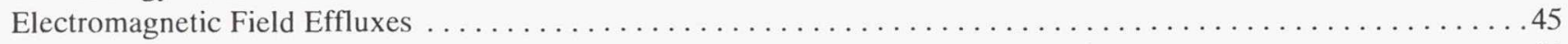

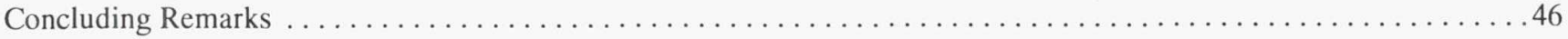

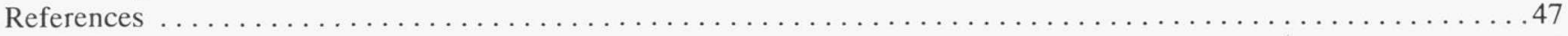

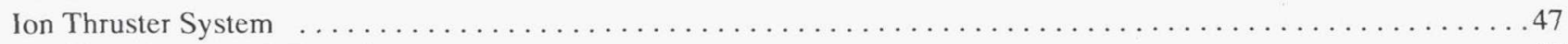

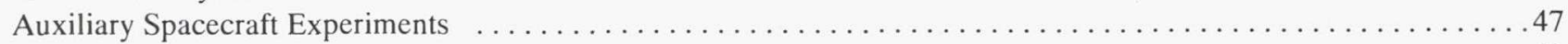

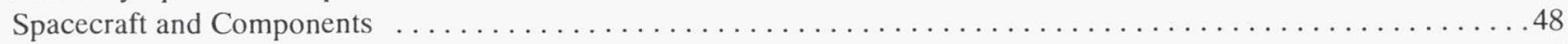

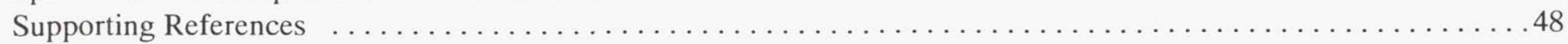




\author{
William R. Kerslake and Louis R. Ignaczak \\ National Aeronautics and Space Administration \\ Lewis Research Center \\ Cleveland, $\mathrm{OH}$
}

\begin{abstract}
$\underline{\text { Abstract }}$
A 25-year historical review of the Space Electric Rocket Test II (SERT II) mission is presented. The Agena launch vehicle; the SERT II spacecraft; and mission-peculiar spacecraft hardware, including two ion thruster systems, are described. The 3 1/2-year development period, from 1966 to 1970 , that was needed to design, fabricate, and qualify the ion thruster system and the supporting spacecraft components, is documented. Major testing of two ion thruster systems and related auxiliary experiments that were conducted in space after the February 3, 1970, launch are reviewed. Extended ion thruster restarts from 1973 to 1981 are reported, in addition to cross-neutralization tests. Tests of a reflector erosion experiment were continued in 1989 to 1991. The continuing performance of spacecraft subsystems, including the solar arrays, over the 1970-1991 period is summarized. Finally, the knowledge of thrusterspacecraft interactions learned from SERT II is listed.
\end{abstract}

\section{Introduction}

The SERT II mission was approved in 1966, and after a $31 / 2$-year development and qualifying period the solarpowered satellite was launched into a $1000-\mathrm{km}$-high polar orbit in 1970. SERT I, which had been launched in 1964, proved that broad-beam ion thrusters would operate and produce thrust in space. The main objective of SERT II was to demonstrate that an ion thruster system could operate for long periods (6 months) in space. Other objectives were to directly measure ion thruster thrust in space and to demonstrate the lack of harmful interactions between the ion thruster system and the spacecraft. Two identical SERT II ion thruster systems (each with $28-\mathrm{mN}$ thrust, 4200-s specific impulse, and $850-\mathrm{W}$ input power) were tested in 1970 for 5 months and 3 months, respectively, in space. Operation was stopped on each ion thruster when a web erosion fragment of the accelerator grid caused an electrical short.

Because the SERT II spacecraft was still functional, additional tests were performed from 1973 to 1981 to demonstrate ion thruster restart capability. The web fragment was cleared from ion thruster 2 in 1973, and testing was resumed until both ion thruster propellant supplies were exhausted in 1981. Hundreds of restarts were demonstrated before propellant supplies ran out. Two new modes of ion thruster operation were evaluated. First, thrust was measured when only the main discharge (no high extraction volt- age) was operating. Second, an ion thruster beam was neutralized in space from a neutralizer cathode located at a distance of $1 \mathrm{~m}$. Finally, from 1989 to 1991 the spacecraft was turned on to obtain long-duration data on the space erosion of an aluminum mirror surface and on solar array degradation.

The SERT II mission was a NASA Lewis Research Center in-house project. The Thorad-Agena launch vehicle was managed by NASA Lewis personnel. The mission control center was at NASA Lewis, and was staffed by NASA Lewis personnel. The primary experiment managers were the NASA Lewis engineers who had invented and developed the ion thruster system. Over 120 either full or parttime NASA Lewis employees worked during the peak years of the project (1968 to 1970). After launch and for the first year 15 people staffed the control room and analyzed data. During the extended mission years (1971 to 1991) two engineers and several technicians supported spacecraft operations on a part-time basis.

The reference list of this paper contains all papers (to the authors' knowledge) ever written on SERT II and is divided chronologically into four major groups: ion thruster system, references 1 to 21 ; auxiliary spacecraft experiments, references 22 to 30 ; spacecraft and components, references 31 to 51 ; and supporting references, references 52 to 74 . Table I gives a time line of the SERT II mission milestones from August 1966, when NASA Administrator James Webb approved the mission, until the end of spacecraft operations in November 1991. Table II gives the propulsion system performance, and Table III gives the system masses.

This paper describes the SERT II ion thruster and spacecraft systems, the ground development program of these systems before launch, the results of the primary mission to space test an ion thruster system (1970), the secondary mission results of six auxiliary experiments conducted in 1970, the results of the unplanned extended mission tests of 1971 to 1991, and the performance of the spacecraft subsystems during their 21-year (to date) operation.

\section{Symbols and Acronyms}

AGC automatic gain control

BACS backup attitude control system

BOL beginning of life 
TABLE I. - CHRONOLOGICAL LIST OF SERT II MISSION MILESTONES

Year

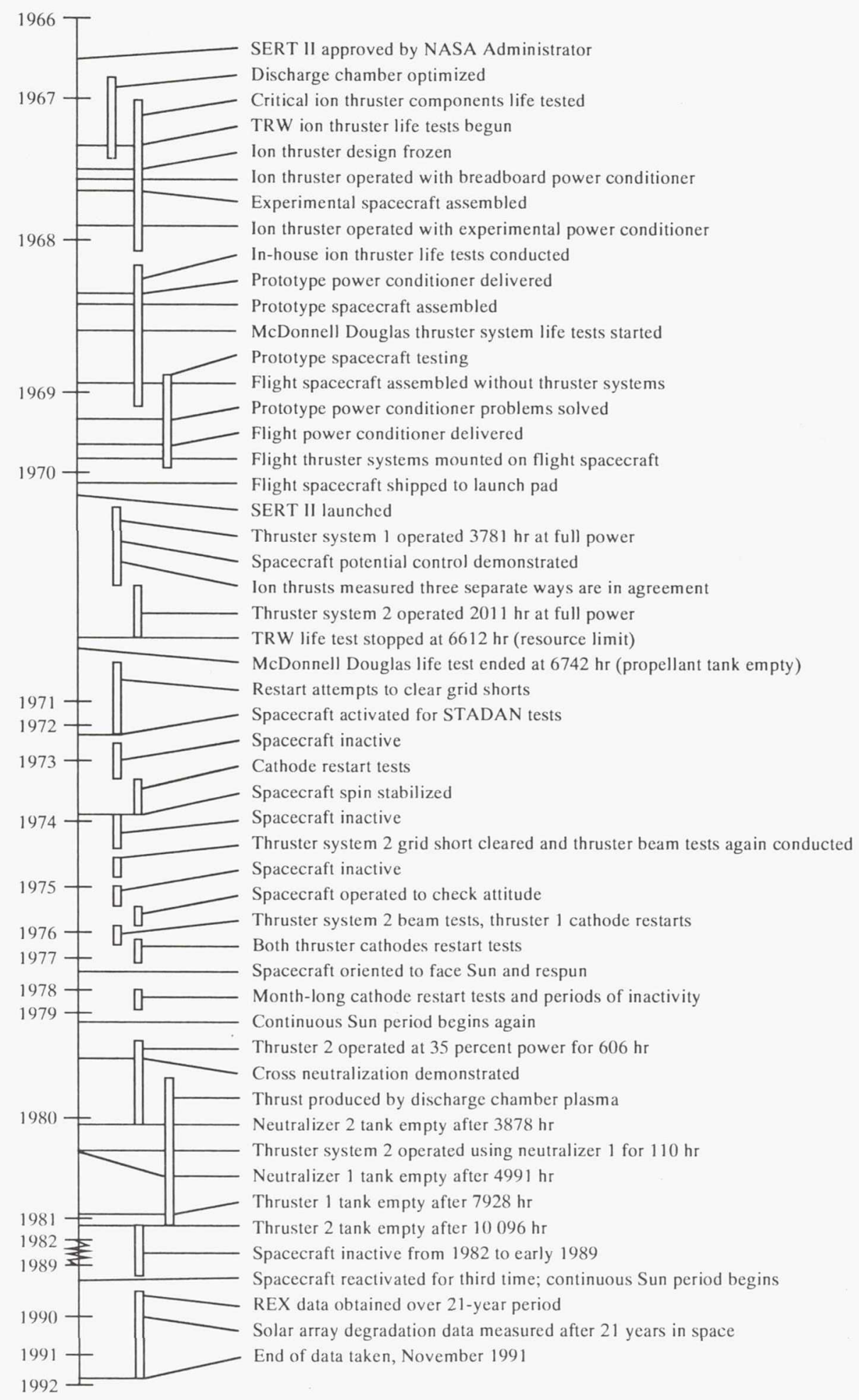


Total power (BOL), w ... . . . . . . . . . . . . . . . . . 1425

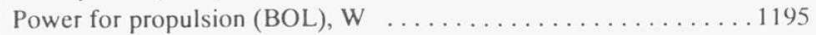

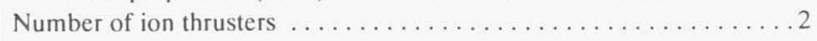

Thrust per thruster $(100$ percent beam $), \mathrm{mN} \ldots \ldots \ldots \ldots \ldots \ldots 28$

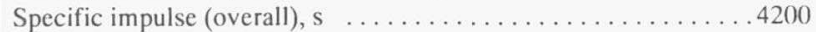

Total propellant flow (with neutralizer), $\mathrm{kg} / \mathrm{s} \ldots \ldots \ldots .9 \times 10^{-7}$

Total propellant utilization, $\eta_{u}$, percent $\ldots \ldots \ldots \ldots \ldots \ldots . \ldots \ldots$

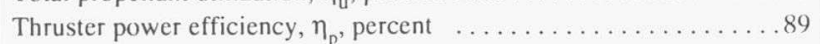

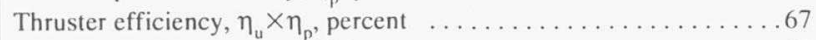

Power conditioner power efficiency, percent $\ldots \ldots \ldots \ldots \ldots \ldots 8$

TABLE III. - SERT II SYSTEM MASSES

\begin{tabular}{|c|c|}
\hline & $\begin{array}{l}\text { Overall } \\
\text { mass, } \\
\text { kg }\end{array}$ \\
\hline Agena launch vehicle (dry) & 740 \\
\hline SERT II spacecraft portion & 282 \\
\hline SERT II spacecraft support unit & 220 \\
\hline Solar array (complete) & 193 \\
\hline Thruster systems (dry) with PCU, two & 59 \\
\hline \multirow[t]{2}{*}{ Total mass in orbit (BOL, wet) } & 1524 \\
\hline & $\begin{array}{l}\text { Ion thruster } \\
\text { system mass, } \\
\text { kg }\end{array}$ \\
\hline Ion thruster & 3.0 \\
\hline Propellant (including neutralizer) & 15.0 \\
\hline Thruster tankage (dry) & 4.3 \\
\hline $\begin{array}{l}\text { Thruster gimbals } \\
\text { (with support structure) }\end{array}$ & 7.7 \\
\hline Power-conditioning unit ${ }^{\mathrm{a}}$ & 14.5 \\
\hline \multirow{2}{*}{$\begin{array}{l}\text { Power-conditioning thermal } \\
\text { control }\end{array}$} & 2.4 \\
\hline & $\begin{array}{l}\text { Specific } \\
\text { mass, } \\
\mathrm{kg} / \mathrm{kW}\end{array}$ \\
\hline Solar array (1425 W BOL) & 135 \\
\hline Thruster (843-W input) & 3.6 \\
\hline Tankage & 5.1 \\
\hline Gimbals & 9.1 \\
\hline $\begin{array}{l}\text { Power-conditioning unit } \\
\text { (952-W input with thermal } \\
\text { control mass) }\end{array}$ & 17.7 \\
\hline
\end{tabular}

Includes $2.0 \mathrm{~kg}$ of nonpropulsion hardwarc.

CMG control-moment gyroscopes (two pairs of two each)

EMI electromagnetic interference

g's one g equals Earth's gravity, $9.807 \mathrm{~m} / \mathrm{s}^{2}$

GSFC Goddard Space Flight Center of NASA

MESA miniature electrostatic accelerometer

PERT program evaluation and rating technique

PCU power conditioner unit

REX reflector erosion experiment

RFI radiofrequency interference
SERT I Space Electric Rocket Test I, launched in 1964

SERT II Space Electric Rocket Test II, launched in 1970

SSU spacecraft support unit

STADAN Satellite Tracking and Data Acquisition Network

$\Theta_{\mathrm{S}} \quad$ angle of Sun line to orbit plane normal, deg

$\Theta_{\mathrm{SA}} \quad$ angle of Sun line to solar array plane normal, $\operatorname{deg}\left(\Theta_{\mathrm{S}}=\Theta_{\mathrm{SA}} \pm 2^{\circ}\right)$ when spacecraft is not spin stabilized)

\section{Spacecraft}

The SERT II spacecraft was launched by a ThoradAgena, which is shown in Figs. 1(a) and (b) on the launch pad and at lift-off. Figure 1(c) shows the maneuvers by the Thorad-Agena that were required to place the spacecraft in the $1000-\mathrm{km}$-high polar orbit. The main bulk of the final spacecraft was an empty Agena rocket that was $1.53 \mathrm{~m}$ in diameter (Fig. 1(d)). On the Agena aft end (up in Fig. 1(d)) the two wings of the main solar array each extended outward for $6 \mathrm{~m}$ and were $1.5 \mathrm{~m}$ wide. Attached to the forward (bottom) end of the Agena was the cylindrical spacecraft support unit. ${ }^{32}$ The spacecraft support unit contained the spacecraft's power conditioning and switching components, telemetry and command system, and attitude control components. Attached to the bottom of the spacecraft support unit was another cylindrical section called the spacecraft. The spacecraft section housed two ion thruster systems and all auxiliary experiments. The overall length from Agena nozzle to ion thruster mounting deck was $7.9 \mathrm{~m}$, and the total mass was $1435 \mathrm{~kg} .{ }^{35}$ A block diagram of the major subsystems is shown in Fig. 1(e).

\section{$\underline{\text { Orbit }}$}

The SERT II spacecraft orbit was $1000 \mathrm{~km}$ high and nearly polar $\left(99.1^{\circ}\right.$ inclination) with a period of $106.2 \mathrm{~min}$. A nonscale representation of the spacecraft and its orbit is shown in Fig. 2. The choice of orbit was influenced by several factors. First, the orbit had to be achieved by using the Thorad-Agena launch vehicle. Second, the solar array had to be in continuous sunlight for at least 6 months. Third, the minimum altitude had to be sufficiently high to avoid excessive aerodynamic drag and torque. Fourth, the maximum altitude had to be sufficiently low that adequate gravity-gradient torques would be obtained for spacecraft stabilization ${ }^{48}$ and that excessive solar array degradation from high-energy protons and electrons would be avoided. Periods of continuous sunlight were achieved from launch (February 1970) to November 1970; from February 1971 to November 1971; from January 1979 to April 1979; from August 1979 to May 1980; from July 1980 to May 1981; from April 1989 to October 1989; from January 1990 to December 1990; and from January 1991 to November 


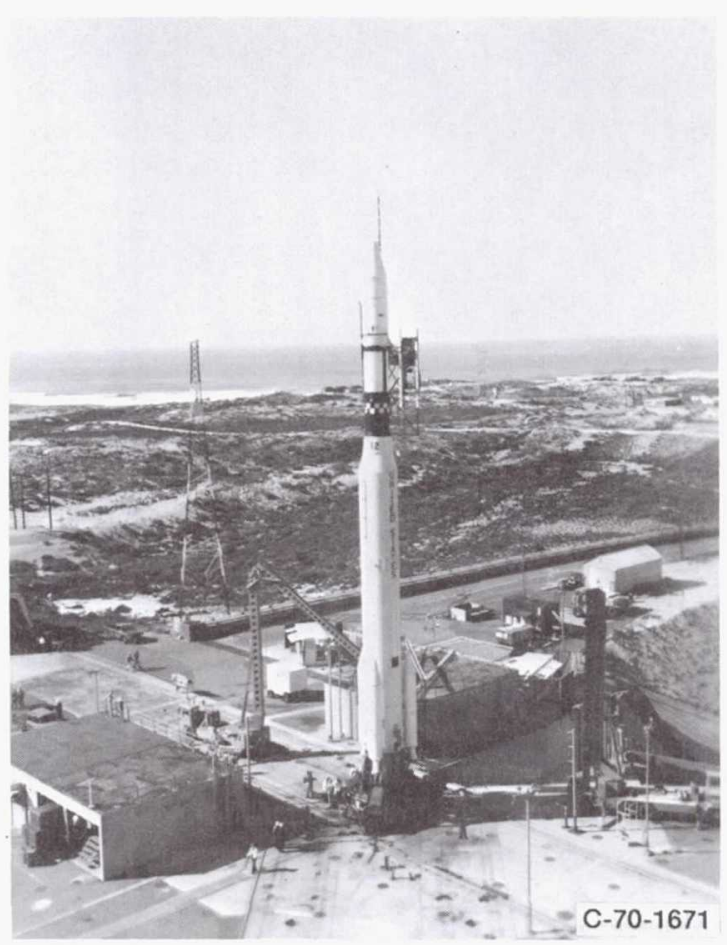

(a) Thorad-Agena launch vehicle on pad.
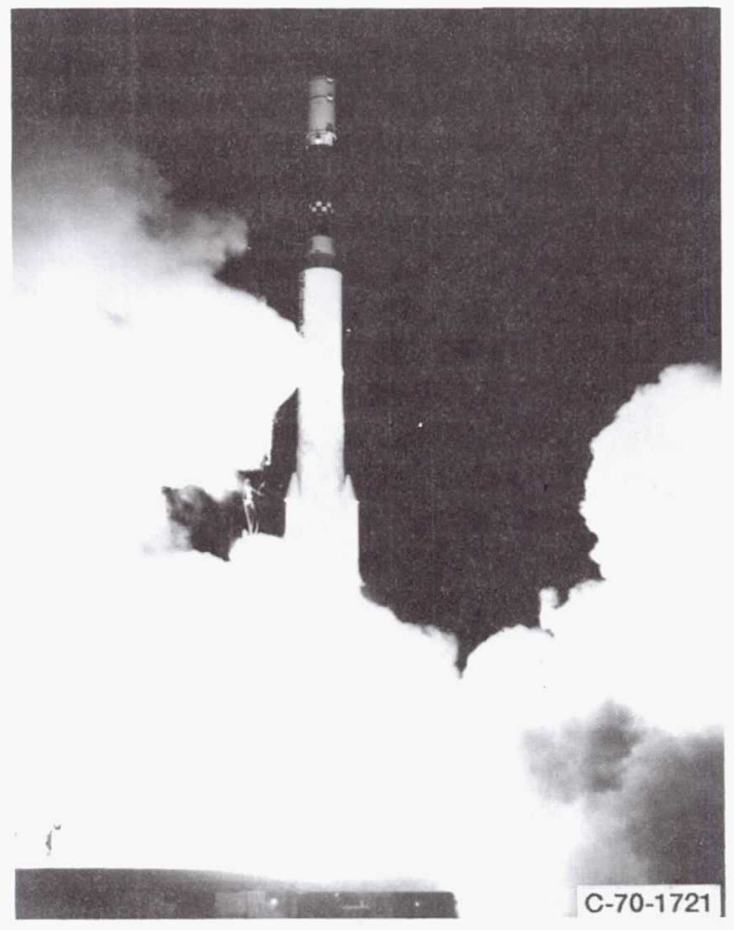

(b) Thorad-Agena launch vehicle at lift-off.

Figure 1.-Space Electric Rocket Test II. 


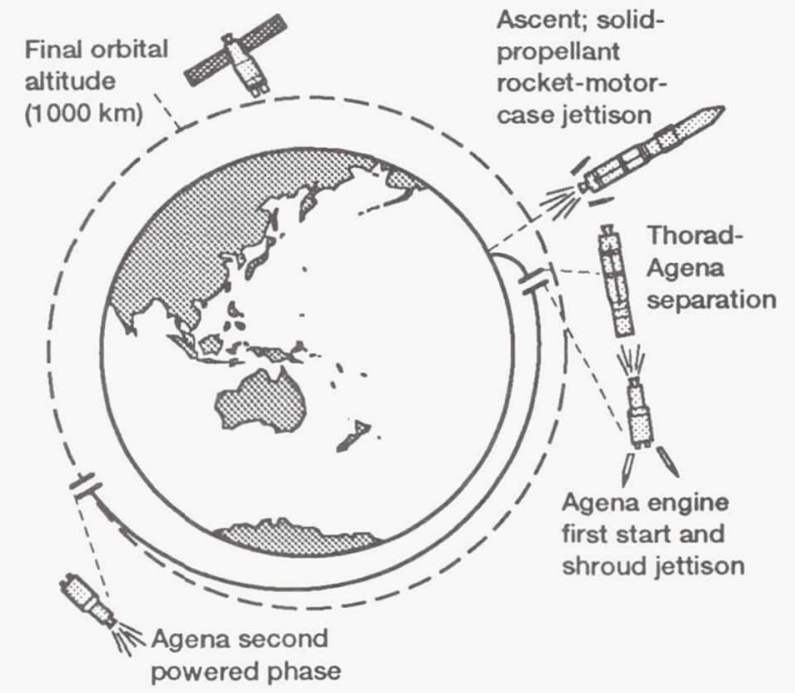

(c) Planned ascent and initial orbit of SERT II.

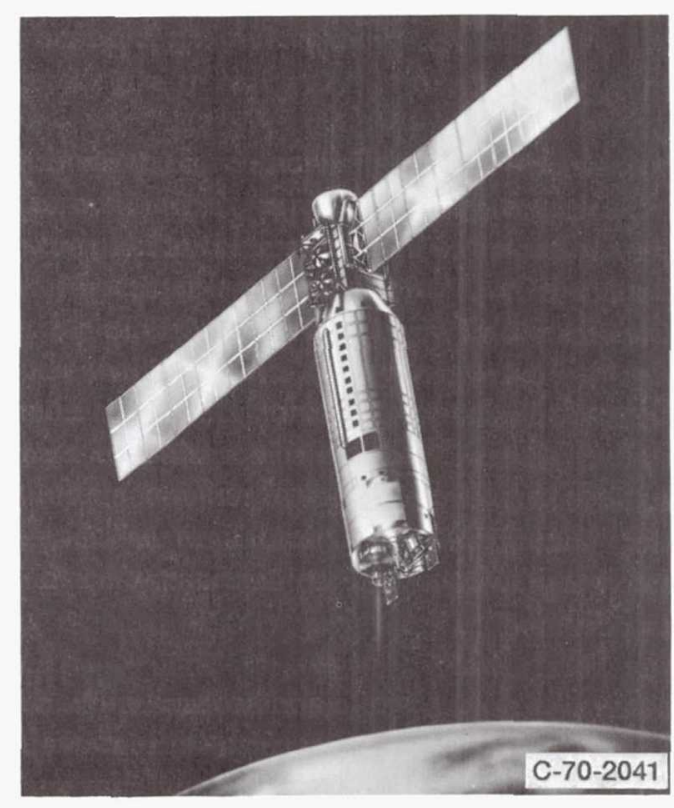

(d) Artist's drawing of SERT II spacecraft in orbit.

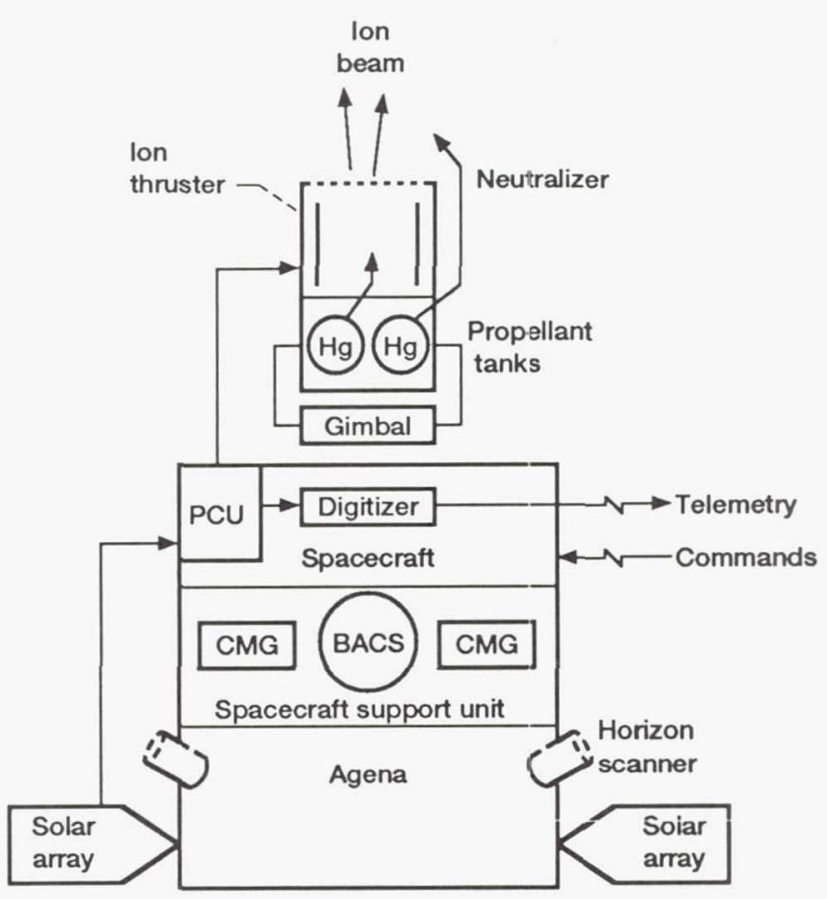

(e) Block diagram of major subsystems.

Figure 1.-Concluded. 


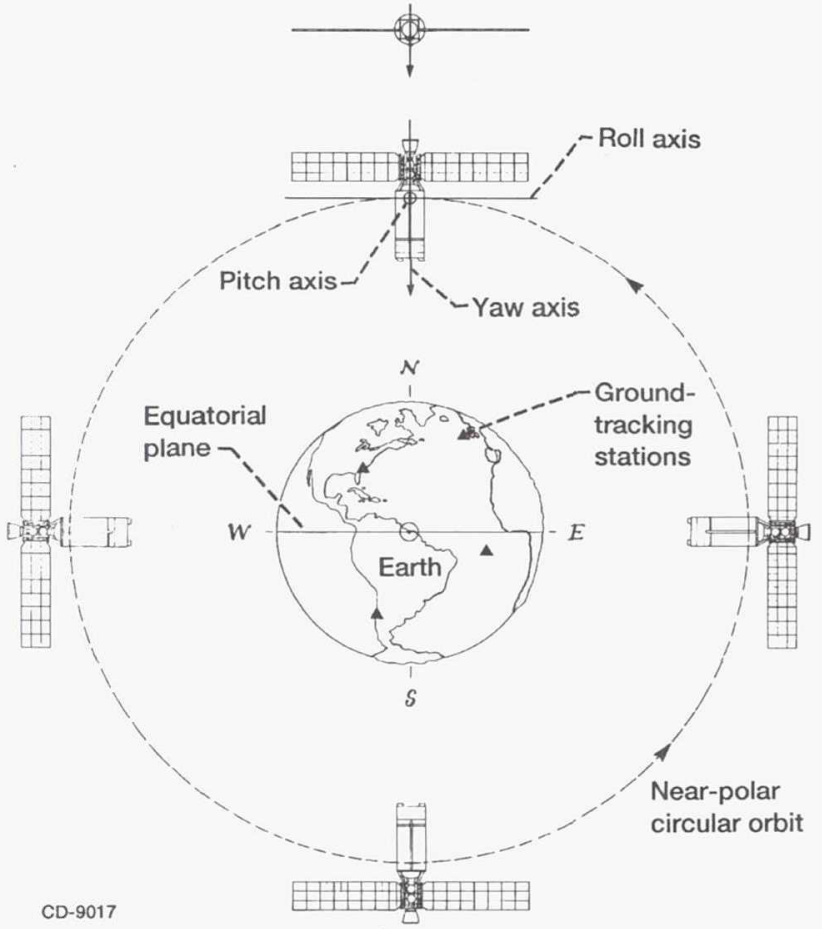

Figure 2.-SERT II vehicle coordinate system in orbit viewed from Sun for spring launch and sunset orbital injection.
1991. Continuous-sunlight orbits will not occur again until the period July 1998 to July 2001.

\section{Solar Array}

The SERT II solar array, which was built by Lockheed Missiles and Space Company, ${ }^{31,72}$ was derived from a design that had flown successfully on several military missions. The configuration of 90 array panels, consisting of 330002 - by 2 -cm N-on-P silicon cells with 0.5 -mm-thick fused silica cover slides, is shown in Fig. 3(a). The main or thruster array of 76 panels furnished a maximum power of $1195 \mathrm{~W}$ at beginning of life (BOL) at $55 \mathrm{~V} \mathrm{DC}$ and 21.6 A with a solar flux of $1292 \mathrm{~W} / \mathrm{m}^{2}$ and an array temperature of $327 \mathrm{~K}$. Individual panel output was measured on the ground and summed to obtain the total array power before launch. Each thruster array panel had 30 of its 370 cells intentionally shorted before launch. This was done to reduce the open-circuit voltage so that it would fall within the specified upper limit of input voltage for the thruster power conditioner. ${ }^{45}$ The remaining 14 panels (called the housekeeping array) furnished $230 \mathrm{~W}$ (BOL) at $30 \mathrm{~V}$ DC to power the spacecraft support unit and auxiliary experiments. The solar arrays were folded at launch and

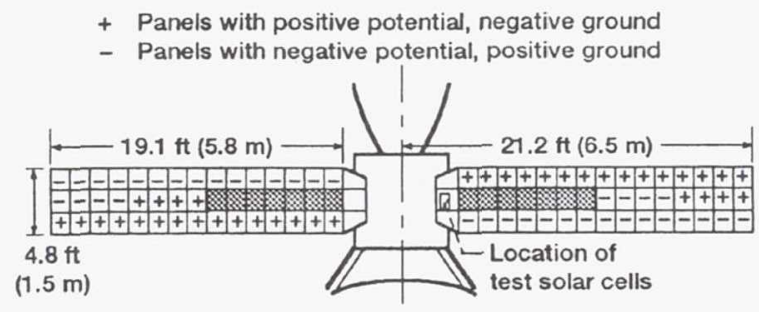

45 panels per wing arranged in 15-by-3 configuration.

(a) Panel arrangement of solar array. (Fourteen gray-shaded panels furnished housekeeping power; 76 other panels powered ion thruster system.)

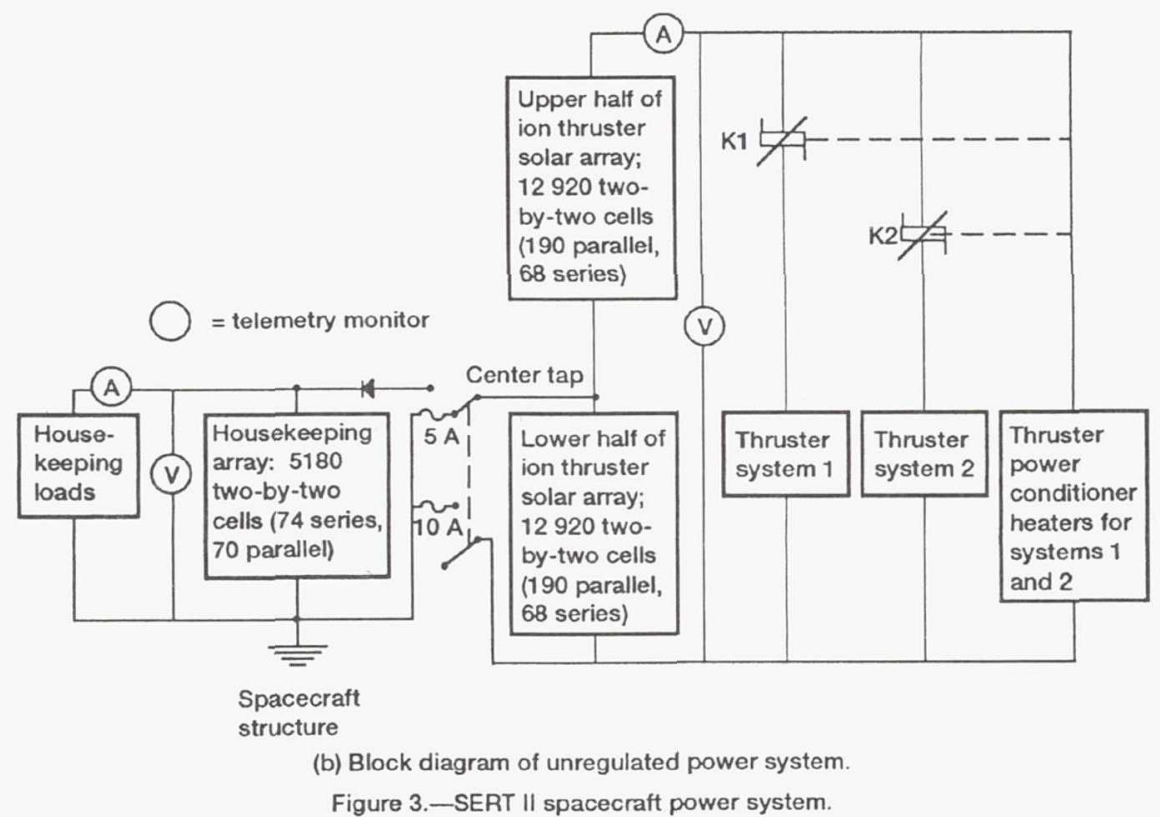


deployed once the spacecraft was in its final orbit. A battery onboard the Agena powered the Agena for the first $50 \mathrm{hr}$, during the launch and solar array deployment periods. The spacecraft housekeeping system included a backup battery to power the essential housekeeping loads in case solar array power should be lost in a solar eclipse or some emergency. ${ }^{44}$ This $40-\mathrm{Ahr}, 33-\mathrm{V}$, silver oxide-zinc battery was kept charged by the solar array until it failed in 1972. From that point on, the solar array became the only source of power.

Figure 3(b) shows a block diagram of the spacecraft power system. The thruster array was capable of being switched off, to either or both of the ion thruster power conditioner inputs, or to the power conditioner heaters. No bus filtering was used, but each power supply in the power conditioner contained filtering across its respective voltage inputs. All prior solar arrays of the SERT II mission type had been flown at 0 to $36 \mathrm{~V}$, using negative-end ground. Because the power conditioner units were designed for 58to $74-\mathrm{V}$ input, the thruster solar array was configured with a center-tap ground to give an array voltage that was no more than $\pm 37 \mathrm{~V}$ from ground. The housekeeping input voltage design was 28 to $37 \mathrm{~V}$, and the housekeeping array used the standard negative-end ground. In the event of power shortage for housekeeping loads, switches such as those shown in Fig. 3(b) were added to parallel the housekeeping loads with the lower half $(0$ to $-37 \mathrm{~V})$ of the thruster solar array. At the same time the thruster solar array was configured with negative-end ground and with the positive end at 58 to $74 \mathrm{~V}$. In 1979 and 1991 the solar array configuration switches were used to measure the change in spacecraft potential for the center-tap and negative-end ground connections. The spacecraft frame was defined as ground. No effect was seen on spacecraft potential for either ground connection when an ion thruster was operating. A shift in spacecraft potential was seen when no ion thruster was operating. With center-tap ground the spacecraft potential was $-7 \mathrm{~V}$; it shifted to $-29 \mathrm{~V}$ with negative solar array ground. ${ }^{19}$ For most of the 1970 tests, the thruster solar array was center-tap ground. With the exception of the spacecraft potential shift, no observable effects occurred to solar array performance or life with either grounding position.

All spacecraft electrical systems, except the ion thrusters and the power conditioner heaters, were operated with housekeeping voltage. If the housekeeping array voltage fell below $28 \mathrm{~V}$, the backup battery system supplied power. The backup battery automatically went on charge when the housekeeping array voltage increased above $28 \mathrm{~V}$. After the backup battery failed in 1972, one-half of the thruster array was configured to enable housekeeping loads to draw power from the thruster array should the housekeeping bus voltage drop below $28 \mathrm{~V}$.
Attitude Control

Gravity gradient. The orientation of the satellite, as depicted in Figs. 1(d) and 2, was maintained in pitch and roll by gravity gradient and in yaw by gravity-gradient cross forces augmented by control-moment gyroscopes (CMG). ${ }^{48}$ The mass distribution of the satellite was like a vertical barbell, thus giving an optimum restoring gravitygradient force. ${ }^{27,48}$ The initial satellite orientation was established by the Agena, using its cold-gas attitude control system, shortly after orbit injection.

Two pairs of CMG's were mounted in the spacecraft support unit. Either or both pairs were used to stiffen the yaw axis and to provide damping in all three axes. With damping there was a sine wave variation of $\pm 2^{\circ}$ in the pitch axis (with a period of one orbit) and less than $\pm 1^{\circ}$ in the roll axis. ${ }^{48}$ The yaw axis offset could not be measured, but the calculated maximum yaw offset was $0.2^{\circ}$. The four CMG's were attached to the spacecraft by Lord Manufacturing Company broad-temperature-range (HT2-series) elastomeric mountings.

Ion thruster gimbals. The thrust vector of each thruster system was designed to pass through the satellite center of mass. A $2^{\circ}$ thrust offset from the center of mass would produce a disturbing torque that was greater than the restoring torques of the attitude control system. The worst-case postulated offset was $5^{\circ}$. Offsets could be caused by initial thruster misalignment, thermal distortions, thruster grid misalignment, center-of-mass position uncertainty, and changes with time of thruster grids or center of mass.

Therefore, each ion thruster was provided with a twoaxis, mechanical gimbal system to adjust the thrust vector if necessary. ${ }^{50}$ The gimbal was the ion thruster's mechanical interface with the spacecraft, and the inner gimbal ring was the main structural member that was used to support the ion thruster and its filled propellant tanks. The gimbals were actuated by two electric-motor-driven screw drives.

Backup attitude control system. A backup attitude control system (BACS) was provided in case a temporary disturbance should cause the satellite to lose orientation. ${ }^{48}$ The BACS consisted of a cold-gas reservoir, which was made from 90Ti-6A1-4V, Airtec P/N 4425019 alloy, was loaded to 24-MPa (3600-psi) pressure with $27 \mathrm{~kg}$ of $\mathrm{CF}_{4}$ (Freon 14), and was located in the middle of the spacecraft support unit, and six cold-gas nozzles that were capable of rotating the satellite about each of the three principal axes. Nozzle propellant valves could be controlled (on or off) by ground command until a desired spacecraft orientation was achieved. Tank pressure was regulated to $0.13 \mathrm{MPa}$, and flow was turned on/off to each nozzle with a metal-tometal-seat solenoid valve (Sterer Engineering part numbers 


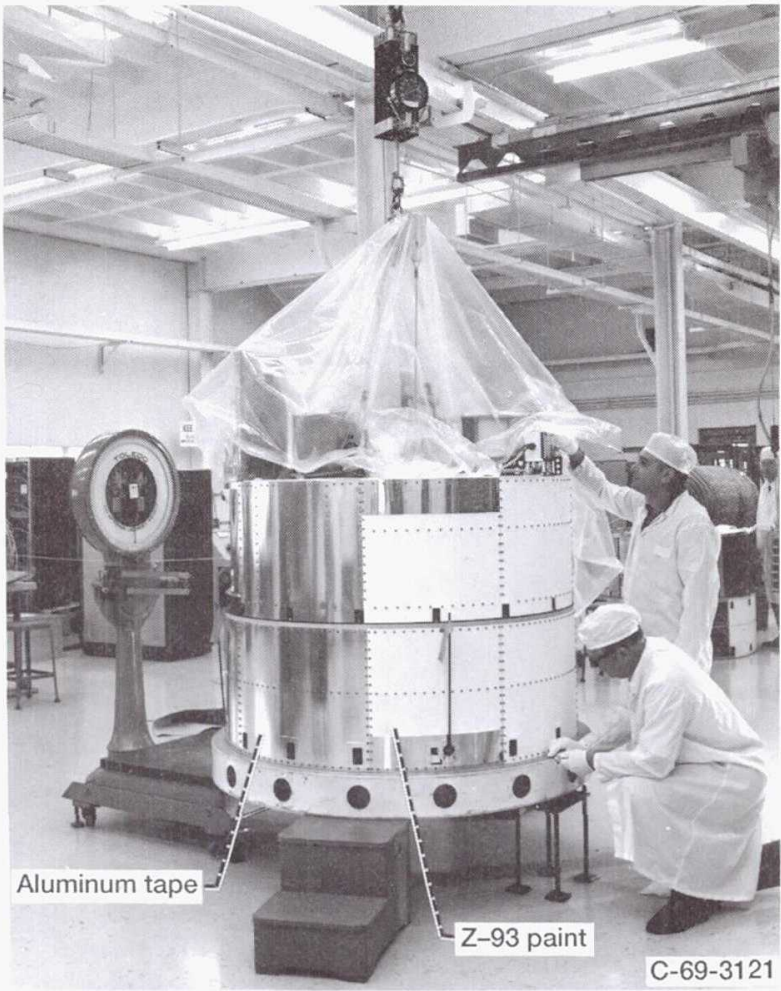

Figure 4.-SERT II spacecraft showing thermal control panels.

28600 and 29210). Each solenoid valve required $4 \mathrm{~W}$ of power to operate. A Millipore Company $10-\mu \mathrm{m}$-porediameter filter, P/N S1-81019, was installed before the regulator. The small-pore-size filter was required to ensure leak-free closing of the metal-to-metal valve seat. Fabrication used 347-CRS tubing and gold-nickel braze.

Horizon scanners. The horizon scanners were two infrared-sensing, rotating optical devices that were located on the Agena vehicle. ${ }^{48}$ The horizon scanners were part of the Agena guidance and control system and were used to control the Agena vehicle from launch through orbit insertion. Once on orbit the Agena vehicle was pitched $90^{\circ}$ to point its nose at the Earth. The horizon scanners were also rotated $90^{\circ}$ from the Agena orientation and reconfigured electronically to read the pitch and roll directions of the SERT II satellite axes as shown in Fig. 2. The horizon scanners were manufactured by the Barnes Engineering Company of Stamford, Connecticut.

\section{Thermal Control}

The design of the passive thermal control system for the spacecraft support unit and the spacecraft was based on controlled surface thermal emissivity, surface solar absorptivity, and the locations of the generated waste heat. Various surface materials used (shown in Fig. 4) were Z-93 white paint, black lacquer, and polished aluminum. ${ }^{33}$ The ion thruster radiated its waste heat directly to space. One critical item was the thruster mercury propellant vaporizer, which had to be maintained cooler than $525 \mathrm{~K}$ to ensure thermal control of the propellant flow. This was accomplished by locating the vaporizer $80 \mathrm{~mm}$ away from the thruster.

The thruster power conditioners were located inside the spacecraft with the mounting plate side (facing away from the Sun) radiating waste heat directly to space. The power conditioner's design operating temperature range was 273 to $322 \mathrm{~K}$. During cold-soak tests, which simulated space operation, the power conditioner baseplate temperature dropped to $261 \mathrm{~K}$, and at this temperature the high-voltage inverters failed to start consistently. Therefore, commercial heaters (described in a later section) were added to the power conditioner's radiator framework. The heaters, about $340 \mathrm{~W}$, not only provided the power conditioners with a temperature to ensure reliable inverter starting, but also supplied heat to bake out each power conditioner at $340 \mathrm{~K}$ before its initial use in space. The same command to apply power to either power conditioner also turned off the heaters. Once operating, the power conditioner produced sufficient waste heat to maintain its temperature within the design range.

\section{Auxiliary Experiments}

Space potential probe. The space potential probe, a hotwire emissive probe, was mounted on a 1.53 -m-long boom (see Figs. 5 and 6). The boom extended forward in the spacecraft motion direction to keep the hot wire away from the spacecraft bow wave. The distance of the boom from the bow wave was much greater than the approximate 0.1$\mathrm{m}$-thick bow wave and plasma sheath surrounding the spacecraft surfaces. The hot-wire emissive probe sensed the space plasma potential and measured the voltage difference between space plasma and spacecraft potential. ${ }^{24}$ Probe construction and operating details are described in Refs. 22 and 27.

Ion beam potential probe. A hot-wire emissive probe was used to measure the plasma potential of each ion beam. The sensing hot wire and associated electronics were similar to those of the space probe. The beam probe was located on a movable arm that swung the probe transversely through the ion beam $8.23 \mathrm{~m}$ downstream of the thruster accelerator (negative) grid (see Figs. 5 and 6). The probe was traversed both to obtain a beam potential profile and to prevent excessive sputtering damage to the hot wire by the high-velocity ion beam. ${ }^{27}$

Surface contamination experiment. This experiment consisted of both a high- and a low-temperature sensor that were mounted on a large radiator in back of each ion thruster and faced the Sun (see Figs. 6 and 7). The sensors were located approximately $0.28 \mathrm{~m}$ downstream of the ion thruster accelerator grid and $0.23 \mathrm{~m}$ from the centerline of 


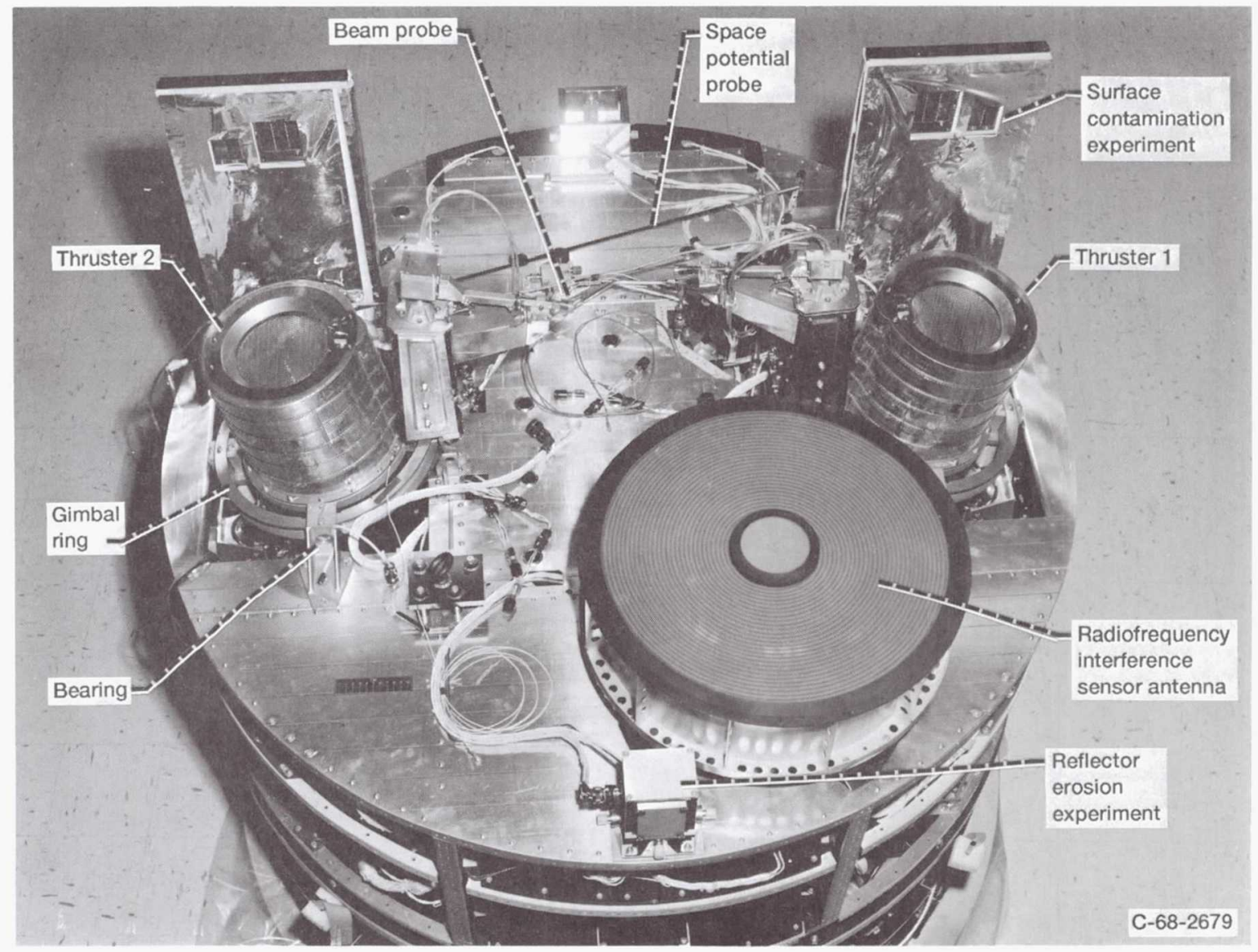

Figure 5.-SERT II spacecraft showing ion thrusters and auxiliary experiments.

the ion beam. The high-temperature (333 K) sensor prevented mercury propellant condensation and detected molybdenum sputtered from the accelerator grid. The low-temperature $(233 \mathrm{~K})$ sensor collected a combination of mercury propellant and molybdenum. The low temperature was maintained because the back surface was radiating to deep space. The short-circuit current of the solar cell sen-

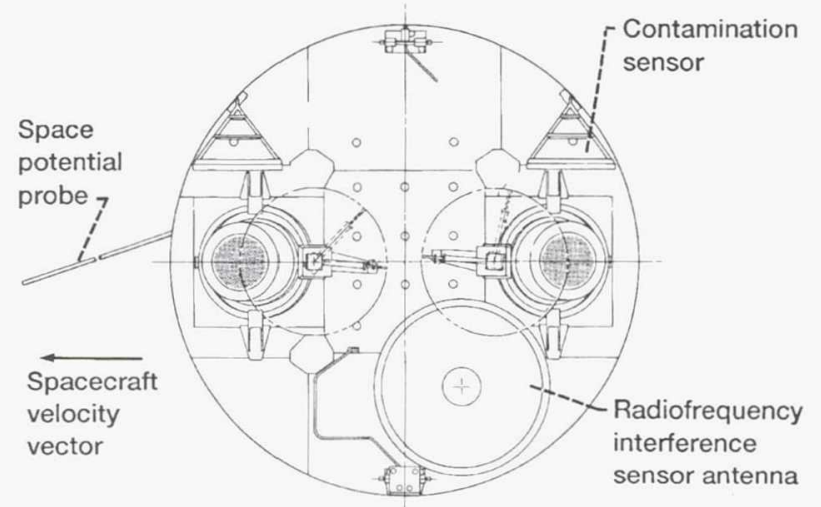

(a) Top view. sors was recorded during flight as a quantitative measurement of surface contamination condensation. ${ }^{25}$

Miniature electrostatic accelerometer. A miniature electrostatic accelerometer (MESA) was mounted in the SERT II spacecraft. Electrostatic forces were used both to support the sensing element (proof mass) and to measure

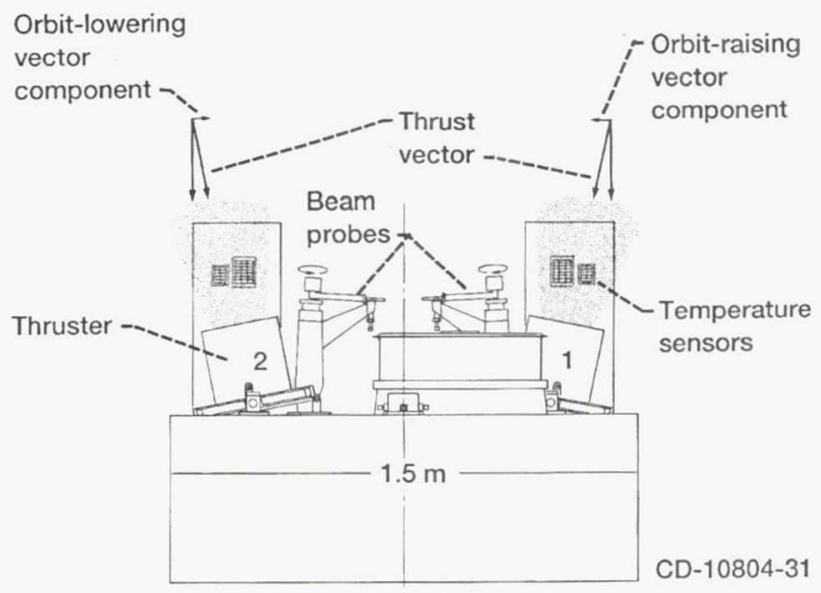

(b) Side view.

Figure 6.-Top and side views of SERT II spacecraft. 


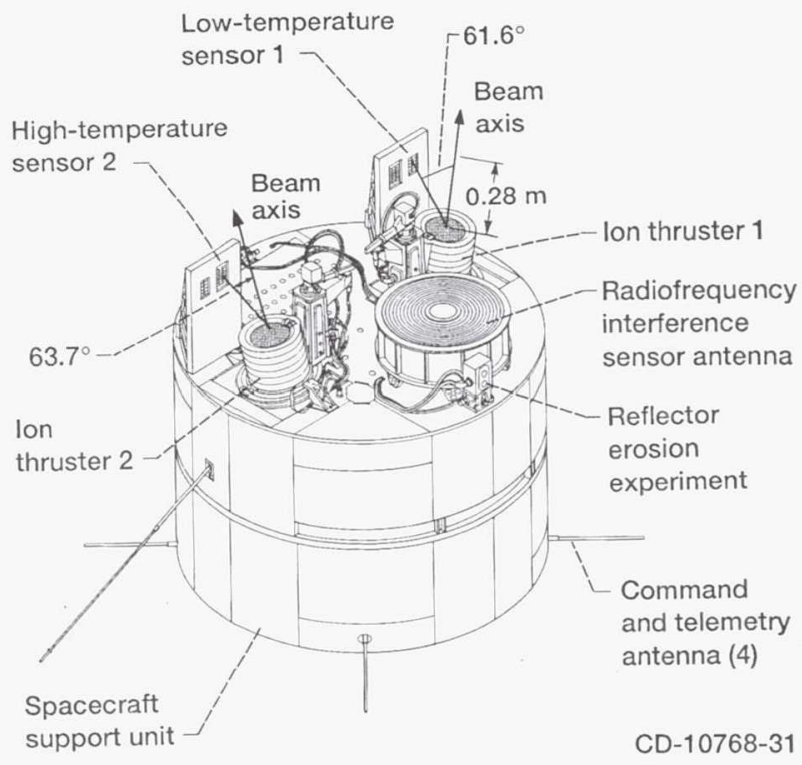

Figure 7.-SERT II spacecraft showing contamination sensor locations.

the spacecraft acceleration. ${ }^{23}$ The MESA was capable of measuring accelerations up to 0.1 g's with a sensitivity of 1 percent of actual reading. At a typical ion thruster thrust of $28 \mathrm{mN}$, the heavy experimental SERT II spacecraft was accelerated about $2 \mathrm{mg}$ 's. The MESA sensitivity at this thrust level was $0.02 \mathrm{mg}$ 's.

Radiofrequency interference experiment. A wideband sensor antenna, shown in Figs. 5, 6, and 7, was used with a multiband receiver to measure power levels of radiofrequencies produced by the ion beam in the radiofrequency interference experiment (RFI). The cylindrical antenna structure, which was located on the spacecraft deck near the ion thrusters, was $0.5 \mathrm{~m}$ in diameter and $0.22 \mathrm{~m}$ high. The antenna plane was approximately parallel with the ion thruster grid plane and faced the Earth. Three bands of frequencies, 300 to $700 \mathrm{MHz}, 1680$ to $1720 \mathrm{MHz}$, and 2090 to $2130 \mathrm{MHz}$, were chosen for measurement because these were thought to be frequencies that might cause interference with spacecraft communications systems used for future deep-space missions.

Reflector erosion experiment. The reflector erosion experiment (REX) consisted of two polished aluminum disks, $24 \mathrm{~mm}$ in diameter, that were capable of measuring surface erosion produced by space particles. ${ }^{29}$ The disks, as shown in Fig. 8, faced the Sun and were mounted in a small box located on the outer edge of the spacecraft deck (see Fig. 7). The box provided a known thermal environment for the disks and permitted an accurate correlation between disk temperature and amount of particle bombardment. ${ }^{29}$ As particles struck the polished, mirror-like surface, the surface solar absorptivity would increase and disk temperature would rise. A ground calibration determined a correlation between the integrated particle flux energy and the change in solar absorption or disk temperature increase. ${ }^{56}$ In 1970 , at the time of SERT II launch, models of space micrometeroid flux contained, in some cases, five orders of magnitude uncertainty. Micrometeroid damage to future spacecraft optical surfaces or solar mirrors therefore was difficult to predict, and the REX data were expected to remove some of the uncertainty.

\section{Data, Command, and Telemetry}

Data from the thruster system, auxiliary experiments, and spacecraft housekeeping were processed as 0- to 5-V DC analog outputs. ${ }^{40}$ Each datum output was sequentially switched through one of four subcommutators to a multicoder that converted the 0 - to 5-V DC analog signal to a 0 - to 61-count digital signal. The digital signal was processed and transmitted to the ground at $136 \mathrm{MHz}$ as a phasemodulated signal. All data were scanned once every $4 \mathrm{~min}$. If more frequent data were needed for a parameter, that parameter was sent to more than one subcommutator or used additional channels within a single subcommutator. The fastest parameter update, once every $4 \mathrm{~s}$, was used for selected parameters such as the beam probe voltage.

Data could be received in real time as the spacecraft passed over a Satellite Tracking and Data Acquisition Network (STADAN) ground receiving station. ${ }^{39}$ The ground station relayed the data by telephone line to the Lewis control room. Here the digital data were processed back to analog and displayed for interpretation and storage. The time limit over which a ground station could receive transmitted spacecraft signals was only 10 to $18 \mathrm{~min}$, as limited by view time from the ground.

Data were also stored onboard the spacecraft by using one of two magnetic tape recorders. Each tape recorder could store $144 \mathrm{~min}$ (more than one orbit) of data and play back the full tape in 9 min while over a single ground station. When one tape recorder was playing back, the other was recording data. The tape recorders were used continuously the first year (1970) of the mission and later only

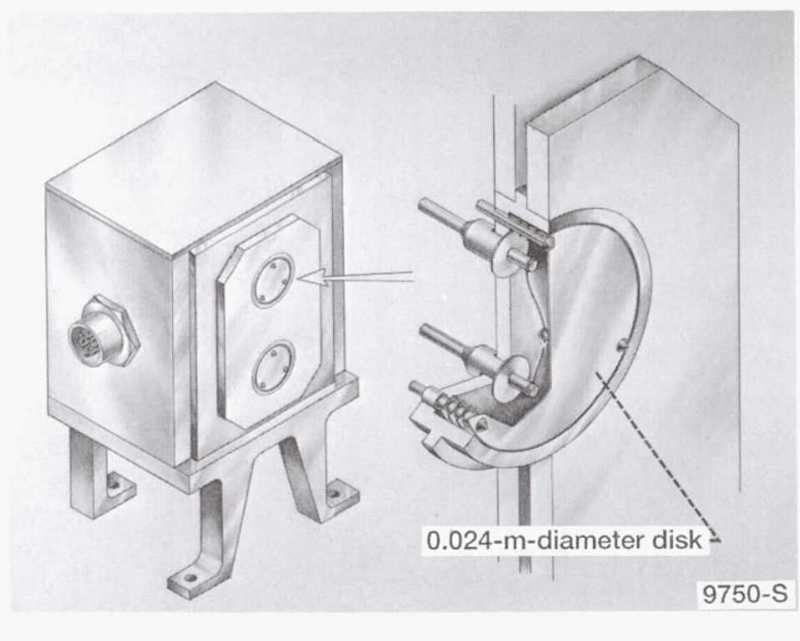

Figure 8.-SERT II reflector erosion experiment. 
when continuous data were needed. The analog tape recorders were made by the Leach Corporation to Fairchild Hiller Corporation specification 833-15404-P001 and used a Dynamics \#372 clutch with a four-belt transport and a 6.3-mm-wide tape. Only real-time commands, originating at the NASA Lewis control room, were used. The command system was an amplitude-modulated 148-MHz system with a 216-command capability. A circularly polarized turnstile configuration of four monopole antennas was used as a common telemetry, command, and data transmitting system. For more detail on the telemetry-data-command system or the STADAN, refer to Refs. 32, 35, and 39.

\section{Ion Thruster System}

Each ion thruster system consisted of a propellant feed system, an ion thruster, a thrust gimbal system, and a power-conditioning subsystem.

\section{Propellant Feed System}

In operation, liquid mercury was fed by positive displacement (nitrogen gas behind a butyl rubber diaphragm) to a porous tungsten vaporizer plug. The vaporizer plug stopped the flow of liquid mercury. The plug was heated to pass a controlled flow of mercury vapor at a pressure level of about $400 \mathrm{~Pa}$ (3 torr) through an electrical isolator and then to the main discharge chamber in which the mercury pressure was approximately $0.1 \mathrm{~Pa}\left(10^{-3}\right.$ torr $)$. The propellant electrical isolator had not been developed in time to meet the flight design freeze date and was replaced by a thermal-equivalent stainless steel tube. Therefore, the main propellant tank was at ion thruster potential $(3000 \mathrm{~V})$ and had to be insulated from spacecraft ground by aluminum oxide $\left(\mathrm{Al}_{2} \mathrm{O}_{3}\right)$ spheres.

Approximately one-third of the mercury vapor from the isolator tube flowed through the thruster main hollow cathode. The remainder flowed through a flow-controlling orifice into the distributor manifold and then into the main discharge chamber. Each main propellant tank contained $14.1 \mathrm{~kg}$ of mercury, an estimated 8-month supply.

\section{$\underline{\text { Ion Thruster }}$}

The SERT II ion thruster was a nominal 1-kW-powerlevel, 0.15-m-diameter mercury electron-bombardment ion thruster. ${ }^{6}$ Figure 9 is a cutaway view of the ion thruster that shows the various components, such as discharge chamber, accelerator grids, neutralizer hollow cathode, and propellant reservoirs.

A small electrode at $400 \mathrm{~V}$ near the main cathode was used to start the mercury discharge. After discharge start, the electrode voltage was decreased to $12 \mathrm{~V}$ to keep the discharge stable. (Later ion thruster designs did not require a keeper electrode to maintain steady discharge operation.)
A 1.7-A discharge current was drawn from the main hollow cathode to the 0.15 -m-diameter main anode and, through electron bombardment of the mercury vapor, created a mercury plasma within the discharge chamber. Permanent bar magnets were located around the chamber to improve the efficiency of the discharge. The shape and strength $(3.5 \mathrm{mT}$, or $35 \mathrm{G})$ of the magnetic field, together with the size of the discharge baffle, were optimized to produce low discharge power and the high level of mercury ionization. 1

Plasma ions in the discharge chamber diffused to the screen-accelerator grids, where they were extracted and focused into a $0.25-\mathrm{A}, 3000-\mathrm{V}$ (28- $\mathrm{mN}$ thrust) mercury ion beam. The screen (positive) and accelerator (negative) grids were flat plates of molybdenum drilled with a hexagonal array of 847 holes within a 0.14 -m-diameter pattern. The plates were 0.75 and $1.5 \mathrm{~mm}$ thick, respectively, and were separated by a gap of $2.5 \mathrm{~mm}$. The screen holes were $3.98 \mathrm{~mm}$ in diameter and the accelerator grid holes were $3.27 \mathrm{~mm}$ in diameter. The holes were drilled on the same centerline with a $4.50-\mathrm{mm}$ equilateral triangle pattern spacing. The beam diameter of $0.14 \mathrm{~m} \mathrm{(10} \mathrm{mm} \mathrm{smaller} \mathrm{than} \mathrm{the}$ anode diameter) eliminated some of the ions with highly divergent trajectories at the edge of the ion beam, as well as reduced the neutral propellant loss. The accelerator grid was made of double thickness in a small area near the neutralizer, because a few $(0.5 \mathrm{~mA})$ neutralizer discharge ions were drawn to this area and produced sputtering wear. ${ }^{58}$ On the basis of ground tests the double thickness would require 12 months of operation to wear through.

The ion beam was neutralized by an equal current of electrons injected from the hollow-cathode neutralizer. ${ }^{59}$ The neutralizer cathode also had a keeper electrode to start and maintain its operation. Mercury vapor was supplied to the neutralizer cathode by a separate flow system that was similar to but smaller than the main propellant system. The neutralizer tank was insulated from spacecraft ground to enable a neutralizer bias experiment to be conducted at $\pm 50 \mathrm{~V}$. Reference 4 gives construction details of the main and neutralizer hollow cathodes.

A perforated (to permit outgassing) ground screen enclosed the entire ion thruster except for the 0.14-mdiameter active area of the accelerator grid. The ground screen, which was connected to spacecraft ground, prevented space plasma electrons from backstreaming to the thruster components at high positive voltage. Freestanding, noninsulated wires inside the ground screen connected each thruster component to one of 13 high-voltage standoff terminals. Kapton-insulated wires from each terminal were combined into a shielded bundle and run through the ground screen to the power conditioner output terminals. Details of the ion thruster mechanical design may be found in Ref. 13. The ion thrusters were designed by and fabricated at NASA Lewis. 


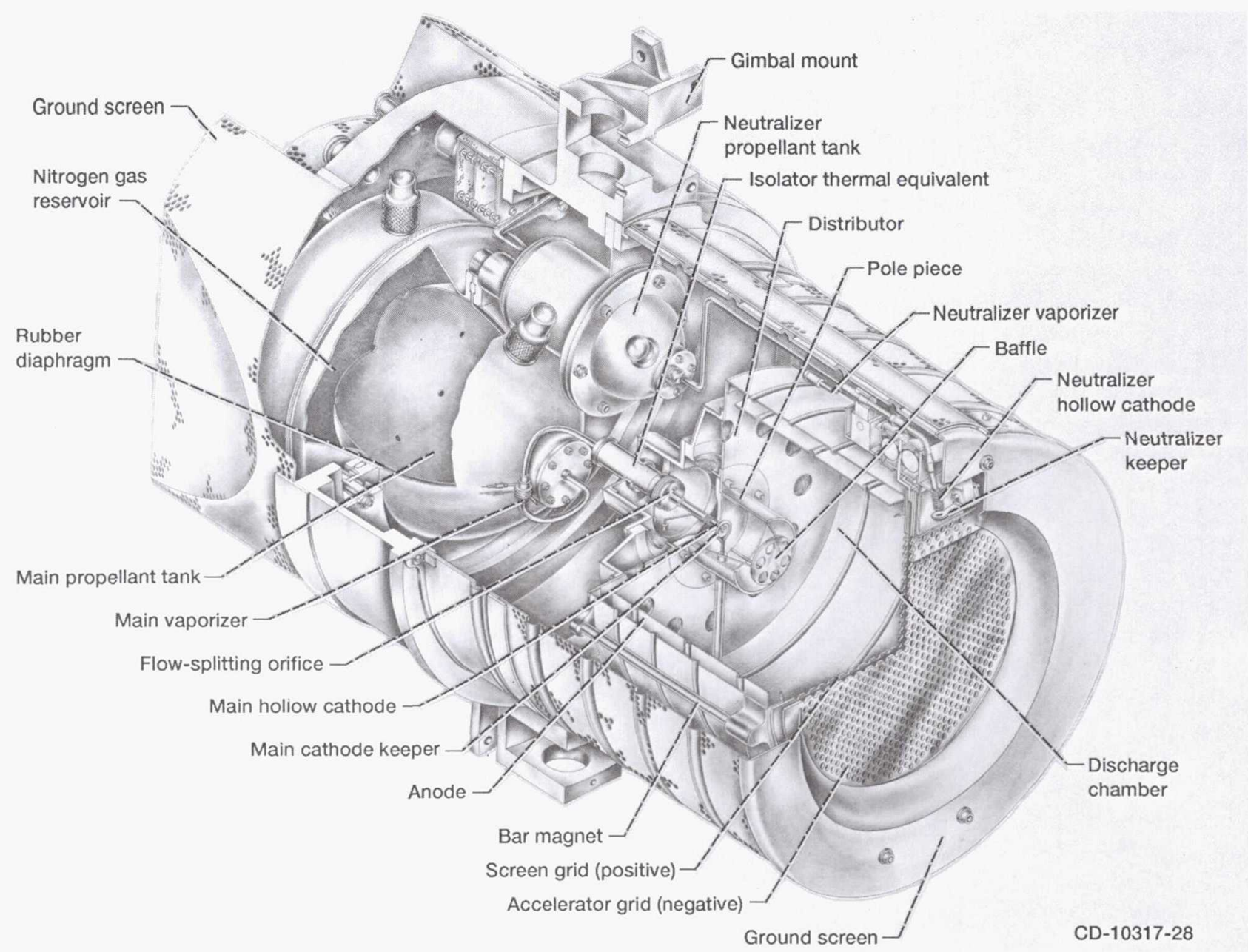

Figure 9.-Cutaway view of SERT II ion thruster.

Two ion thrusters were installed on the SERT II spacecraft as shown in Figs. 1(d), 5, and 6. Thruster 1 (left side when viewed from the Sun and with the thruster firing toward the Earth, Fig. 1(d), or right side in Fig. 6) was oriented to raise the satellite orbit, and thruster 2 lowered the orbit. The amount of orbit change is discussed in the section "SERT II Flight Results." The two thruster systems were nearly identical, and each provided backup for the other in the event of failure. The only difference in the ion thrusters was the polarity of the permanent magnets used for the discharge chamber. One chamber used the north pole magnet end at the distributor, and the other chamber used the south pole. This orientation was chosen to minimize the satellite magnet dipole moment. ${ }^{48}$

\section{Gimbal System}

The gimbal system consisted of two motor-driven, screw-drive linear actuators, mounting rings, and four bearings. ${ }^{50}$ The gimbal design was similar to a Hooke universal joint and could reposition the beam thrust axis to anywhere within $\mathrm{a} \pm 10^{\circ}$ cone angle centered about a line perpendicular to the accelerator grids and passing through the centerline of the grids. The gimbal rings and bearings are shown in Fig. 5, but Ref. 50 gives a more complete gimbal system description.

Each flight ion thruster, when fully loaded and including the gimbal system, had a mass of $30 \mathrm{~kg}$, which breaks down as shown in Table IV.

TABLE IV.-ION THRUSTER MASS

\begin{tabular}{|l|r|}
\hline \multicolumn{1}{|c|}{ Component } & $\begin{array}{c}\text { Mass, } \\
\mathrm{kg}\end{array}$ \\
\hline Thruster & 3.0 \\
Propellant tanks (empty) & 4.3 \\
Propellant: & \\
Main tank & 14.1 \\
Neutralizer tank & .9 \\
Gimbal system & 7.7 \\
\hline Total & 30.0 \\
\hline
\end{tabular}


Power-Conditioning Subsystem

The power conditioner converted solar cell electrical power into power required to operate the ion thruster. 5,10 The SERT II solar array provided a nominal direct-current voltage of $60 \mathrm{~V}$ during full-beam thruster operation. The power conditioner converted the solar array power into nine different electrical outputs, totaling approximately $860 \mathrm{~W}$ for the ion thruster. Each supply was designed to operate continuously into a shorted load without damage to itself or any other spacecraft component. The major amount of electrical power was delivered for the ion beam at $3000 \mathrm{~V}$ and $0.25 \mathrm{~A}$. The nominal conversion efficiency of the power conditioner was 87 percent.

Figure 10 shows the power conditioner with and without its cover installed. The rectangular box was $0.52 \mathrm{~m}$ long, $0.27 \mathrm{~m}$ wide, and $0.14 \mathrm{~m}$ high. The power conditioner mass was $14.5 \mathrm{~kg}$. Its nine electrical outputs were terminated on 13 high-voltage ceramic standoffs. Kaptoninsulated wires coming from the 13 standoffs were bundled, shielded, and run to the ion thruster. The power conditioner waste heat was conducted by internal trays to its baseplate.

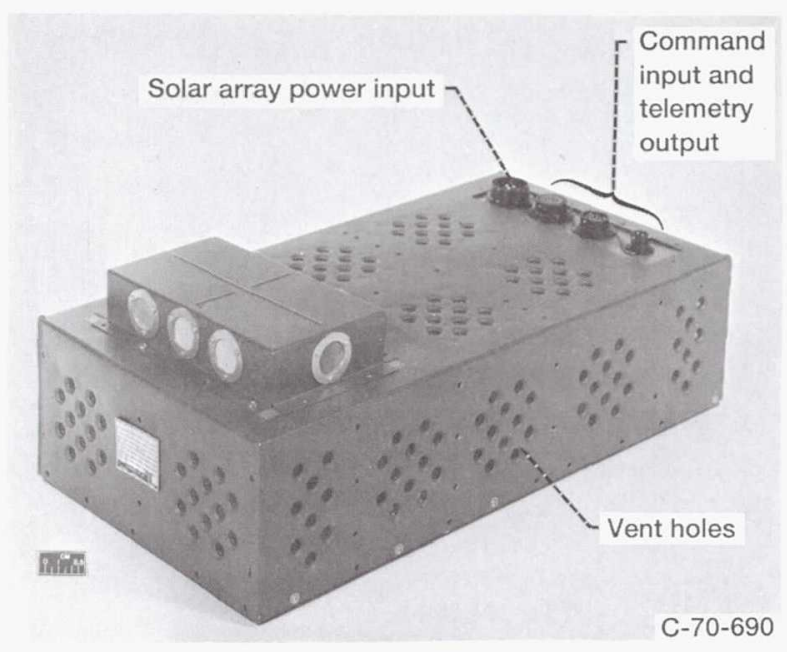

(a) With cover installed.

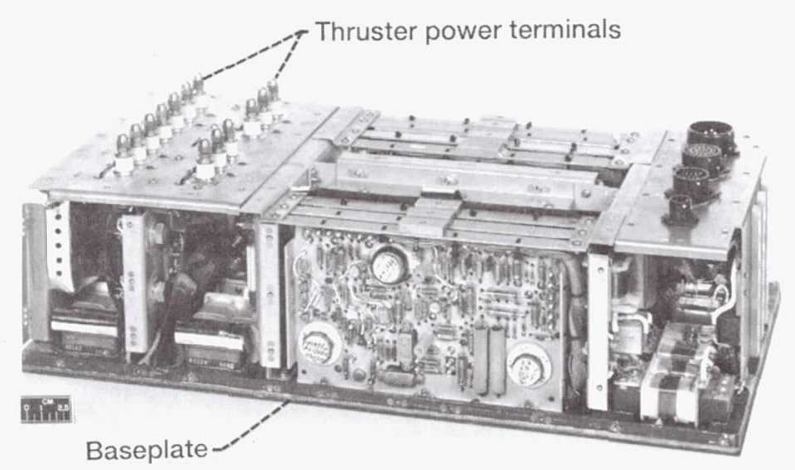

C-70-691

(b) Without cover.

Figure 10.-Ion thruster power conditioner.
The baseplate was bolted to a radiator that was part of the spacecraft outer surface. The radiator was sized to maintain an internal temperature of less than $322 \mathrm{~K}$ at rated operation.

An electrical block diagram of the SERT II ion thruster system is shown in Fig. 11. The V5 supply (3000 V) consisted of three modified Jensen inverters. ${ }^{10}$ Each provided one-third of the output voltage. A fourth redundant inverter could be commanded to operate in the three-inverter series string if one of the other inverters should fail. The V5 supply was connected to the thruster shell, as well as to the main vaporizer, the main propellant tank, the main hollow cathode, and the discharge chamber screen grid. The V6 $(-1550 \mathrm{~V})$ supply was connected only to the accelerator grid and collected about $1.5 \mathrm{~mA}$ of the ions that impinged on this grid. It used a single Jensen inverter to give a maximum rated $-1800-\mathrm{V}$ output. A master modified Jensen inverter operated at $8 \mathrm{kHz}$ and supplied input power to all other supplies. The V10 supply provided $400 \mathrm{~V}$ to start the main cathode discharge and about $12 \mathrm{~V}$ at $0.3 \mathrm{~A}$ for the keeper discharge during normal operation. The V4 supply (discharge) consisted of a transformer and a full-wave bridge rectifier. The V4 supply supported the main discharge, which produced ions for the beam. It used magnetic amplifier control to provide voltage regulation and current limiting. It normally ran at $37 \mathrm{~V}$ and $1.7 \mathrm{~A}$ and was controlled at constant V4 voltage. The heater supplies (V2, V3, and V7) used magnetic amplifiers to control output power by pulse width modulation. The V2 supply heated the main vaporizer and was part of a closed-loop control that sensed beam (I5) current and regulated propellant flow to maintain constant beam current. The V3 supply was used to heat and activate the main hollow cathode and to supply preheat to the thruster shell. Once the main discharge began, V3 was cut back to extend cathode life because sufficient heat for normal operation was generated by the cathode and main discharges. The V7 and V8 supplies operated the neutralizer vaporizer/cathode heater and the neutralizer starter/keeper electrode, respectively. The neutralizer vaporizer temperature was controlled by a closed-loop control that sensed and maintained a constant neutralizer keeper voltage. The neutralizer keeper (like the main keeper) provided $400 \mathrm{~V}$ at a few milliamperes for starting the hollow cathode discharge and then cut back to a lower voltage ( $23 \mathrm{~V}$ at $0.20 \mathrm{~A}$ ) to sustain (keep) the discharge going. The cathode keeper supplies, V8 and V10, consisted of a transformer and a series inductor with a fullwave diode bridge. The V9 supply was part of an experiment to bias the neutralizer $( \pm 25$ or $\pm 50 \mathrm{~V})$ in a test to control the spacecraft potential relative to the space plasma potential. Normally, V9 potential was $0 \mathrm{~V}$. The V9 supplied an electrical path for neutralizer electrons from thruster common or spacecraft frame (ground).

The SERT I power-conditioning system had used a sealed, pressurized enclosure for its 1-hr spaceflight. A 


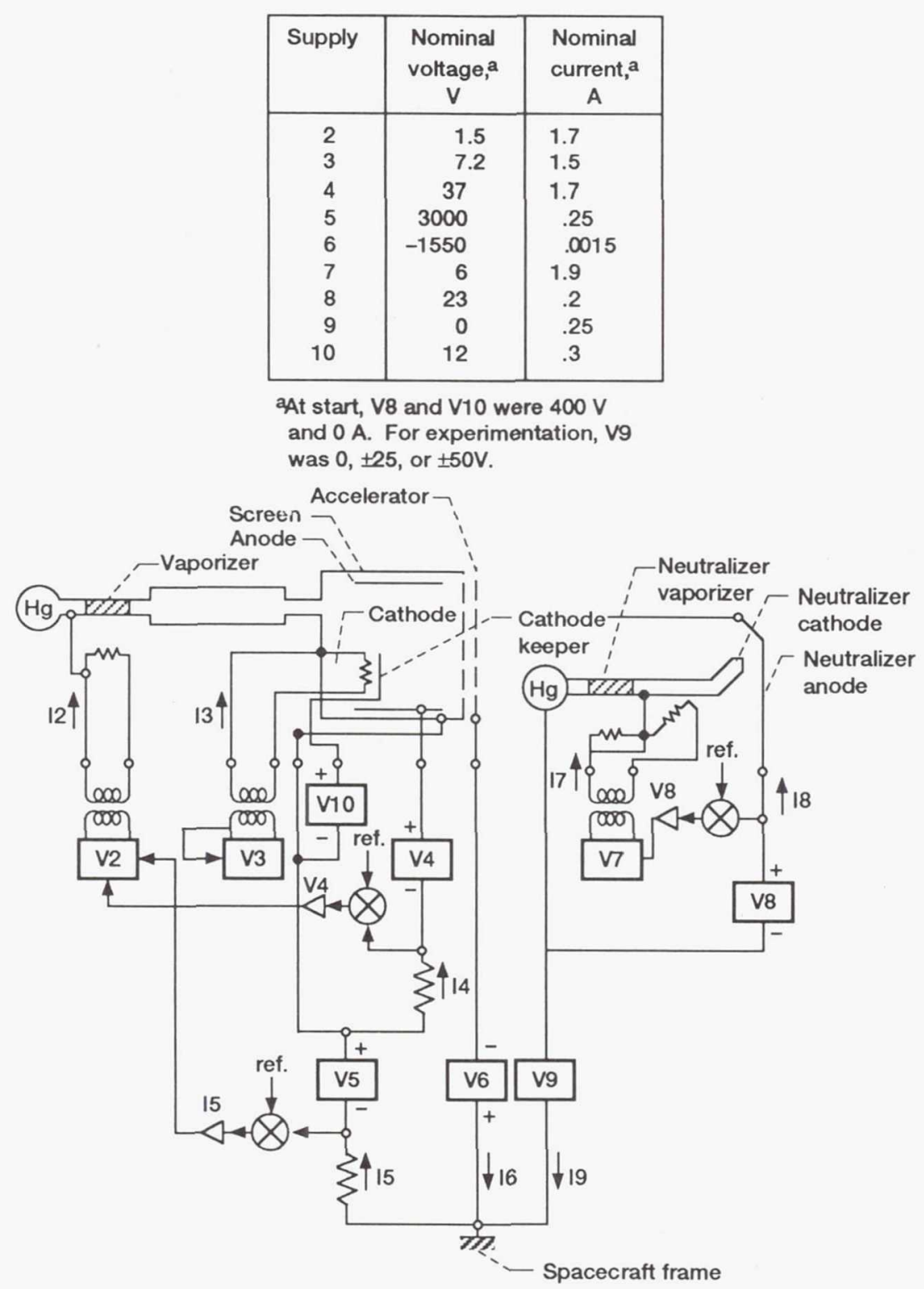

Figure 11.-Block diagram of ion thruster electrical system.

pressurized enclosure was not considered reliable for long-term missions. Therefore, the insulation within the SERT II power conditioner was provided by a vacuum of less than $0.013 \mathrm{~Pa}\left(1 \times 10^{-4}\right.$ torr $)$, by some conformal coating, and by aluminized Mylar sheets. Potted or foamed insulation was not used because of breakdown problems in vacuum. Screen-covered vent holes (see Fig. 10) provided for outgassing. Short-term arcs occurred between the ion thruster accelerating grids with a frequency of between one per hour and one per week. The high-voltage (V5 and V6) supplies were designed to quickly turn off $(0.12 \mathrm{~ms})$ when a grid arc occurred and then start back up $0.1 \mathrm{~s}$ later, giving time for the arc to extinguish.

The SERT II power conditioners were built by the Westinghouse Corporation in Lima, Ohio, under contract to NASA Lewis.

\section{$\underline{\text { Development Program }}$}

After the SERT II flight approval in August 1966, the development proceeded along two parallel programs. One was for the ion thruster system and the other was for the flight spacecraft. The ion thruster system efficiency optimization and component life tests were performed by a research group of six engineers. The mechanical thruster design fabrication and auxiliary experiments were done by a group of eight development engineers. A block diagram of some of the major subsystems is shown in Fig. 1(e). The spacecraft and the spacecraft support unit were the responsibility of a Lewis group (30 to 60) of development engineers. The Thorad and Agena launch vehicles were managed through the NASA Lewis Launch Vehicle Division. The total program cost (1966 to 1970) was $\$ 30$ million, which included the launch vehicle cost. In addition, 
220 person-years of NASA personnel time were used. There were approximately 120 full or part-time NASA Lewis people working at the peak (1969) of the program. The spacecraft and the ion thrusters were fabricated in house. The spacecraft support unit, thruster power conditioner (PCU), and solar array were designed and fabricated under individual contracts. The final assembly and acceptance testing was done in house. The launch and satellite operation were also conducted by NASA Lewis personnel. The earlier SERT I ballistic flight in 1964 cost $\$ 15$ million (including the Scout launch vehicle) and used 45 personyears of NASA personnel time according to Raymond J. Rulis, SERT I and SERT II project manager.

During the development and flight qualification programs, the following SERT II components were fabricated: 14 ion thrusters: 6 experimental, 4 prototype, and 4 flight; 18 power conditioners: 4 breadboard, 4 experimental, 6 prototype, and 4 flight; 8 propellant tank sets and gimbal systems; 4 spacecraft and spacecraft support units: a mass dummy, an experimental, a prototype, and a flight. An experimental model was defined as one that was as close to flight design as possible and would serve to define design changes. A prototype model design was identical with the flight design. Prototype models were used to test to flight qualification standards but at a higher level. After qualification tests, two of the prototype thruster systems (including PCU's) received major ground life testing. Flight models were built to prototype designs and qualified for a limited time $(60 \mathrm{hr})$ but at lower vibration and thermal specifications. Two flight thruster systems were made as backups for the two that were actually flown. The prototype spacecraft and spacecraft support unit served as flight backups. Only one Agena and one solar array were built for flight. All components, before assembly into the spacecraft, were tested at SERT II prototype qualification levels or greater. ${ }^{41}$ Where possible, components were chosen that had been used successfully in prior flight missions.

\section{Thruster Efficiency Optimization}

The 0.15-m diameter of the ion thruster was determined by the design power level $(850 \mathrm{~W})$, the ion-current-density extraction capability of the grid system, and the thruster specific impulse. The specific impulse of $4200 \mathrm{~s}$ was chosen to be representative of that required by primary electric propulsion planetary missions.

A laboratory test program ${ }^{1}$ determined the length of the main discharge chamber, the strength and shape of the magnetic field, and the main discharge operating voltage. A discharge chamber that was too long resulted in excess plasma losses to the walls, whereas one that was too short resulted in insufficient chamber volume or propellant resident time to ionize the mercury propellant. The soft iron pole pieces shaped a divergent magnetic field, with the strongest region close to the centerline near the cathode.
TABLE V - NOMINAL SERT II OPERATING PARAMETERS

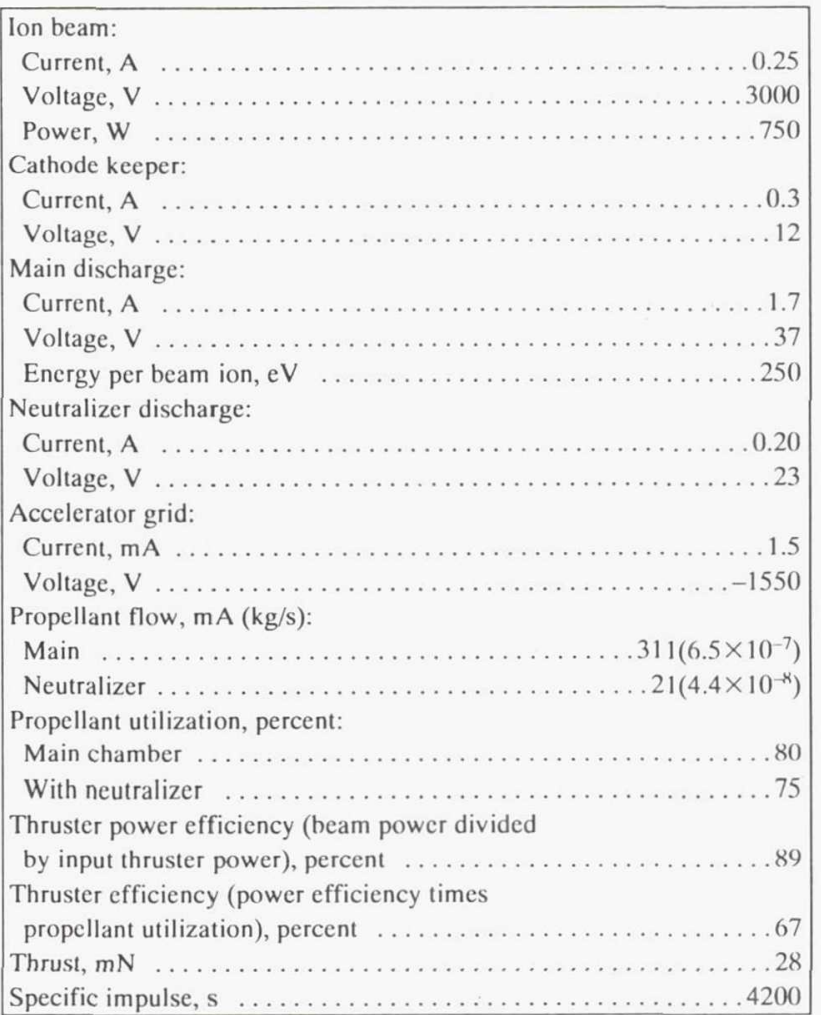

The magnetic field caused the electrons to spiral, increasing their probability of making an ionization collision before striking the anode. Magnetic divergence permitted the plasma to expand to the extraction grids. The voltage level of the main discharge voltage was a tradeoff between efficient ionization at high voltage $(50 \mathrm{~V})$ and long thruster discharge chamber life at low voltage $(30 \mathrm{~V})$. The baffle on the cathode pole piece provided a plasma electrical impedance so that most of the main discharge voltage was added to the electrons as they entered the main chamber. Table $\mathrm{V}$ gives the nominal SERT II operating parameters, thruster electrical efficiency, propellant utilization, and overall thruster efficiency.

\section{Critical-Life Thruster Components}

Cathodes. The SERT I thruster used refractory metal filament cathodes. Its main discharge cathode life was less than $200 \mathrm{hr}$. The wire neutralizer cathode, which was immersed in the ion beam, had a life of tens of hours. This life was more than adequate for SERT I, which had a flight operating time of less than $1 \mathrm{hr}$. Useful space applications of ion thrusters need 5000 to $10000 \mathrm{hr}$. Various metal oxide magazine cathodes were invented and tested from 1963 to 1967 , but these showed lives only in the thousands of hours and were complex designs.

Reference 57 proposes using a hollow-cathode design for the neutralizer cathode. The initial advantage of a hollow 
cathode was in its internal discharge, which produced a "plasma bridge" for the neutralizer electrons to travel over into the ion beam. The plasma bridge permitted the neutralizer cathode to be located well out of the beam, thus affording long life. Other advantages of the hollow cathode were its low consumption of heater power and its ability to be exposed to air after each test without refurbishment. No special protection of the hollow cathode was required from initial fabrication through launch operations.

Because of the design simplicity of a hollow cathode and its low consumption of heater power, it also was proposed for the SERT II main discharge cathode. At this time (early 1966), a research program ${ }^{4}$ was started to measure and extend the hollow-cathode life to $10000 \mathrm{hr}$. Reference 4 reports hollow-cathode tests of both the main discharge and the neutralizer. Within defined operating limits the projected life of the main discharge hollow cathode was $15000 \mathrm{hr}$ and the projected life of the neutralizer hollow cathode was $33000 \mathrm{hr}$. A barium-oxide-coated insert was added to ensure restart capability. ${ }^{59}$ At the time of the SERT II thruster design freeze, April 15, 1967, only several hundred hours of life testing was complete. Projected life looked promising, however, and life tests were begun to verify the projected life. Tests of over $10000 \mathrm{hr}$ on a single cathode were demonstrated by the end of $1968 .^{4}$

Grids. The design of the accelerating grids was essentially the same as that of the SERT I grids (i.e., two flat parallel grids made of molybdenum). ${ }^{3}$ The screen grid erosion was low because only low-energy $(\sim 40 \mathrm{~V})$ ions at low current density $\left(1.4 \mathrm{~mA} / \mathrm{cm}^{2}\right)$ struck it, and life was not a major issue. The screen grid open area was increased from 50 percent (SERT I) to 72 percent to obtain an increase in the fraction of ions extracted to those that were approaching the screen grid. The accelerator grid remained heavy (twice the 0.75 -mm screen thickness) to provide tolerance for erosion by the up to $4500-\mathrm{V}$ ions that struck it and to give a 10000 -hr design life. The open area (50 percent) of the accelerator grid was a compromise between low neutral propellant loss (low open area) and low direct ion impingement (high open area). The predominant wear to the accelerator grid was caused by neutralizer and beam charge exchange ions which struck the grid with up to 1550-V energy. ${ }^{9}$

\section{Neutralizer}

The position of the neutralizer cathode needs to be outside the ion beam to avoid direct beam impingement but close enough to have low coupling voltage between it and the ion beam plasma. Because time was short between the decision to use a hollow-cathode neutralizer and the thruster design freeze, and because thermal-emission neutralizer cathodes needed to be located close to the ion beam edge, the position chosen for the hollow-cathode neutralizer was also close to the ion beam edge. It was $19 \mathrm{~mm}$ down- stream of the accelerator grid and $19 \mathrm{~mm}$ radially outward from the last accelerator grid hole. At this position the neutralizer cathode was well out of the direct ion beam and had a low coupling voltage of about $45 \mathrm{~V}$. The neutralizer axis was $19^{\circ}$ downstream of a line perpendicular to the thrust axis.

A life problem of the accelerator grid that was caused by neutralizer discharge ions was not recognized until after the design freeze. Normally, the potential of the ion beam plasma was high enough to reflect neutralizer ions from the central areas of the accelerator grid, but because of low beam plasma potential at the outer edges of the accelerator grid, the neutralizer discharge ions could sense the accelerator grid edge potential and be drawn back to the grid. Thus, an erosion groove (about eight grid holes long and two grid holes wide) was produced on the outer rim of the accelerator grid (see Fig. 12). Also shown in Fig. 12 is evidence of minor direct beam ion erosion on the upstream side of the accelerator grid. This was caused by a nonuniform and low-density plasma arriving at the edge screen grid holes and subsequent inadequate ion focusing into the accelerator grid holes. This erosion tended to undercut the web between grid holes and may have helped detach the web fragments that are believed to be responsible for the flight grid shorting.

Relocating the neutralizer cathode to reduce the accelerator groove erosion would have required a significant change in the thruster ground screen and neutralizer propellant tank supports. Instead of making this change, which would have caused a mission schedule delay, a sheet metal shield (at ground screen potential) was added between the accelerator grid and the neutralizer cathode. This shield reduced the number of neutralizer discharge ions that found their way back to the accelerator grid. The shield reduced the groove erosion to a rate that required about 6 months to wear through the single-thickness accelerator grid. Wearthrough of the grid would not produce a failure until the groove

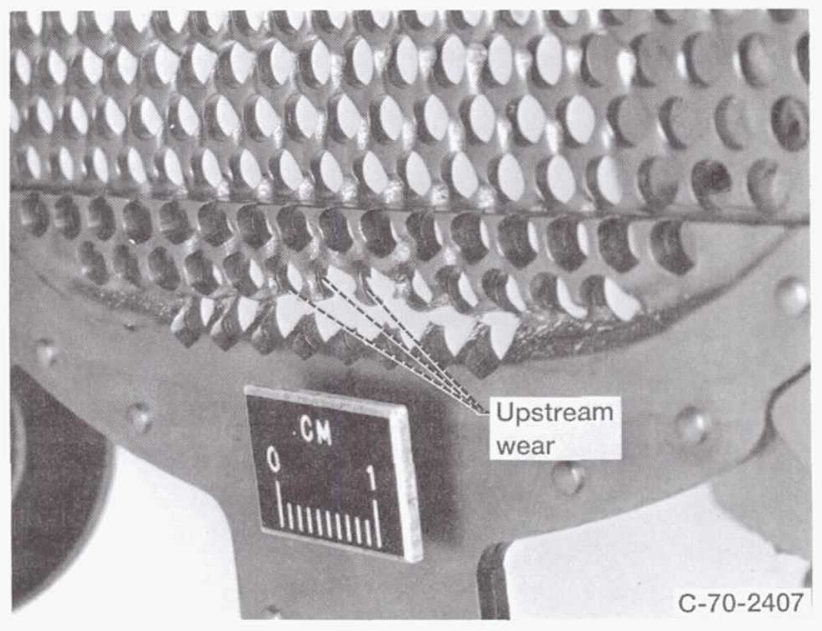

Figure 12.-Ground-tested (4000 hr) accelerator grid of SERT II ion thruster. 62 
became wide enough to permit electron backstreaming to the $3000-\mathrm{V}$ screen grid. This would require an estimated $12000 \mathrm{hr}$ to occur. (Mission design time was 6 months, or $4300 \mathrm{hr}$, with a $20000-\mathrm{hr}$ design life.) Nevertheless, a doubler plate ( 3 holes wide by 8,13 , and 16 holes long) was added to the accelerator grid where the groove erosion was occurring. The doubler plate design survived thousands of hours of in-house testing, $5700 \mathrm{hr}$ of test T, and $8000 \mathrm{hr}$ of test $\mathrm{M}$ without causing any failures. ${ }^{8}$ (Test T and test $\mathrm{M}$ life tests are described in following sections.) Flight thruster failures caused by groove erosion are discussed later in the section "SERT II Flight Results."

\section{$\underline{\text { Propellant Feed System }}$}

Control of liquid mercury. The concept of using a heated porous metal plug to both control the mercury liquid-vapor interface and regulate the vapor flow rate was used on SERT I. ${ }^{52}$ This concept was refined and used on SERT II also. The mercury storage tank materials of stainless steel and butyl rubber, which were picked for chemical compatibility, were found to have no corrosion change after $4 \mathrm{yr}$ of ground testing. ${ }^{13}$ Several designs for welding the porous tungsten plug into a tantalum tube and a change of the heater on the tube were required before finding a design that was free of thermal-expansion-caused cracks in the porous-to-solid tube weld area. ${ }^{13}$

A pore size (2.4- $\mu \mathrm{m}$ diameter) was picked for the vaporizer that was small enough to prevent intrusion by liquid mercury and large enough to permit desired vapor flow rates at operating temperatures. Design values for vapor flow rates through porous material and for the liquid intrusion pressure level are available in the literature. ${ }^{61}$ A flow snubber orifice, $0.38 \mathrm{~mm}$ in diameter and $1.6 \mathrm{~mm}$ long, was placed in each liquid mercury flow line about $10 \mathrm{~mm}$ upstream of the porous plug to prevent "water hammer" (dynamic pressure) from causing mercury intrusion into the pores. The water hammer pressures were caused by launch vibrations sloshing the liquid mercury back and forth in the lines and the propellant tank.

The intrusion of liquid mercury into the pores was a serious failure mode because the subsequent flow of liquid mercury through the pores was 1000 times greater than the required vapor flow and was uncontrollable. Normally, the surface tension of mercury was greater than the liquid backpressure trying to force mercury into the pores. The backpressure was the 2-atm pressure of the blowdown nitrogen plus any dynamic pressure caused during launch vibrations. The intrusion problem was doubly serious because even after the intrusion pressure was removed, the liquid mercury remaining in the pores provided a continuous liquid column for sustaining liquid mercury flow. Some samples of porous tungsten have a property that permits the liquid mercury to "pop" out of the pores, ${ }^{61}$ thus enabling the surface tension to prevent further liquid flow, but these samples were not available in time for the flight.
A vexing vaporizer failure occurred when the prototype thruster systems were first installed on the prototype spacecraft. The ion thruster was performance acceptance tested by using mercury flow tubes to supply and measure propellant consumption. Next, the ion thruster was connected to loaded propellant tanks, placed on the gimbal system, and assembled to the spacecraft. The spacecraft was put through vibration testing and then into a vacuum tank for thermal vacuum testing and ion thruster operation. During preheating of the thruster, liquid mercury was found to be dripping out of the main cathode in about half of the tests. After 3 months of trouble shooting Charles Low of NASA Lewis discovered that the problem was caused by the propellant tanks being too fully loaded at room temperature. During thruster preheat in the vacuum tank, the liquid mercury expanded in the tank and created a pressure large enough to force liquid mercury through the vaporizer pores. The solution was off loading the propellant tanks by 1 percent, which provided sufficient volume for propellant thermal expansion. From this point forward no failures of the propellant feed system occurred.

Propellant electrical isolator. An ion thruster system designer has a choice between electrically insulating the propellant tank at the high positive voltage of the ion thruster or grounding the tank and placing an electrical isolator between the tank and each ion thruster. Because liquid mercury is an electrical conductor, the isolator must be in the vapor-flow part of the system. Electrical flow isolators were not fully developed when the SERT II program started (August 1966) and were therefore classified as an experiment to be attempted if ready in time.

The design of an electrical flow isolator was not easy because the vapor-flow pressure was about $100 \mathrm{~Pa}$. This pressure was near the minimum of the curve for Paschen breakdown. If the vapor pressure had been lower (0.01 Pa) or higher $\left(10^{5} \mathrm{~Pa}\right)$, a simple ceramic-wall tube would have sufficed to insulate against the $3-\mathrm{kV}$ potential difference.

An experimental isolator concept that used multiple screens inside a ceramic tube was successfully tested. The multiple screens divided the full high voltage into segments, each one of which had a voltage drop smaller than the Paschen breakdown minimum. The experimental design was incorporated into the SERT II feed system and tested. The isolator allowed excessive leakage current in some of the tests because of fabrication contaminants on the ceramic surfaces. The isolator was then dropped from the SERT II design, although later research designs by the Hughes Research Laboratory perfected a successful isolator. Because the thruster mechanical design had been completed, there was less impact on the program from keeping the same geometric design and replacing the electrical flow isolator with an thermal-equivalent-sized stainless steel tube. The isolator was an experiment; therefore the main propellant tanks were always designed to be mounted on insulating supports in case the isolator should fail. A 
stainless steel tube was used because a ceramic tube introduced a possibility of problems with mechanical cracking of the ceramic tube walls. The replacement stainless steel tube had to be warm enough to prevent mercury vapor condensation during warmup and had to have enough thermal resistance to prevent the hot ion thruster from conducting heat back to the vaporizer and causing thermal runaway of the vaporizer. ${ }^{13}$

\section{Thruster Power Conditioner}

Development. A brief description of the SERT II thruster power conditioner was given in an earlier section. Photographs are shown in Fig. 10 and electrical circuits, in Fig. 11. The development program ${ }^{10}$ was divided into four levels: (1) a breadboard model for testing circuit designs and components; (2) an experimental model that packaged all components into the size of a flight power conditioner for vibration testing and was rated for vacuum operation; (3) a prototype model that would pass all levels of thermal, vacuum, and vibration testing required for flight operation; and (4) flight models that would be identical with the final prototype design. Because internal arcing problems in the prototype models caused a schedule delay, no final prototype models were fabricated before flight model manufacturing. Retrofitted prototype models were used in life tests $\mathrm{T}$ and $\mathrm{M}$.

The breadboard model operated an experimental thruster in mid-1967, confirming the designs of various supplies and the working of the thruster control loops. (Closed-loop control of the beam current was done by main flow adjustment. Closed-loop control of the neutralizer keeper voltage was done by neutralizer flow adjustment. ${ }^{6}$ ) Each magnetic component from breadboard to flight model was subjected to a 12 -week life test before final assembly. The experimental model was constructed within the volume required for flight and provided thermal paths (metal trays connected to the baseplate) for waste heat removal. The experimental model successfully operated an ion thruster in late 1967.

Minor electrical components failed and were replaced with higher-rated components. The metal trays experienced excessive resonant motion during vibration tests. New tray designs that used stiffening members passed vibration tests. Vibration qualification levels were up to 9 g's sinusoidal, $19 \mathrm{~g}$ 's random, and 9 g's shock, in 8-ms pulses, for the Thorad-Agena launch vehicle. ${ }^{41}$ Components were vibrated up to $30 \mathrm{~g}$ 's random before design acceptance.

The first experimental power conditioner was delivered in mid-1968. It was installed on the experimental spacecraft in vacuum tank 5 (4.5-m diameter) at NASA Lewis ${ }^{54}$ and operated a prototype ion thruster (Fig. 13). The test lasted for $21 / 2 \mathrm{hr}$, and after much erratic power conditioner-thruster operation was shut down by a power conditioner diode failure. Severe thruster system arcing that occurred during the test fed back into the telemetry subcommutators and caused erratic data sampling and damage to the solid-state components. A filter box was installed in the telemetry lines and prevented any further erratic data or spacecraft systems damage from thruster arcs.

The basic cause of the arcing was not easy to determine. It is a characteristic of ion thrusters that small arcs (sparks) will jump between the accelerating grids from time to time. The power conditioner was designed to sense these sparks, turn off the high-voltage power supplies in $0.12 \mathrm{~ms}$, wait $100 \mathrm{~ms}$, and then turn the supplies on again. The quick offtime prevented damage to the accelerating grids, and $100 \mathrm{~ms}$ was long enough for the spark to clear itself before reapplication of high voltage. ${ }^{10}$

This spark-clearing process was satisfactory for the ion thruster, but inside the power conditioner box, high voltage gradients were causing breakdowns to low-voltage (high current) power supplies. These internal breakdowns were elusive because they caused failures in different areas of the power conditioner. Reference 10 gives many of the postulated problem causes and solutions. Finally, after 10 months of testing the following changes were made: Conformal coating was applied to exposed wires and connections because the vacuum insulation was not enough to suppress arcs started by high field gradients at sharp corners. The conformal coating alone was not sufficient protection because certain sharp edges in the geometry of the $3000-\mathrm{V}$ supply prevented thick enough $(0.13 \mathrm{~mm})$ coating to be applied. Therefore, in addition to the conformal coating, aluminized Kapton (trademark of DuPont) film was installed between power supplies. The film was folded double with the metal surface inward. In this manner it filled the dual function of controlling the electric field between power supplies and providing additional dielectric insulation. These insulating techniques were used in all later power conditioner assemblies. No further internal arcing problems occurred during the balance of flight qualification tests, nor were any observed in 21 years of space operation. In 1989 to 1991, the SERT II spacecraft was reactivated $^{30}$ and the power conditioning still operated normally, although no plasma loads were available for testing.

From the beginning of the SERT II development program the power conditioner was the critical PERT path. (PERT stands for Program Evaluation and Rating Technique.) Delays in solving these problems caused the flight power conditioners to be ready less than 3 months before launch, instead of the planned 15 months.

Power conditioner heaters. During a ground cold-soak test with the power conditioner, one of the Jensen inverters in the V5 supply failed to start (oscillate) owing to its cold temperature (about $261 \mathrm{~K}$ ). Therefore, strip heaters were added to the spacecraft framework supporting the power conditioner radiator plate. These added heaters not only 


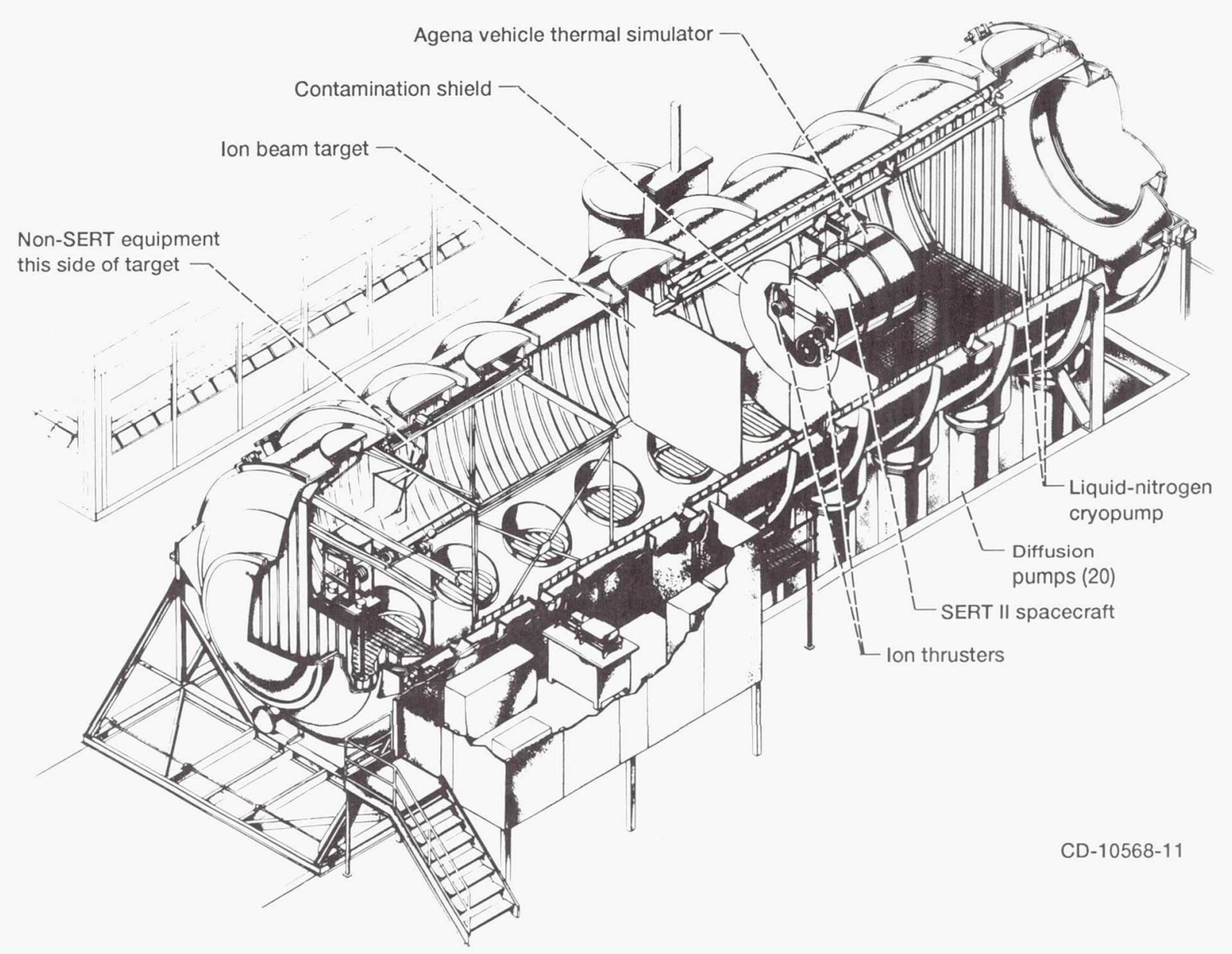

Figure 13.-Installation of SERT II spacecraft in vacuum tank 5 at NASA Lewis.

maintained the inverters at an assured starting temperature ( $>280 \mathrm{~K}$ ), but also provided a thermal bakeout $(340 \mathrm{~K})$ of the power conditioner before its initial operation in space. The heaters were automatically turned off when either power conditioner was turned on. The initial bakeout was done for $80 \mathrm{hr}$. Subsequent bakeout periods in the first year were 1 to $20 \mathrm{hr}$, but later no bakeout was needed. In 1989 and 1990 the heaters were used for long periods (3 months) to warm the spacecraft and to stop erratic output of the telemetry data.

The power conditioner heaters have operated reliably for $9423 \mathrm{hr}$ (79 duty cycles) since launch. The duty on-time has been from $1 \mathrm{~min}$ to $2349 \mathrm{hr}$. The heaters were electrically connected directly through a switch to the thruster solar array and have shown no change in resistance with time. The heater operating power dropped from $340 \mathrm{~W}$ in 1970 to $237 \mathrm{~W}$ in 1991 owing to radiation degradation of the thruster solar array voltage.

The power conditioner heaters were made of 12 heater strips in parallel. Each strip contained a Nichrome heater wire $760 \mathrm{~mm}$ long by $0.077 \mathrm{~mm}$ in diameter. The heater wire was embedded in a four-ply strip of fiberglass- reinforced red silicon rubber that was $25 \mathrm{~mm}$ wide, $380 \mathrm{~mm}$ long, and $1.8 \mathrm{~mm}$ thick. The heater wire ran down one part of the strip, turned $180^{\circ}$, and returned to the same end from which it began. Heater lead wires were $0.64-\mathrm{mm}$-diameter copper wire with silicon rubber insulation. The red silicon rubber strip was bonded to the metal spacecraft frame with cement, type EFH 2167. The heaters were rated for a maximum power flux of $1.6 \mathrm{~W} / \mathrm{cm}^{2}$ when bonded to a metal plate and a maximum operating temperature of $500 \mathrm{~K}$. The heaters were made by Electro-Flex Heat, Inc. Iridium foil $0.13 \mathrm{~mm}$ thick was used between metal-to-metal joined surfaces on the spacecraft frame to ensure good thermal conduction across the joined parts.

\section{Thruster Performance Acceptance Tests}

A written procedure for fabrication, assembly, and checkout was made. Standard reliability and quality assurance programs were followed from selection of raw materials through final fabrication. Assembly of an ion thruster required completing nine checksheets with 25 pages of description. Mercury (99.999 percent pure) was carefully weighed and loaded into propellant tanks to avoid contaminating substances. Spacings of thruster mechanical parts 
were measured. The screen-accelerator grid spacing was especially important because too small spacing might cause electrical breakdown and too great spacing would defocus the ion beam. Discharge chamber magnetic field strength and shape were documented. High-voltage standoff resistances were measured. These assembly procedures were carefully documented to ensure consistency and to avoid dependence on a single person.

After assembly the thruster was performance tested by following a 16-page written document. First, the ion thruster was operated with mercury flow tubes to measure propellant consumption over three levels of beam current and three levels of discharge voltage. If the propellant consumption or discharge current were outside specified ranges, the propellant flow-splitting orifice was changed to achieve the correct ranges. The accelerator grids were run over a range of voltages to ensure normal limits of beam extraction capability. The neutralizer cathode was operated to determine the correctness of neutralizer keeper voltage set points. If the neutralizer flow was too high or the keeper voltage was out of range, the neutralizer cathode was rejected.

After the electrical performance tests had been passed, the loaded mercury propellant tanks were added. A power conditioner was connected and used to operate the ion thruster. Correct operating currents and voltages were ascertained, as well as control loop stability. Then the ion thruster system was deemed ready to support tests on the prototype or flight spacecraft.

The first flight power conditioner was not delivered until November 1969. When it was connected to a flight thruster and put into operation, a slow oscillation was present between the power conditioner and the thruster beam control loop. Usually, small changes in an operating point would damp out such oscillations, but in this case they did not. Because the launch was only 2 to 3 months away, time was not available to fix the cause of this problem. Instead, a different combination of flight thruster and flight power conditioner was tested and found not to have the oscillation problem. Two flight ion thruster systems and two flight backup systems were qualified by selecting compatible pairs of ion thruster and power conditioner.

Even though the flight power conditioners checked out under resistive loads at the manufacturer, serious problems would have occurred in flight if the total ion thruster flight system had not been integrated and tested before launch as described. It is highly recommended that any flight ion thruster system be vacuum operated on the flight spacecraft prior to launch. If the flight spacecraft cannot be used, the complete ion thruster system should be operated in vacuum on a flight-equivalent spacecraft.

\section{Thruster System Ground Life Tests}

Before the prototype thruster system was available for life testing, over $20000 \mathrm{hr}$ of component testing ${ }^{4}$ and nearly $4000 \mathrm{hr}$ of thruster testing ${ }^{9}$ including 1000 -hr and 1500-hr life tests were completed. The prototype ion thruster system was operated in vacuum for $375 \mathrm{hr}$ on the experimental spacecraft and $2400 \mathrm{hr}$ on the prototype spacecraft. ${ }^{41}$ The flight ion thrusters were each operated over $50 \mathrm{hr}$ on the flight spacecraft before launch. In addition to these in-house tests, two contracted ion thruster system life tests were conducted.

Test M. Test M was conducted in a horizontal (2.43-m diameter) vacuum tank with a frozen mercury beam target to minimize facility backsputtering material. ${ }^{8}$ The tank provided for mounting an ion thruster and a power conditioner in close proximity inside the same vacuum chamber. The ion thruster was mounted at the top of the chamber and fired vertically downward. The electrical cabling between thruster and power conditioner was the same as the flight cabling. The final life test was started with a prototype ion thruster (including loaded propellant tanks) and a retrofitted prototype power conditioner. Both were identical in design to flight models and were vibration tested to levels 50 percent higher than launch levels before the life test was started in December 1969. The life test continued for $6742 \mathrm{hr}$ without loss of vacuum until September 1970, when the main propellant tank became empty. The thruster performance for the test was very similar to space performance. ${ }^{7}$ The presence of mercury vapor and mercury plasma in the tank had no effect on the power conditioner. Test M was conducted by the McDonnell Douglas Company in St. Louis, Missouri.

Test $\mathrm{T}$. Test $\mathrm{T}$ was conducted in a 1.5 -m-diameter vertical vacuum tank with the thruster firing downward. The tank had a frozen mercury target at the bottom and mercury-coated, liquid-nitrogen-cooled cylindrical baffles at the sides. The ion thruster was located at the tank top. The power conditioner was located in a separate, nearby vacuum chamber. Testing was begun in March 1967 on various combinations of experimental thrusters and power conditioners (including laboratory-type power supplies). Seven short life tests totaling $4000 \mathrm{hr}$ were conducted between March 1967 and December 1969. In December 1969 a final life test was begun on a flight-design prototype ion thruster (with loaded propellant tanks) and a retrofitted prototype power conditioner in the nearby vacuum chamber. Again, all components were identical to flight designs. The test was voluntarily terminated in September 1970, after $5169 \mathrm{hr}$ of thruster operation. During operation the thruster system performance was very similar to that of the flight thrusters. Test T was performed at TRW Systems, Inc., in Redondo Beach, California. 


\section{Spacecraft Development}

In this section the word "spacecraft" will always apply to the combined assembly of the spacecraft support unit and the spacecraft, as shown in Fig. 7. The purpose of the spacecraft development program was to qualify the flight spacecraft to serve as a testbed for operating two thruster systems in space and to meet the following goals: (1) survive expected vibration and shock levels, (2) remain operational through simulated vacuum cold-soak and heating periods, (3) meet specialized goals of operating in a vacuum chamber containing ion thruster plasma efflux and power conditioner voltages of 3000 and $-1550 \mathrm{~V}$, and (4) show endurance capability to meet the 6-month space goal. The program was carried out on four models: the experimental mass dummy, the experimental operational model, the prototype, and the flight model. ${ }^{41}$

Experimental mass dummy spacecraft. This spacecraft model was a mechanical equivalent of the flight spacecraft, but it had no electrical capability nor was it designed for vacuum testing. It was used to demonstrate the ability of the structure to meet the vibration and shock environment. This same structure was also used as a vibrational fixture to qualify components for the prototype and flight spacecraft. The structure qualification was complete by August 1967. A total of several hours of vibration testing was logged on this model.

Experimental operational spacecraft. The purposes of this spacecraft model were (1) to show compatibility between the power and communications systems and the ion thruster system, (2) to develop harness assembly techniques, (3) to refine ground support equipment that later would be required to test the flight spacecraft, (4) to check the electrical operation and compatibility of all the spacecraft housekeeping systems, (5) to support the first ground operation of an ion thruster on a spacecraft, and (6) to provide a thermal testbed for verifying the analytical techniques of the thermal design.

All electrical tests proceeded smoothly to qualify the housekeeping systems. The first test on an ion thruster that was powered by laboratory supplies outside the vacuum tank showed no problems with the spacecraft systems operating in the presence of a mercury plasma. Later, when a flight-sized experimental power conditioner was available, integration tests showed transient electrical interference in the telemetry lines, as noted earlier. Filters were added to prevent these electrical transients from reaching the telemetry system.

Thermal testing was done, using 150 thermocouples, with an operating thruster and power conditioner installed on the experimental spacecraft. ${ }^{49}$ These tests generally showed agreement between actual and predicted spacecraft temperatures. The thruster, which was mounted on its gim- bal system, rapidly (approximately a $20^{\circ}$-min time constant) reached thermal equilibrium independently of the spacecraft. This indicated negligible thermal conduction across the gimbal system, which was the mechanical interface. In addition, predicted thermal inputs from the operating power conditioner to the spacecraft were verified.

The experimental spacecraft continued to be operated in order to gain experience and to document all operating modes. The experimental spacecraft logged $500 \mathrm{hr}$ of operation from April 1968 to November 1968. Of these hours, 375 were with an operating ion thruster. The last test was a 192-hr uninterrupted test using an operating thruster and power conditioner. The test was stopped when the prototype spacecraft became available for testing in November 1968.

Prototype spacecraft. The main design principle of the prototype spacecraft was that it be mechanically and electrically identical with the flight spacecraft. Its components were fabricated and tested before spacecraft assembly to the same or higher specifications as for the flight spacecraft. Whenever possible, equipment was chosen that had successful flight histories on prior missions. If this were not possible, the equipment or subsystem would be tested to stress levels in excess of flight-level stresses before being specified in the design. Also, each component, regardless of prior test success, would be subjected to flight-level environmental testing before being installed on the prototype or flight spacecraft.

The prototype spacecraft with all its components was vibration tested. No electrical equipment problems occurred, but the thruster gimbal pyrotechnic pin puller failed, permitting unconstrained motion of the thruster. The pin puller was redesigned to improve its strength and passed later vibration tests without problem.

Next, two thermal-vacuum tests were performed. The prototype spacecraft was placed in vacuum tank 5 at NASA Lewis, as shown in Fig. 13. The vacuum chamber was lined with liquid-nitrogen-cooled panels to simulate the cold of space. Heat was applied to the Sun side of the spacecraft by quartz heat lamps that simulated solar power. ${ }^{49}$ In addition, heaters were added at the spacecraft end toward the Agena launch vehicle. These heaters simulated the thermal interface with the Agena. The vacuum tank was able to maintain a pressure of $0.3 \mathrm{mPa}\left(2 \times 10^{-6}\right.$ torr) or better with the spacecraft and a thruster system at full operating conditions.

The first thermal-vacuum test was done without the ion thruster system operating. The prototype spacecraft was cold soaked and then operated over the temperature extremes expected in flight for 5 days. All systems, including auxiliary experiments and the firing of pyrotechnic squibs, were tested during these 5 days. The most serious problem 
that occurred was the flaking of thermal control coatings on the spacecraft skin. Better process control in applying the thermal coating solved the problem. ${ }^{38}$

During the second thermal-vacuum test the ion thruster systems were operated. After a 20 -hr cold soak the ion thruster systems were separately started and tested through their operating ranges. Finally, an exercise was conducted in which supposed tumbling of the spacecraft occurred, causing loss of the main solar array power. The thruster was turned off and essential spacecraft loads were supported by the onboard battery. After a period of several hours (time assumed necessary to reacquire the spacecraft orientation when using the cold-gas backup system), both thruster systems were restarted in turn. Several minor failures $^{41}$ occurred during this test, and spacecraft component redesigns were made to correct the failures.

Other uses of the prototype spacecraft were to check out ground telemetry and command equipment and to train ground personnel in the mission control room. With an ion thruster system on the prototype spacecraft in vacuum tank 5, a radio link was used to send commands to the spacecraft to turn on the thruster. The data were sent back by radio link to, and recorded at, the control room. Realtime decisions were made, on the basis of data received, while conducting all proposed flight operations. Essentially, the prototype spacecraft was "flown on the ground" for over 6 months. This exercise developed a high level of proficiency in experimenters, test conductors, and associated tests, such that actual in-flight control was nearly routine.

During the period from November 1968 to November 1969 the prototype spacecraft was tested for $3500 \mathrm{hr}$. Of this test time $3200 \mathrm{hr}$ were in vacuum and $2400 \mathrm{hr}$ were with a thruster system operating. ${ }^{41}$

In summary, the prototype spacecraft tests established the electrical compatibility of the total integrated spacecraft system (very important because of the high-voltage connector failure of one SERT I thruster), confirmed the total thermal design, evaluated the spacecraft under simulated launch environment, confirmed component reliability for the long mission, and evaluated in-flight control procedures and trained ground personnel.

\section{Flight Spacecraft Qualification}

The flight spacecraft was to be ground tested for sufficient time and at such levels to prove it ready for flight. It was not to be tested, however, so that components would be put in jeopardy of failing during the flight. All components completed flight-level acceptance tests before they were installed on the flight spacecraft. Vibration testing at flight levels was done on the completely assembled flight spacecraft. (Prototype vibration was at 1.5 times flight levels.)
Then a thermal-vacuum acceptance test was made. All systems were operated at high and low design temperatures. Each ion thruster system was operated over its control range for a total of $50 \mathrm{hr}$. Two random minor failures occurred in these thruster tests: An operational amplifier failed in a telemetry circuit and was replaced. A thermistor measuring a structure temperature gave erroneous readings and was also replaced.

The ion thruster operating period was limited to $100 \mathrm{hr}$ to reduce the amount of facility backsputtered material that condensed on the thruster and spacecraft surfaces. Much of the spacecraft, except an ion thruster beam opening, was shielded from backsputtered material by a line-of-site baffle and received minimal contamination. Sputtered deposit films of 0.1 to $0.5 \mu \mathrm{m}$ or greater, had they been allowed to form, could have peeled off when exposed to air and caused electrical shorts between the accelerator grid and the ground screen or the thruster screen grid. Film thicknesses of less than $0.05 \mu \mathrm{m}$ ( $100 \mathrm{hr}$ of ion thruster running) were small enough that no peeling occurred upon atmospheric exposure. If additional ion thruster operating time for other missions would be required before launch, a frozen mercury or insulator beam target surface would allow greater operating time before sputtered film deposits would become a problem.

A compatibility test of the spacecraft communications system with ground receiver stations was performed. ${ }^{41}$ The command threshold and telemetry signal strength was found to be marginal. As a result, the degree of carrier modulation was reduced to permit more reliable ground tracking by using the telemetry signal carrier. The original flight transmitter, which had a phase instability, was replaced with a flight backup transmitter.

\section{Flight Spacecraft Launch Integration}

Launch-based testing was performed by using the prototype spacecraft and spacecraft support unit for the first integrated tests on the launch pad (Western Test Range, Lompoc, California.) The prototype spacecraft was used to allow a late arrival date for the flight spacecraft and to lessen the exposure of the flight spacecraft to the pad environment (dust, salt air). These first tests demonstrated that the ground support equipment was satisfactory to support preflight testing and that there were no spacecraft/launch vehicle electrical interface problems.

When the flight spacecraft arrived at the launch pad, it was checked out in a laboratory area to see if any damage had occurred during shipment. Electrical and mechanical checks were made without disassembly of components that had been validated in prior vibration and thermal-vacuum tests. An exception was made for the power conditioners because they were the heart of the main experiment. The electrical harness was disconnected at the power 
conditioner, and a dummy load was attached. The dummy load was a resistive simulation of the thruster. Successful operation of the power conditioners into the dummy load was noted and the electrical harness from the thruster was reattached to the power conditioner. Easy accessibility of the harness and single-post terminals made reestablishing the system integrity possible.

Electrical tests of the communications and power systems were carried out. Various spacecraft components, such as the squibs, were rechecked. The Freon-14 BACS gas bottle was pressurized to $24 \mathrm{MPa}$ (3600 psi) and leak checked. The horizonal Thorad-Agena was moved to the launch pad and positioned vertically for launching. The spacecraft was then mated to the Thorad-Agena. A standard Agena clamshell shroud was the only protection for the ion thrusters while on the launch pad and during launch to altitude.

On the launch pad, simple communications checks showed that the launch vehicle was able to support spacecraft operation and that the electrical interface was functioning. ${ }^{41}$ Telemetry data from the nitrogen pressure reservoir of a neutralizer propellant tank showed a slight drop in pressure since leaving NASA Lewis (Cleveland, Ohio). This indicated a possible nitrogen leak. Twenty percent xenon gas had been added to the nitrogen to enable leak-detector tests to be performed on the propellant tanks. A leak test that was performed on the pad was negative and the launch schedule was resumed. No anomalous leaking was noted in space, and the neutralizer had sufficient gas pressure to expel all the mercury in the tank, which became empty in 1980, 10 1/2 years after launch. ${ }^{20}$

\section{$\underline{\text { SERT II Flight Results }}$}

The primary objective of the SERT II flight was to demonstrate 6 months of operation of one ion thruster system in space. Auxiliary experiments included (1) direct thrust measurement by two methods, (2) measurement of the beam potential with a beam plasma probe, (3) a neutralizer bias experiment to control the spacecraft potential, (4) thruster efflux measurement, (5) measurement of RFI produced by the ion beam, and (6) measurement of micrometeroid erosion of an aluminum mirror surface. Later (1973 to 1981) additional experiments or tests were performed: (1) cyclic restart tests, (2) extended ion thruster operation, (3) obtaining thrust from the discharge chamber plasma, and (4) demonstrating beam neutralization by using a neutralizer located $1 \mathrm{~m}$ away from the ion beam. The results of all these tests are described in the following sections. The final section of the paper describes thrusterspacecraft interactions.

\section{Initial Ion Thruster System Tests, 1970}

Although the spacecraft was launched on February 3, 1970 , the first ion thruster operation was not begun until
February 10, 1970. The seven days were used to perform a planned series of spacecraft maneuvers and operational confirmations. The sequence to start an ion thruster included $11 / 2 \mathrm{hr}$ of preheat to ensure that mercury would not condense in any part of the ion thruster system. During preheat the neutralizer hollow-cathode discharge was lit and stabilized. In later tests, 1973, it was found that shorter preheat periods of 2 to 12 min were sufficient to preheat and light the hollow cathode. ${ }^{14}$ Following preheat, the main discharge was turned on and stabilized by a discharge control loop that maintained constant discharge current (2 A) by regulating the main propellant flow. The value of discharge current selected produced a known plasma density in the main discharge chamber. The discharge voltage was regulated to $40 \pm 0.8 \mathrm{~V}$. When the beam extraction high voltage was turned on, only enough ions were extracted that the high-voltage-supply current limit (300 mA) was not exceeded. At this point the discharge control loop was disengaged and the normal control loop (propellant regulated to give constant beam current) took over.

Because of the postulated uncertainty of the ion thrust vector causing a possible uncontrolled spacecraft tumbling, the ion thrust was increased stepwise from 30 to 80 to 100 percent of full thrust. The 30 percent step was low enough thrust that if an ion thruster vector misalignment were present, the spacecraft would not tumble out of control and the thruster gimbals could be adjusted to bring the ion thrust vector back through the spacecraft center of mass.

As space operation of the ion thruster showed, no gimbal realignment was required for either thruster at any level of thrust operation nor over their full thruster operating lives. This confirmed (1) that the initial ground alignment of the thruster grid centerline through the spacecraft center of mass was correct, (2) that no grid or support misalignment occurred during launch vibration, and (3) that no measurable ion beam thrust vector change occurred from operational erosion of the grid system.

Ion thruster system 2 was turned on first in space and operated for $42 \mathrm{hr}$ to confirm its correct, nominal, operation. It was turned off and ion thruster system 1 was started on February 14, 1970. It operated continuously (with two brief interruptions) until July 22, 1970. The first interruption was caused by the spacecraft passing through the Moon's shadow during the solar eclipse of March 7, 1970. The shadow caused temporary loss of the main solar power. The thruster was manually shut down before the eclipse and then restarted after the eclipse was passed. The second interruption (July 5, 1970, 2385 hr) was an automatic shutdown initiated by a 2 -min period of repeated high-voltage current overloads. The start attempt, following the shutdown, was normal and the thruster operated until July 22, 1970, when a second 2-min period of high-voltage (current overloads) arcing again caused shutdown. After $3781 \mathrm{hr}$ (5 1/4 months) of operation, ion thruster system 1 had 
developed a high-voltage grid short that would not clear, and endurance testing of thruster 1 stopped. (A detailed discussion of grid shorts can be found in a following section.)

Ion thruster system 2 was started on July 24, 1970, and operated for $2011 \mathrm{hr}$ (nearly 3 months) before a permanent high-voltage grid short occurred on October 17, 1970.

Thruster 2 was manually turned off once during the $2011 \mathrm{hr}$ to allow the spacecraft to pass through the solar eclipse of August 31, 1970. Attempts to clear the grid short in 1970 were unsuccessful, and testing was halted at that time.

Thruster operating characteristics. The two flight thrusters operated in space in a very similar way to that experienced during the ground qualification tests and during the two major ground life tests, $\mathrm{M}$ and $\mathrm{T}$. The thruster power efficiency for all tests was $88 \pm 1$ percent. The thruster overall efficiency was $67 \pm 1$ percent for the two flight thrusters. Ground test T thruster overall efficiency was somewhat lower at 64 percent, possibly owing to an intentional lowering of the power conditioner input voltage during the test. Ground test $\mathrm{M}$ thruster overall efficiency was higher at 73 percent, owing to a lower neutralizer flow rate. The accelerator grid impingement of the flight thrusters, $1.5 \mathrm{~mA}$, was the same in space as when they operated during ground tests. This result indicated that a negligible amount of vacuum-tank-generated charge-exchange ions fell back to the accelerator grid at the vacuum tank pressure of $0.7 \times 10^{-3} \mathrm{~Pa}\left(5 \times 10^{-6}\right.$ torr $)$.

Because the thruster main propellant flow rate could not be measured in flight, ground test values of flow rate were assumed for the flight. This assumption was validated in 1980 to 1981 when the main tanks became empty and integrated flow rates matched (to within 1.6 percent) the total tank capacity. The neutralizer tank had a pressure sensor on the gas side of the blowdown tank, and the reduction in the gas pressure could be used to calculate the neutralizer flow rate. Both neutralizers in flight used the same flow rate, $25 \mathrm{~mA}$ of "equivalent" mercury, but each used only $21 \mathrm{~mA}$ in the ground flight qualification test. Ground endurance test $\mathrm{T}$ used $25 \mathrm{~mA}$ of neutralizer flow and test $\mathrm{M}$ used $14 \mathrm{~mA}$. Whereas test $\mathrm{M}$ had anomalously low mercury flow rates, the flight thruster flow rates were nearly identical in space to those measured in all other ground tests.

At the time of flight the main ion thruster life concern was for erosion of the hollow-cathode orifices. ${ }^{4}$ Excessive main cathode orifice enlargement would have caused a shift in the discharge current beyond the range limit of the discharge supply, leading to a severe drop in discharge voltage and discharge extinction. The cathode, at this point, would still have had many operational hours remaining, but a different discharge control (not available as a flight option) would be required. Neutralizer orifice erosion could lead to an increased neutralizer mercury flow with early emptying of the neutralizer propellant tank. As often happens, the worry items do not cause a problem. The history of the flight operation of both thrusters indicated less erosion change in both the main cathodes and the neutralizer cathodes than was experienced in ground endurance tests. Projected ground-test cathode lives were 7000 to $10000 \mathrm{hr}$, but the projected space-operated cathode lives were 10000 to $15000 \mathrm{hr}$. More details of thruster operation in space and ground tests may be found in Refs. 7, 9, and 12.

Space thrust measurements. Many ion thruster scientists believed that the ion thrust or beam momentum was accurately given by electrically measured values of beam current and accelerating voltage. Beam divergence and multiply charged ions will cause a small loss of thrust, but ground measurements can determine what these values should be. The SERT II mission was able to conclusively demonstrate the correctness of the electrical calculation of thrust by two independent, direct thrust measurements during the flight. ${ }^{23}$ Later, in 1974, a vacuum thrust stand was developed and used for ground thrust measurements of an operating ion thruster. ${ }^{74}$

The first way used to measure the ion thrust was a miniature electrostatic accelerometer (MESA), which measured spacecraft acceleration directly. ${ }^{55}$ Knowing the spacecraft mass, the thrust was determined to an accuracy of \pm 1 percent. Unfortunately, the MESA developed an electronic problem on February 19, 1970, and ceased to function thereafter. Thrust data before failure were obtained at three thrust levels for thruster 1 . These data are summarized and compared with the other thrust measurements in Table VI.

The second way to measure ion thrust was using the ion thruster to change the spacecraft orbital altitude. The thrust vector components for ion thrusters 1 and 2 are shown in Fig. 6. The main thrust vector was along the thruster axis. The thrust vector can be equally represented by a small vector component that is parallel with the orbital velocity vector and a large vector component that is at a right angle and points toward the Earth. The large vector component's thrust had a negligible effect on the spacecraft position. The small vector component, however, did slowly change the spacecraft orbital velocity. For ion thruster 1 this vector component was in the same direction as the orbital velocity,

TABLE VI. - SERT II THRUST MEASUREMENTS

\begin{tabular}{|l|c|c|c|c|l|}
\hline \multicolumn{1}{|c|}{ Method } & \multicolumn{2}{|c|}{$\begin{array}{c}\text { Thrust at three } \\
\text { nominal levels } \\
\text { (in percent), } \\
\mathrm{mN}\end{array}$} & $\begin{array}{c}\text { Error band, } \\
\text { percent }\end{array}$ & Thruster \\
\cline { 2 - 4 } & 30 & 80 & 100 & & \\
\hline MESA & 10.4 & 22.7 & 27.4 & \pm 1 & 1 \\
Orbital change & ---- &.--- & 28.0 & \pm 5 & 1 and 2 \\
Electrical & 11.2 & 23.0 & 28.2 & \pm 2.2 & 1 \\
& 10.5 & 23.3 & 28.4 & \pm 2.2 & 2 \\
\hline
\end{tabular}


added to the orbital velocity, and raised the spacecraft orbit. With ion thruster 1 operating at full thrust, the spacecraft altitude was raised $570 \mathrm{~m}$ per day. For comparison, the natural orbital decay with no thrusting was $0.8 \mathrm{~m}$ per day. For ion thruster 2 with an opposite-to-orbit velocity vector, the spacecraft orbit was lowered. The change in altitude was measured by ground radar skin tracking of the spacecraft. Two to 3 weeks of orbital change was required to obtain an accurate rate of altitude change. Orbital altitude change was measured for each ion thruster. The thrust values thus measured for the two ion thrusters were similar and well within the \pm 5 percent error band of measuring orbital change.

The calculated thrust from electrical data (third thrust evaluation technique) was subject to an error band of \pm 2.2 percent that was caused by the error band of the electrical data. Error due to beam misalignment was assumed to be less than 1 percent because no initial thruster gimbal corrections were needed to correct the spacecraft attitude. Beam divergence was estimated to cause an electrically calculated thrust loss of 1 to 3 percent. ${ }^{23}$ One percent was assumed more likely and was used as a correction factor. Doubly ionized ions in the beam were less than 2 percent and were assumed to have a negligibly small effect on thrust reduction.

As Table VI shows, the three methods used to determine thrust agreed within experimental error. The agreement also confirmed the use of electrical beam current and voltage as a reliable indicator of ion thrust.
Spacecraft potential bias experiment. As Fig. 11 shows, the neutralizer cathode could be biased by the V9 supply. This was done to demonstrate that the spacecraft potential could be controlled by bias of the neutralizer cathode. The normal spacecraft potential was -6 to $-12 \mathrm{~V}$ relative to the space plasma potential with no ion thruster operating and -15 to $-25 \mathrm{~V}$ with a thruster operating. The range of spacecraft potential was caused by orbital position. ${ }^{24}$ The actual value of spacecraft potential was an equilibrium balance between emissions from the spacecraft and ions being received from the local space plasma. Without ion thruster operation, photoemission of electrons and space plasma ram ion current determined the equilibrium potential. With the ion thruster operating, photoemission and ram ion current were small factors. The dominant factor was the ion thruster operation and a balance between ion beam potential and neutralizer-coupling-to-beam voltage drop.

For most of the SERT II mission the neutralizer bias was set at zero. Only when experimenting with spacecraft potential control was the neutralizer bias voltage turned on. Figure 14 shows the result of biasing the neutralizer cathode both positively and negatively. The spacecraft potential was near-linearly controlled by this means over a range of +8 to $-75 \mathrm{~V}$. Good comparison was noted with ground data, which were only several volts higher in potential. No deleterious effect on the spacecraft or subsystems was noted during spacecraft potential bias experiments.

The beam plasma potential is shown in Fig. 15. The most dominant feature was the positive potential electron

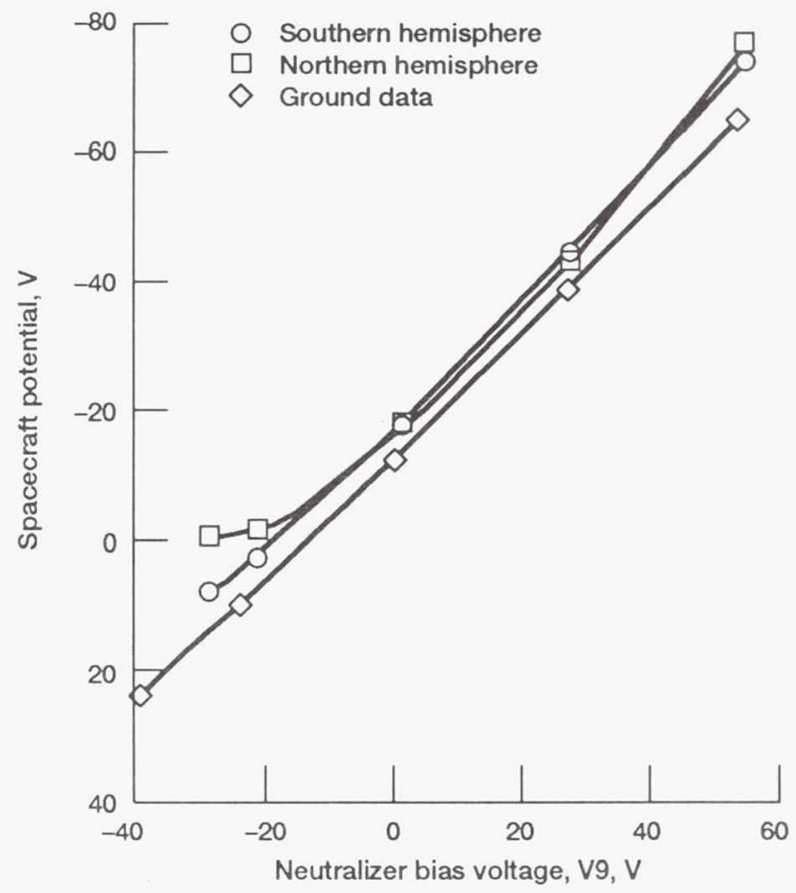

Figure 14.-SERT II spacecraft potential control. Fixed neutralizer parameters: mass flow, $0.05 \mathrm{mg} / \mathrm{s}$; keeper current, $0.2 \mathrm{~A}$; keeper voltage, $23 \mathrm{~V}$. 


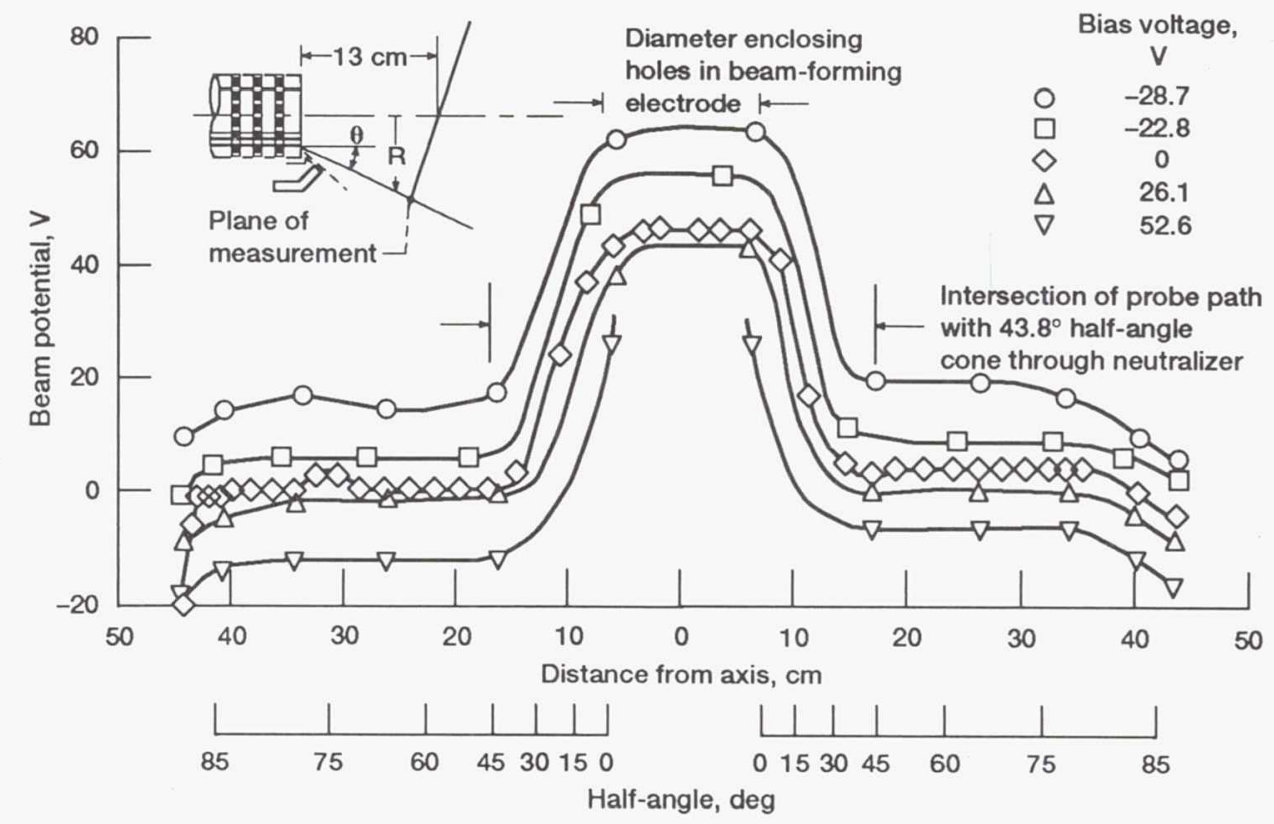

Figure 15. - SERT II thrust beam plasma potentials.

well in the ion beam. The magnitude of the well depth (relative to the spacecraft) changed as the neutralizer cathode bias was changed. The positive beam potential (bottom of the electron well) was close to the space plasma potential. The dropping potential region (sides of the well) was at the beam edge and in the wings (radially outward) were areas of negative (to space) plasma potential that were needed to balance plasma flows to the spacecraft. ${ }^{19}$

The space potential probe operated essentially continuously from launch through August 3, 1970, when a decreasing probe heater current was observed. The probe was then commanded off on August 3, 1970, to conserve the remaining filament life for possible future use. The probe had accumulated $4245 \mathrm{hr}$ of operation by this time. On August 31,1970 , the probe was commanded on to support a test, but the filament failed open at turnon. The space probe electronics were then commanded off and not used for further testing. From tests performed in 1970 the beam plasma potential probe of a nonoperating ion thruster indicated space plasma potential within a few volts. Neither beam probe filament burned out and spacecraft potentials could be measured through 1991 by using the beam probes. ${ }^{19}$

Contamination panel test results. The location of the solar cell contamination panels was poorly chosen. They were located in the region known to have the highest incidence of sputtered accelerator grid atoms. ${ }^{26}$ As predicted, the test solar cell panels became quickly (several days) coated with molybdenum atoms from the accelerator grid, and the experiment was no longer useful. ${ }^{25}$ The possible measurement of condensed mercury propellant atoms was masked by heavy molybdenum condensation. A better panel location would have been in the plane of the accelerator grid or somewhat upstream. ${ }^{66}$ In this location the question of how few accelerator grid atoms were in the forward hemisphere of an ion thruster might have been answered.

Accelerator grid shorts. An operating ion thruster will normally produce thin film deposits of sputtered atoms on all surfaces within the line of sight (or perhaps one "bounce") of the discharge chamber or accelerating grids. These thin deposits, if on a surface with high voltage gradient, can cause a breakdown or spark. The spark will often clean the deposit and stop future breakdowns. (Breakdowns may also initially occur from grid manufacturing surface irregularities or dirt.) The number of breakdowns occurring on the flight thrusters was about the same as those that occurred during ground life tests $\mathrm{T}$ and $\mathrm{M}$. Breakdown frequency ranged from 1 per hour to 1 in $131 \mathrm{hr}$, with time between breakdown usually in the range of 3 to $14 \mathrm{hr}$. The average mean breakdown time for the two flight thrusters and two ground test thrusters were all about the same, $7 \mathrm{hr}$. These spark types of breakdown were not serious. The high-voltage supplies sensed the spark overload and shut off the voltage in $0.12 \mathrm{~ms}$. About $1 \mathrm{~J}$ of energy flowed to a spark before the power supply shut off. This was enough to clean the grid surface but not damage it. $^{10}$

A permanent grid short occurred in each flight thruster after months of operation in 1970 and precluded further thruster operation in 1970. (The short in thruster 2 grids was cleared in 1974 by mechanically spinning the spacecraft.) The permanent grid shorts were believed to be caused by neutralizer-produced mercury ions falling back to and sputtering the accelerator grid. The sputter erosion 
pattern produced a groove in the grid after $4000 \mathrm{hr}$ of ground testing, as shown in Fig. 12. As the erosion groove developed, web-like fragments of the grid were produced, broke off, and in ground tests were later found at the bottom of the vacuum tank. In space where the ion thrusters were in near-zero gravity, the web fragments (it was believed) would not fall away from the grids but would be electrostatically attracted and spotwelded between the grids. The energy of the power supplies before turnoff was not great enough to melt the web fragment. Ground tests performed after the flight grid short failure showed that a piece of wire placed across the screen-accelerator grid system could be lightly spotwelded between grids by using a prototype power conditioner.

The groove erosion was known before flight ${ }^{59}$, but the best solution to reduce groove erosion required mechanical redesign of the thruster, whose design had been frozen. The solution of adding a local double thickness to the accelerator grid provided sufficient assumed life for the grid. The grid short problem caused by the web fragments was not anticipated. The web fragment short problem was never encountered in any ground life test. Other ground research tests, subsequent to the flight failures, showed that relocating the neutralizer farther away from the beam reduced the backflow of neutralizer ions to the accelerator grid to a negligible rate. ${ }^{62}$

\section{$\underline{\text { Radiofrequency Interference Tests, } 1970}$}

Three bands of radiofrequency (RF) radiating from the beam were sensed by antennas located near the ion thrusters. The bands measured were (1) 300 to $700 \mathrm{MHz}$ in 14 steps, (2) $1700 \pm 20 \mathrm{MHz}$, and (3) $2100 \pm 20 \mathrm{MHz}$. In the 300- to 700-MHz band no firm conclusions could be drawn. In these bands the signal was saturated by Earth background RF noise or some apparent malfunction. It was noted, however, that no difference was observed when an ion thruster was turned on. For the $1700 \pm 20-\mathrm{MHz}$ band an average background noise level of about $400 \mathrm{~K}$ was observed for the $\pm 20-\mathrm{MHz}$ bandwidth and no change was observed when an ion thruster was turned on. The results from the $2100 \pm 20 \mathrm{MHz}$ band were the same as for the $1700 \pm 20-\mathrm{MHz}$ band, except that the background noise level was about $200 \mathrm{~K}$. The $200 \mathrm{~K}$ and $400 \mathrm{~K}$ noise levels were assumed to be about the level that one would expect from Earth noise.

Also, there was no RF interference caused by ion thruster operation in the uplink (command) channel of $148.98 \mathrm{MHz}$ or in either of two downlink (command verify and telemetry) channels, $136.23 \mathrm{MHz}$ or $136.92 \mathrm{MHz}$. The onboard receiver contained an automatic gain control (AGC). From time to time the AGC signal would have microvolt-level "jumps" in its output. These jumps in no way affected the quality of data, nor did they necessarily occur concurrently with thruster arcing. No quantitative values of noise level were determined.

\section{Thruster Cycling Tests, 1973 to 1981}

When the SERT II mission was conceived in 1966, most electric propulsion interest was in primary propulsion. Hence, the requirement for the SERT II ion thruster system was that it be capable of an occasional restart any time during its 6-month mission goal. No specific number of restarts was required. By 1973, interest had grown in auxiliary electric propulsion for north-south stationkeeping with hundreds or more restarts required. The main limit of restart capability for a Kaufman thruster was its hollow cathodes. The hollow cathode required a rolled tantalum foil insert containing barium oxide/strontium oxide $(\mathrm{BaO} /$ $\mathrm{SrO}$ ) powder that was heated to activate the cathode surfaces for starting and efficient discharge operation. Although the $\mathrm{BaO}$ chemical reaction was slow, high preheat temperatures and long-term operation could eventually consume all the available $\mathrm{BaO}$ and result in hollow-cathode failure.

When the flight ion thrusters each had a high voltage grid short and could not produce an ion beam, the balance of the ion thruster system was still functional. The mercury propellant tanks contained more than enough mercury to operate the hollow cathodes for many thousand of hours. The spacecraft was working and able to turn on the ion thruster hollow-cathode discharges. Therefore, a new series of tests was conceived for the SERT II spacecraft: namely, to demonstrate the multiple restarts of its hollow cathodes that would be required for auxiliary propulsion applications.

The normal precession of the SERT II orbital plane, however, had resulted in the spacecraft passing through the Earth's shadow during every orbit. During the shadow periods there was no solar power for conducting tests. Therefore, cathode restart tests had to be performed in much less than one orbital period (104 min), and the usual preheat time of $90 \mathrm{~min}$ or longer was not available. In initial tests during 1973 it was found that cathodes would restart in 2 to $12 \mathrm{~min}$. The conservatively long 90 -min or longer preheat period was not needed.

During 1973, thruster 1 cathodes were restarted 82 times and thruster 2 cathodes were restarted 126 times. ${ }^{14}$ Occasionally (six times), the thruster 2 main cathode would not start its discharge in the time available over a ground data receiving station. Rather than leave the cathode in the hot preheat mode with no data retrieval or command capability, the thruster system was shut down when no restart was seen.

Hollow-cathode restart tests were continued when feasible through 1981. During 1980 and early 1981, all mercury propellant tanks were emptied. Each of the four hollow cathodes (two main and two neutralizer) continued to restart for more than 10 years in space until its propellant supply was depleted. Table VII lists the number of hours and restarts before the propellant tanks were empty. The 
TABLE VII. - OPERATING HOURS OF SERT II FLIGHT VAPORIZERS AND CATHODES

(a) Thruster 1

\begin{tabular}{|l|r|r|r|r|r|r|r|}
\hline \multirow{1}{*}{ Year } & \multicolumn{2}{|c|}{ Vaporizer } & \multicolumn{2}{c|}{ Main cathode } & \multicolumn{2}{c|}{ Neutralizer } & Cycles \\
\cline { 2 - 7 } & $\begin{array}{c}\text { Full } \\
\text { power }\end{array}$ & $\begin{array}{c}\text { Reduced } \\
\text { power }\end{array}$ & $\begin{array}{c}\text { Full } \\
\text { power }\end{array}$ & $\begin{array}{c}\text { Reduced } \\
\text { power }\end{array}$ & $\begin{array}{c}\text { Full } \\
\text { power }\end{array}$ & $\begin{array}{c}\text { Reduced } \\
\text { power }\end{array}$ & \\
\hline $1969-81$ & 30 & 7790 & 40 & 7900 & 3031 & 4909 & 240 \\
1989 & 1129 & 0 & 1129 & 0 & 1129 & 0 & 3 \\
1990 & 1178 & 0 & 1178 & 0 & 1178 & 0 & 4 \\
1991 & 6000 & 0 & 6000 & 0 & 6000 & 0 & 4 \\
Subtotal & 8337 & 7790 & 8347 & 7900 & 11338 & 4909 & 251 \\
\hline Total & \multicolumn{2}{|c|}{$16127 \mathrm{hr}$} & \multicolumn{2}{|c|}{$16247 \mathrm{hr}$} & \multicolumn{2}{c|}{$16247 \mathrm{hr}$} & 251 \\
\hline
\end{tabular}

(b) Thruster 2

\begin{tabular}{|l|r|r|r|r|r|r|r|}
\hline $1969-81$ & 35 & 9810 & 106 & 9920 & 5948 & 4078 & 300 \\
1989 & 528 & 0 & 528 & 0 & 528 & 0 & 2 \\
1990 & 1456 & 0 & 1456 & 0 & 1456 & 0 & 4 \\
1991 & 5976 & 0 & 5976 & 0 & 5976 & 0 & 4 \\
Subtotal & 7995 & 9810 & 8066 & 9920 & 13908 & 4078 & 310 \\
\hline Total & $17805 \mathrm{hr}$ & \multicolumn{7}{|c|}{$17986 \mathrm{hr}$} & \multicolumn{1}{|c|}{$17986 \mathrm{hr}$} & 310 \\
\hline
\end{tabular}

total number of restarts was 240 for thruster 1 and 300 for thruster 2. ${ }^{21}$ These tests also demonstrated the long-term space integrity of all the other ion thruster system components, such as the propellant feed system and the power conditioner, as well as the ancillary support and data systems.

\section{Grid Short Cleared, 1974}

The SERT II orbital plane precession was such that by 1974 only a shallow Sun angle illuminated the solar arrays. This shallow angle limited available solar power to less than that required for cathode restarts. Therefore, a new, spin-stabilized spacecraft mode was conceived by Bruce LeRoy of NASA Lewis. In the new mode the spacecraft was turned out of the orbital plane to face the Sun and then spun to $1 \mathrm{rpm}$ by the cold-gas backup attitude control system (BACS) to hold it facing the Sun. The spacecraft still passed through the Earth's shadow, but at other times it received sufficient solar power to perform restart tests. Cathode restarts were resumed in 1974 with the new attitude mode. On September 18, 1974, following normal cathode starting, the thruster high voltage was turned on as a convenient way to shut down the thruster system. Instead of overcurrent cycling until the system overload caused turnoff, thruster 2 sparked a couple of times and again operated with an ion beam. ${ }^{15}$ The centrifugal spin acceleration of 0.001 g's was 2000 times greater than the gravitygradient accelerating force acting on the presumed web fragment short prior to spacecraft spinup. A detailed modeling of possible short-clearing procedures is presented in Ref. 15. The grid short on thruster 1 was still present and continues to be there as of the writing of this paper (November 1991).

Thruster 2 was operated 19 times in 1974 at beam current levels of 30 and 80 percent of the nominal $0.25 \mathrm{~A}$. Normal space degradation of the solar array power limited thruster operation to the 80 percent level. Total beam-on time was only several hours in 1974 because (as for 1973 restart tests) test times were limited to available time over a ground station. Usually, only 6 to $10 \mathrm{~min}$ of beam operation was possible before losing radio contract with the ground station. Later (1979 to 1980) continuous solar power was available, and $664 \mathrm{hr}$ of beam operation was demonstrated in 1979 and 1980 until the neutralizer tank ran dry on July $29,1980 .{ }^{18,20}$ After thruster 2 was run with no neutralizer for $53 \mathrm{~min}$ and at a spacecraft potential of perhaps $-3000 \mathrm{~V}$, a short developed between the thruster body and ground. ${ }^{20}$

\section{5 to 1978 Tests}

In 1975 the SERT II orbital plane was turning the spacecraft solar array away from the Sun, and only limited tests were performed in the months of June and December. Thruster 1 cathodes were restarted three times. Thruster 2 was operated once for $10 \mathrm{~min}$ at the 30 percent thrust level and once for less than $1 \mathrm{~min}$ at the 80 percent thrust level.

In 1976 the thruster 1 cathodes were restarted eight times. Thruster 2 was operated twice at the 30 percent thrust level. In late 1976 the Sun orientation was becoming critical and a solar array reorientation maneuver was planned by Tom Flatley of the NASA Goddard Space Flight Center (GSFC). This maneuver used the BACS to stop the spacecraft spin, then to turn the spacecraft to better face the Sun, and finally to respin the spacecraft in order to maintain the new direction. The maneuver was successful and the new solar array direction provided operational power through $1981 .^{16}$

In 1977 to 1978 , thruster 1 cathodes were restarted 11 times and thruster 2 was operated once at the 30 percent thrust level. ${ }^{17}$ All test results of the 1975 to 1978 period were normal with no problems noted. The main objective was to monitor and maintain the spacecraft to support the 1979 test period when continuous sunlight and power became available to perform long-term continuous operation of thruster 2 .

\section{Cross-Neutralization Test, 1979}

The cross-neutralization test, as were all the tests performed from 1973 to 1991, was not planned as part of the original SERT II mission, which was to operate an ion thruster system in space for 6 months during the year 1970 . The test was conceived inadvertently one day in 1979. On this day thruster 2 was operating at $85-\mathrm{mA}$ beam current to demonstrate continued life. Thruster 1 was also turned on to demonstrate restart capability. After the thruster 1 neutralizer lit, it was observed to be emitting electrons $(8 \mathrm{~mA})$ to space, and the thruster 2 neutralizer emission was reduced by $13 \mathrm{~mA}$. When the discharge chamber of thruster 1 lit, the neutralizer from thruster 1 began to emit $50 \mathrm{~mA}$ of 


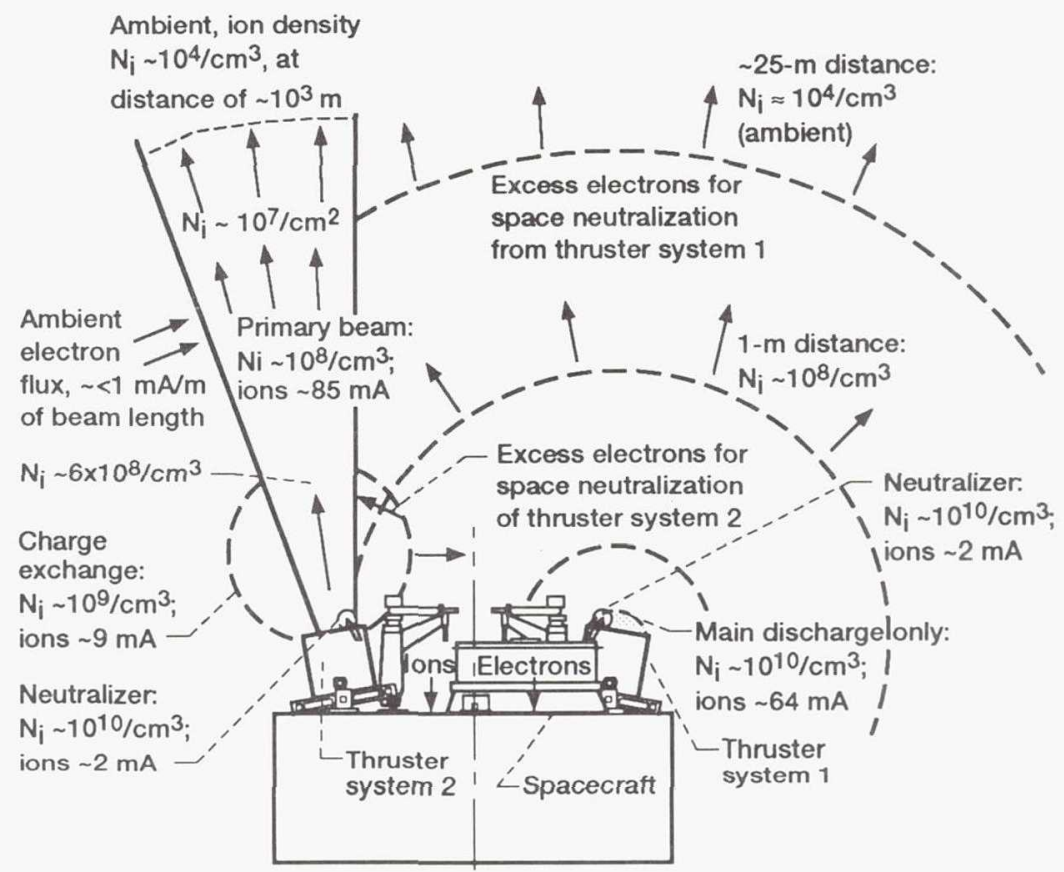

Figure 16. - SERT II spacecraft plasma densities. (Main discharge density measured by Colorado State University in ground tests.)

electrons and thruster 2 neutralizer emission was reduced by $59 \mathrm{~mA}$. These results indicated that the ion beam current of thruster 2 was being partially neutralized by electrons from the thruster 1 neutralizer nearly $1 \mathrm{~m}$ away. ${ }^{19}$ This phenomenon was called cross neutralization. The geometry of the thrusters and neutralizers and their calculated plasma densities are shown in Fig. 16.

A series of planned cross-neutralization tests were performed in 1979. Refer to Ref. 19 for a complete discussion of how cross neutralization was possible with the plasma densities involved. Cross neutralization could be completely controlled by voltage bias of either neutralizer; that is, a positive bias to neutralizer 2 reduced its emissions to zero with all the neutralizing electrons coming from neutralizer 1, and conversely. Tests also showed that neutralizing electrons could even be drawn from the main discharge chamber of thruster 1 when neutralizer 1 was turned off.

The results of the cross-neutralization tests provide the future ion thruster designer with many useful options: (1) The neutralizer may be far away from an ion thruster, thus reducing neutralizer ion erosion of the accelerator grid, (2) a single neutralizer could neutralize the beams of an array of ion thrusters, giving system simplicity and possibly saving neutralizer propellant and power, and (3) neutralizer redundancy is gained by using the main discharge of an idle thruster to provide neutralizer electrons, if required.

\section{Final Thruster Tests, 1979 to 1981}

Continuous sunlight on the solar arrays during 1979 to 1981 provided power for a number of ion thruster tests.
The emphasis during 1973 to 1978 was to demonstrate restart capability when only short (less than $1 \mathrm{hr}$ ) power periods were available. After hundreds of restarts were demonstrated with no change, the emphasis shifted to testing ion thruster endurance, studying new phenomena relating to new modes of thrust operation, and estimating efflux patterns from the ion thruster system. Tests continued until all propellant tanks were emptied.

Beam endurance tests. Because the high-voltage grid short of thruster 1 that occurred in 1970 still remained, only thruster 2 beam was operated. Thruster 2 was run in 1979 and 1980 for a total of $606 \mathrm{hr}$ at $85-\mathrm{mA}$ beam current, $58 \mathrm{hr}$ at $200-\mathrm{mA}$ beam, and $30 \mathrm{~s}$ at $250-\mathrm{mA}$ beam current. Solar array power was marginally low for 250 -mA beam current, and array undervoltage occurred quickly.

While thruster 2 beam was being operated, the thruster gimbals were used to give an offset between the line of thrust and the spacecraft center of mass. This offset and the ion beam thrust caused a torque on the spacecraft and increased its spin rate. ${ }^{18}$ The rate of spin increase corresponded to an ion thrust value of $11.0 \mathrm{mN}$, a value that was in agreement ( \pm 3 percent) with that measured with the miniature electrostatic accelerometer (MESA) in $1970^{12}$ and also in agreement with a thrust calculated from electrical measurement of beam current and beam voltage, $11.2 \mathrm{mN}$.

Thruster 2 was operated with $85-\mathrm{mA}$ beam current until its neutralizer tank became empty on July 29,1980 . With no neutralizer the spacecraft voltage was driven highly negative $(-3000 \mathrm{~V})$ and beam turnaround caused high current overload to the accelerator grid and automatic 
shut-down after $2 \mathrm{~min}$. Later, the automatic overload shutdown was disengaged, and the thruster was operated as a test for $53 \mathrm{~min}$, in which 32000 accelerator grid overloads caused momentary $(0.1 \mathrm{~s})$ shutdowns and reapplication of high voltages. The test was stopped by ground command. On the next day thruster 2 was operated for $1.5 \mathrm{hr}$ by using neutralization from neutralizer 1 . This test was automatically stopped when a short $(<10 \mathrm{k} \Omega)$ occurred between the thruster body and the spacecraft ground. This short ended high-voltage $(3000 \mathrm{~V})$ beam current testing. ${ }^{20}$ Highvoltage cycling tests in 1991 indicated that the short between the thruster body and ground was no longer present but that there was now a short between grids (thruster body to accelerator grid).

Plasma thrust tests. In late 1979 the gimbals on thruster 1 were run to their position limits and allowed to "bump" off the end of the mechanical screw. This bumping action was tried in an attempt to dislodge the web fragment grid short. The short was not cleared and the gimbals were left at an $11^{\circ}$ offset position. Later, when thruster 1 plasmas were turned on to obtain cathode endurance hours, the spacecraft spin rate was slowing down more quickly than the normal damping rate. (Natural damping forces caused a slow despin rate.) Thruster 1 was producing thrust with no high voltage, and because of the gimbal offset was producing a torque that changed the spin rate.

The source of the thrust was discharge chamber ions being accelerated through a sheath of $40 \mathrm{~V}$ (discharge voltage level) as they left the discharge chamber plasma. The torque that was produced corresponded to a thrust of $0.8 \mathrm{mN}$. Assuming the ions had an energy of $40 \mathrm{~V}$, a calculated $64-\mathrm{mA}$ beam of ions was being accelerated. The estimated neutral mercury flow to the discharge chamber was $135 \mathrm{~mA}$. Five or more days were needed to give a torque measurement accuracy of \pm 5 percent.

The plasma potential measured $17 \mathrm{~cm}$ downstream indicated a broad (about 0.4-m diameter) but low potential (3 V) plasma beam (see Fig. 20). When the plasma thrust mode was operated without a neutralizer, the potential profile was still broad, but the potential was much higher ( $31 \mathrm{~V}$ peak). Both thrusters were simultaneously run in the plasma thrust mode to demonstrate cathode durability and propellant tank reliability. During 1979 to 1981 , thruster 1 was operated in the plasma thrust beam mode for $3943 \mathrm{hr}$; and thruster 2, for $6953 \mathrm{hr}$. Testing of both thrusters was stopped when their main propellant tanks were empty. Table VIII gives performance values in the plasma thrust mode.

The SERT II ion thruster was not designed to operate in the plasma thrust mode, and with optimization tests the performance listed in Table VIII should be improved. Knowledge of the plasma thrust mode should benefit spacecraft designers using electric propulsion. For example, (1) an ion thruster in the plasma thrust mode might be used for
TABLE VIII. - PERFORMANCE IN PLASMA THRUST MODE

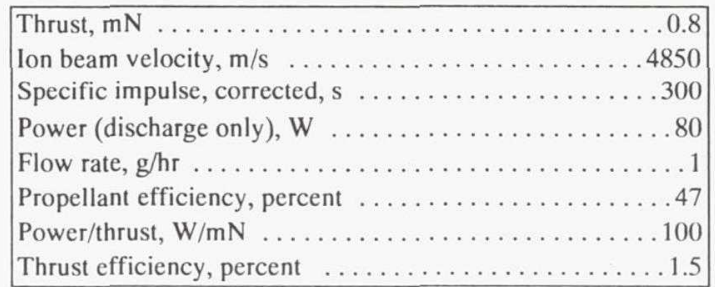

spacecraft attitude or potential control, without the need for a high-power thruster to be operating; (2) an ion thruster in a discharge warmup mode will produce thrust and might require adjustment to account for disturbing torques; and (3) if an ion thruster has suffered a high-voltage failure, it could still produce useful thrust in the plasma thrust mode.

Cathode endurance tests. As already noted in the thruster cycling tests and the plasma thrust tests, the hollow cathodes of the SERT II thrusters showed great durability in space operation. Table VII summarizes the hours and restarts for each hollow cathode.

Operation of each cathode was stopped only by exhaustion of its propellant tank. Life concerns for the hollow cathode were two: depletion of the $\mathrm{BaO}$ activator and cathode orifice erosion. Depletion of $\mathrm{BaO}$ would cause loss of restart capability. This was not seen in SERT II restart tests. All cathodes continued to restart until no mercury remained to support their discharge. Orifice erosion was indicated by a shifting in the hollow-cathode discharge operating characteristics. Main cathode erosion was indicated by an increase in discharge current with time. During flight the discharge current increased at a rate of one-half that which occurred in ground endurance tests. The flight rate of change indicated $15000 \mathrm{hr}$ or more of main cathode life. Neutralizer cathode erosion was indicated by an increase in mercury flow rate. Flight neutralizer flow rates were constant within telemetry accuracy. Ground-test neutralizer flow rates increased 10 to 20 percent with time, but no quantitative estimate of relative cathode erosion rate can be made, except that flight erosion was less.

Neutralizer cathodes received less space testing because their propellant tanks were emptied sooner. This was caused by the higher neutralizer flow rate required for the 85-mA beam current used in later years and a small tank. (When the tank size was chosen, the research neutralizer test flow rates were about two-thirds of those needed by the final qualified flight thrusters.) The main tank, which was designed for a 300-mA mercury flow rate, produced many more hours of flow at the $135-\mathrm{mA}$ flow rate of the plasma thrust tests during 1979 to 1981 , and hence supported more total operating hours for the main hollow cathode.

Cathode heater tests in 1989 to 1991 were conducted at full heater power. This placed greater stress on the heater 
element. Because the propellant tanks were empty, there was no discharge to produce a heater cutback signal. The greater stress produced little or no change in the heater resistances, as is discussed in the next section.

Vaporizer and cathode heaters. The construction details of the cathode and vaporizer heaters may be found in Refs. 13, 59, and 61. The cathode heaters, which were required to preheat the cathode tip to $1500 \mathrm{~K}$ in order to activate the $\mathrm{BaO}$-tantalum reaction, utilized a unique design of flame-sprayed $\mathrm{Al}_{2} \mathrm{O}_{3}$ over and under tungsten-rhenium heater coils to reliably achieve this temperature. The tantalum cathode tube was coated with a thin layer of flamesprayed tungsten, which prevented $\mathrm{Al}_{2} \mathrm{O}_{3}$-tantalum corrosion. After the hollow-cathode discharge was lit, the heater power was reduced to lower the cathode temperature to $1300 \mathrm{~K}$ and conserve both $\mathrm{BaO}$ and heater life. The heating requirement of the vaporizers was less $(600 \mathrm{~K})$, and a swaged heater brazed to the vaporizer wall was used. The heater wire was $1.3-\mathrm{mm}$-diameter Nichrome swaged inside a tantalum tube with $\mathrm{Al}_{2} \mathrm{O}_{3}$ as an insulator. The neutralizer cathode and vaporizer were connected in series and heated by one supply. The mock isolator flow tube was heated by a brazed-swaged heater connected in series with the main cathode heater.

Table IX gives representative values of heater voltages and currents from prelaunch tests through the last tests at the time of this writing (November 1991). As shown in the table the values of heater resistance $(\mathrm{V} / \mathrm{I})$ changed very little even after 16247 to $17986 \mathrm{hr}$ of operation. This total includes many more hours at full heating power (7498 to $13340 \mathrm{hr})$ than originally required $(50 \mathrm{hr})$. Reduced heater power for early mission operation was 30 percent of full for the vaporizer and main cathode heaters and 46 percent of full for the neutralizer heater. Typically, heaters when reaching end of life experienced a resistance increase. The resistance values of Table IX show a random change with time (probably owing to thermal nonequilibrium or to the telemetry system changes with varying spacecraft temperatures and solar array voltages). If any trend in resistance changes is shown in Table IX, it is that resistances were

TABLE IX. - SERT II HEATERS AND KEEPER ELECTRODE DATA ${ }^{a}$

(a) Thruster system 1

\begin{tabular}{|c|c|c|c|c|c|c|c|c|c|c|c|c|}
\hline Date & $\mathrm{V}_{2}$ & $\mathrm{I}_{2}$ & $\mathrm{~V}_{2} / \mathrm{I}_{2}$ & $\mathrm{~V}_{3}$ & $\mathrm{I}_{3}$ & $\mathrm{~V}_{3} / \mathrm{I}_{3}$ & $v_{7}$ & $\mathrm{I}_{7}$ & $V_{7} / I_{7}$ & $V_{10}$ & $\mathrm{~V}_{\mathrm{S} / \mathrm{A}}$ & $\begin{array}{c}\text { Time, } \\
\text { hr }\end{array}$ \\
\hline $12 / 28 / 69$ & (b) & 2.80 & (b) & 15.6 & 2.92 & 5.3 & 10.0 & 2.78 & 3.6 & $>425$ & 73.9 & 83 \\
\hline $02 / 14 / 70$ & 2.74 & 2.80 & 0.98 & 15.6 & 2.88 & 5.4 & 10.4 & 2.90 & 3.6 & $>425$ & 70.3 & 83 \\
\hline $02 / 11 / 71$ & 2.67 & 2.88 & .93 & 15.6 & 2.88 & & 10.4 & 2.90 & 3.6 & 416 & 66.7 & 3877 \\
\hline $05 / 25 / 73$ & 2.74 & 2.80 & .98 & 15.3 & 2.83 & & 10.6 & 2.90 & 3.7 & (b) & 61.3 & 3952 \\
\hline $12 / 06 / 76$ & 2.77 & 2.90 & .95 & 15.3 & 2.83 & $\downarrow$ & 10.2 & 2.94 & 3.5 & 390 & 64.8 & 3977 \\
\hline $07 / 14 / 78$ & 2.67 & 2.88 & .92 & 14.9 & 2.88 & 5.2 & 10.4 & 2.90 & 3.6 & (b) & (b) & 3981 \\
\hline $12 / 05 / 79$ & 2.70 & & .93 & 14.2 & 2.83 & 5.0 & 10.6 & 2.94 & 3.6 & 344 & 59.5 & 4581 \\
\hline $12 / 01 / 80$ & 2.70 & & .93 & 14.5 & & 5.1 & 10.4 & 2.94 & 3.5 & 344 & 57.6 & 7938 \\
\hline $08 / 14 / 89$ & 2.60 & & .90 & 14.5 & & 5.1 & 10.2 & (b) & (b) & 357 & 59.5 & 8177 \\
\hline $10 / 02 / 89$ & 2.67 & & .93 & 14.7 & & 5.2 & 10.2 & 2.58 & 3.9 & 342 & 58.8 & 8680 \\
\hline $05 / 14 / 90$ & & & & 14.5 & & 5.1 & 10.2 & 2.73 & 3.7 & 342 & 57.7 & 9165 \\
\hline $08 / 29 / 90$ & & & & 14.9 & & 5.3 & 10.4 & 2.82 & 3.7 & 342 & 57.7 & 9833 \\
\hline $10 / 30$ & & & & 14.9 & $\downarrow$ & 5.3 & 10.2 & 2.87 & 3.6 & 349 & 59.5 & 10247 \\
\hline $11 / 06 / 91$ & $\downarrow$ & $\downarrow$ & $\downarrow$ & 14.9 & 2.88 & 5.2 & 10.2 & 2.92 & 3.5 & 349 & 59.5 & 16247 \\
\hline $\begin{array}{l}\text { One data } \\
\text { count equals }\end{array}$ & 0.07 & 0.09 & $-\ldots$ & 0.38 & 0.05 & $-\cdots$ & 0.24 & 0.05 & --- & 7 & 1.8 & \\
\hline
\end{tabular}

(b) Thruster system 2

\begin{tabular}{|c|c|c|c|c|c|c|c|c|c|c|c|c|}
\hline Date & $V_{2}$ & $\mathrm{I}_{2}$ & $V_{2} / I_{2}$ & $\mathrm{~V}_{3}$ & $\mathrm{I}_{3}$ & $\mathrm{~V}_{3} / \mathrm{I}_{3}$ & $v_{7}$ & $\mathrm{I}_{7}$ & $\mathrm{~V}_{7} / \mathrm{I}_{7}$ & $V_{10}$ & $\mathrm{~V}_{\mathrm{S} / \mathrm{A}}$ & $\begin{array}{c}\text { Time, } \\
\mathrm{hr}\end{array}$ \\
\hline $12 / 21 / 69$ & (b) & 2.88 & (b) & 15.8 & 2.78 & 5.8 & (b) & 2.87 & (b) & 395 & 66.7 & 63 \\
\hline $02 / 11 / 70$ & 2.77 & 2.88 & 0.96 & & 2.87 & 5.5 & 10.2 & 2.97 & 3.4 & $>425$ & 70.3 & 63 \\
\hline $02 / 26 / 71$ & 2.70 & 2.97 & .91 & & 2.87 & 5.5 & 10.4 & 2.97 & 3.5 & 393 & 66.7 & 2126 \\
\hline $07 / 17 / 73$ & & & & $\downarrow$ & 2.81 & 5.6 & 10.4 & 2.97 & 3.5 & 363 & 61.3 & 2162 \\
\hline $09 / 22 / 76$ & & & & 15.0 & 2.87 & 5.2 & 10.2 & 2.92 & 3.5 & 363 & 63.1 & 2178 \\
\hline $11 / 29 / 77$ & & & & 15.4 & & 5.4 & 10.0 & 2.92 & 3.4 & 386 & 66.7 & 2279 \\
\hline $03 / 07 / 79$ & & & & 14.8 & & 5.2 & 10.4 & 2.92 & 3.6 & 358 & 61.3 & 2757 \\
\hline $02 / 29 / 80$ & $\downarrow$ & & & 14.8 & & 5.2 & 10.1 & 2.94 & 3.4 & 344 & 59.5 & 2985 \\
\hline $12 / 01 / 80$ & 2.63 & & $\downarrow$ & 15.2 & & 5.3 & 10.3 & 2.94 & 3.5 & 344 & 59.5 & 6542 \\
\hline $10 / 02 / 89$ & 2.53 & & .85 & 13.4 & & 4.7 & 9.3 & 2.87 & 3.2 & 313 & 58.8 & 10296 \\
\hline $05 / 14 / 90$ & 2.60 & & .87 & 13.8 & & 4.8 & 9.5 & 2.87 & 3.2 & 320 & 57.7 & 10420 \\
\hline $08 / 29 / 90$ & 2.60 & & .87 & 14.6 & & 5.1 & 10.0 & 2.92 & 3.4 & 335 & 57.7 & 10800 \\
\hline $11 / 30 / 90$ & 2.67 & & .90 & 14.9 & & 5.2 & 10.2 & 2.92 & 3.5 & 349 & 59.5 & 12010 \\
\hline $11 / 06 / 91$ & 2.60 & $\checkmark$ & .87 & 15.2 & $\nabla$ & 5.3 & 10.2 & 2.92 & 3.5 & 349 & 59.5 & 17986 \\
\hline
\end{tabular}

${ }^{a} \mathrm{~V}$ denotes voltage in volts; $I$ denotes current in amperes; subscript 2 denotes main vaporizer:

subscript 3 denotes main cathode and isolator; subscript 7 denotes neutralizer cathode and vapor-

izer; subscript 10 denotes main cathode keeper; subscript S/A denotes solar array.

Data not taken or unavailable. 
getting better (lower) rather than increasing with operating time. The heater designs used in the SERT II ion thrusters are highly recommended for future space applications.

Later, cathode flame-sprayed heaters, which were made by an outside manufacturer for larger (6-mm diameter) cathodes and larger diameter ion thrusters, proved unsatisfactory in ground testing owing to spalling of the flame-sprayed $\mathrm{Al}_{2} \mathrm{O}_{3}$ outer layer.

Insulator resistive changes. The components of a SERT II ion thruster requiring an electrical insulator were (1) accelerator grid to thruster body ( -1500 to $3000 \mathrm{~V})$; (2) thruster body and main propellant tank to spacecraft frame (3000 to $0 \mathrm{~V}$ ); (3) neutralizer keeper to spacecraft frame (430 to $0 \mathrm{~V})$; (4) main cathode keeper to thruster body ( 3430 to $3000 \mathrm{~V}$ ); (5) anode to thruster body (3037 to $3000 \mathrm{~V})$; and (6) neutralizer tank to spacecraft frame $( \pm 50$ to $0 \mathrm{~V})$. Insulators 1 and 2 used sapphire spheres for mechanical alignment within metal caps to provide shadow shielding (see Fig. 9 of Ref. 13). No measurable leakage current was noticed across the sapphire spheres, indicating a standoff resistance of at least $1 \mathrm{M} \Omega$, Insulators 3, 5, and 6 were made of 96-percent-vitrified $\mathrm{Al}_{2} \mathrm{O}_{3}$ with a metal foil shadow shield. Insulator 4 was magnesium oxide $(\mathrm{MgO})$ swaged between an outside tube and a center wire electrode with a metal shield to protect the exposed $\mathrm{MgO}$ surface at the end of the support tube. Insulators 3 and 4 supported cathode keeper electrodes whose mechanical alignment was not as critical as that of the main accelerator grids.

The neutralizer keeper insulator design (96-percentvitrified $\mathrm{Al}_{2} \mathrm{O}_{3}$ ) showed a decrease in resistance with time as Table $\mathrm{X}$ below indicates.

The resistance decrease caused no starting problem although the decreased resistance dropped the neutralizer keeper starting voltage from greater than $400 \mathrm{~V}$ in 1970 to 310 to $340 \mathrm{~V}$ in 1980 and to 280 to $310 \mathrm{~V}$ in 1990 . There was still sufficient keeper voltage to reliably start the neutralizer hollow cathodes until their mercury tanks were empty in 1980. The resistance value in 1980 was temperature sensitive. When the vitrified-alumina insulator was cold (about $300 \mathrm{~K}$ ) its resistance was near 1970 values $(130 \mathrm{k} \Omega$ ), but after 5 to $10 \mathrm{~min}$ of cathode heating (about 400 to $500 \mathrm{~K}$ insulator temperature) the resistance value had dropped to $18 \mathrm{k} \Omega$ (neutralizer 1) and $35 \mathrm{k} \Omega$ (neutralizer 2). No reason can be proven for the resistive changes, but possible causes were (1) condensed sputtered tantalum

TABLE X.-NEUTRALIZER

KEEPER RESISTANCE

\begin{tabular}{|c|c|c|}
\hline Year & $\begin{array}{c}\text { Unit 1 } \\
\text { V8/18 } \\
\mathrm{k} \Omega\end{array}$ & $\begin{array}{c}\text { Unit 2 } \\
\mathrm{V} 8 / 18^{\mathrm{a}} \\
\mathrm{k} \Omega\end{array}$ \\
\hline 1970 & 120 & 130 \\
1980 & 18 & 35 \\
1990 & 11 & 23 \\
\hline
\end{tabular}

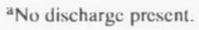

or stainless steel from the beam probe, which was traversed many times in 1979 and 1980; (2) more accelerator grid sputter deposition in space than in ground life tests (where no such resistive changes were noted); or (3) change in bulk resistivity value for the vitrified-alumina insulator material.

The main cathode keeper (V10) showed no drop in opencircuit keeper voltage, except that expected from decreasing solar array voltage with time. Both keeper power supply output voltages were unregulated for input voltage variations. The V10 open-circuit voltage varied from $417 \mathrm{~V}$ at $72-\mathrm{V}$ input in 1970 to 300 to $345 \mathrm{~V}$ at $59-\mathrm{V}$ input in 1980 and 1990. No telemetry channel was used to measure I10 current. The authors believe the swaged-MgO main cathode keeper insulator to be a superior design to the vitrifiedalumina exposed neutralizer keeper insulator; also, the $\mathrm{MgO}$ operating temperature was higher (450 to $550 \mathrm{~K}$ ) than that for the vitrified alumina (400 to $500 \mathrm{~K}$ ).

Propellant feed tank tests. No problems occurred in any propellant tank after 9 to 11 years in space. The operating hours for each propellant feed system corresponded to those hours discussed previously in the section "Cathode endurance tests," or in Table VII.

The neutralizer tank was equipped with a pressure transducer on the gas side ( 80 percent nitrogen plus 20 percent xenon added as a tracer for leak tests). The transducer measured the pressure change with time and, using Boyle's law, gave a calculated mercury volume change with time (i.e., mercury flow rate). Flight neutralizer flow rates so measured were apparently 10 to 20 percent higher than those measured with flow tubes during ground tests. Once the neutralizer tank was empty, all flow rate times and flow rates assumed from ground tests were integrated. This integration confirmed that the flight flow rates were the same as those measured during ground tests. The reason for the apparent higher flight flow rates measured using Boyle's law was that a higher than expected flow of nitrogen was diffusing through the rubber bladder and causing an error in the use of Boyle's law. The flight tank temperature, $375 \mathrm{~K}$ versus $320 \mathrm{~K}$ for ground life tests $\mathrm{T}$ and $\mathrm{M}$, caused the higher nitrogen diffusion rate through the rubber bladder. The calculated change in gas diffusion rates between the two temperatures matched the extra gas pressure drop measured during flight. ${ }^{20}$ Even the higher diffusion rate was low enough to cause no problem with expulsion of mercury from the liquid side. Thus, the design of the propellant feed tank was validated. An improvement for future flights would be in the thermal location of propellant tanks to provide for cooler ( 300 to $320 \mathrm{~K}$ ) temperatures where gas diffusion through the rubber bladder would be negligibly small.

The main propellant tank was of similar design but larger. No pressure transducer was used because the main tanks were at high voltage and a breakdown of the transducer wire insulation would cause failure of the ion thruster 
system. Therefore, no intermediary flight flow rates could be calculated. Once the main tanks were empty, all the times and flow rates were integrated. The integrated flow for main tank 1, assuming ground-measured flow rates, was $13830 \mathrm{~g}$, only 1.6 percent less than the $14050 \mathrm{~g}$ loaded into the tank. The integrated flow for main tank 2 was $14103 \mathrm{~g}$, only 0.4 percent more than what was loaded. ${ }^{21}$ Mercury remaining in the propellant line was less than 0.06 percent. Main tank ullage was never measured, but the flexible bladder should have squeezed tightly against the tank wall. Perhaps less than 0.2 percent ullage remained. This good agreement confirmed that the thruster propellant utilization in space was the same as that measured during ground testing.

Power conditioner performance. The power conditioner performance in space has been perfect from the launch in February 1970 to date (November 1991) without exception. All control loops have been steady and measured operating parameters have been consistent, within telemetry accuracy, with those measured before flight. There has been no evidence of the internal arcing that plagued the ground development program before solutions were achieved.

The power efficiency of the power conditioner was 82.7 percent at full load (i.e., 1055-W input from the solar array bus and $872 \mathrm{~W}$ to the thruster load). The passive thermal control radiated the $183 \mathrm{~W}$ of waste power, primarily from the base plate at $310 \mathrm{~K}$. The internal power conditioner temperature (at full power) was $317 \mathrm{~K}$, in contrast to an anticipated $322 \mathrm{~K}$ and a qualification test temperature of $333 \mathrm{~K}$.

Table XI summarizes the operating hours, off-on cycles, and high-voltage current overloads experienced for each power conditioner unit.

TABLE XI. - POWER CONDITIONER OPERATION

\begin{tabular}{|l|r|r|}
\hline & \multicolumn{1}{|c|}{ Unit 1 } & \multicolumn{1}{|c|}{ Unit 2 } \\
\hline Operating time, hr & 15957 & 17418 \\
Number of off-on cycles & 251 & 310 \\
Number of V5-V6 current trips & 48.4 million & 48.5 million \\
\hline
\end{tabular}
aThesc arc not grid arcs but current overload trips on the V5-V6 supplics.

\section{$\underline{\text { Reflector Erosion Experiment, } 1970 \text { to } 1991}$}

Because of the five-order-of-magnitude uncertainty in micrometeoroid flux models at time of launch, the reflector erosion experiment (REX) (see description in section "Auxiliary Experiments" and Fig. 8) was added to the SERT II spacecraft in order to sense micrometeroid erosion. This erosion would cause a change in the mirror-like quality of the polished aluminum REX disks. The mirror should become a better absorbing surface and its temperature should rise. The heat so absorbed would be reradiated at low thermal temperature. Emittance values at low temperature do not change much for smooth or rough surfaces, so that disk temperature rise becomes a good indicator of surface erosion. The absorptivity of the disks was measured ( 0.111$)$ before flight, as well as the heat transfer constant between the disk and the surrounding box. The REX experiment was designed to measure a $50 \mathrm{~K}$ increase in 6 months if the micrometeroid flux were near the middle of that predicted by the flux models of 1966.56

Space data from the REX showed only a $5 \mathrm{~K}$ rise in temperature during the first 1.5 years (1970 to 1971). The error band, which was caused mainly by the telemetry system, was $\pm 3 \mathrm{~K}$. Thus, only a small flux of micrometeoroids was indicated and longer periods of space exposure were needed to obtain a better quantitative flux number.

REX data were obtained again in 1979 to 1981 and showed almost no increase in disk temperature since 1971. ${ }^{29}$ The disk temperature data had a greater uncertainty, $\pm 6 \mathrm{~K}$, because the spacecraft was spinning and the angle of Sun on the disk was changing. The REX experiment was designed for a normal (perpendicular) Sun angle, and now a correction factor as a function of Sun angle was needed.

In 1990 the SERT II spacecraft was reactivated to obtain data from the REX. The spacecraft orbital precession had gone through one full 20-year period and was returning to an orbit identical to that at launch. The spacecraft no longer needed to be spin stabilized, and Sun direction was excellent for good REX data. Between 1981 and 1990 the spin rate decayed to zero, and the spacecraft turned to face the Sun (minimum-energy position) and was captured in an inverted gravity-gradient-stabilized position. The REX disk temperature again was found to be unchanged $( \pm 3 \mathrm{~K}$ error band) in 1989 to $1991^{30}$ from the value measured in 1970, 1971, 1979, 1980, and 1981. The maximum loss in solar reflectivity after 21 years in space was estimated to be 0.02 (0.89 initial value to 0.87 in 1991$)$. Reflectivity equals one minus absorptivity. Refer to Refs. 29 and 30 for more detailed discussion of surface optical properties, micrometeoroid fluxes, and ram oxygen effects.

\section{Spacecraft Subsystem Performance}

The SERT II spacecraft and its components were designed for a minimum life of 1 year. Where feasible, a goal of a 2-year life or greater was used in selecting components. The purpose of this section is to show that a spacecraft with an electric propulsion system can be built to last many years. Also, many of the spacecraft components that have lasted so long may have uses in other types of spacecraft.

Solar array. The thruster solar array current and voltage output is plotted in Fig. 17(a) for three years (1970, 1980, and 1990). These years were chosen because the Sun angle on the array was closest to perpendicular and the array was 


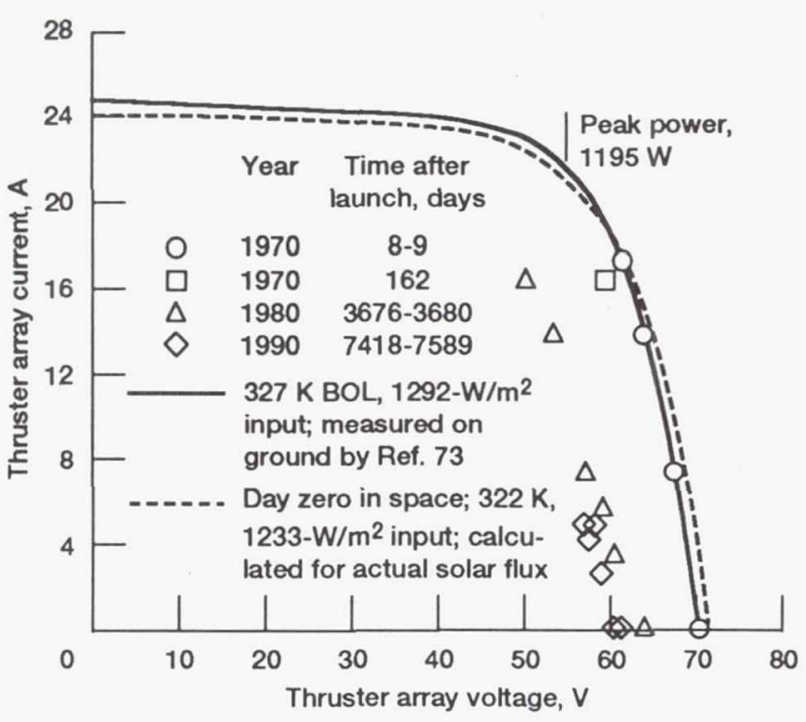

(a) Thruster array.

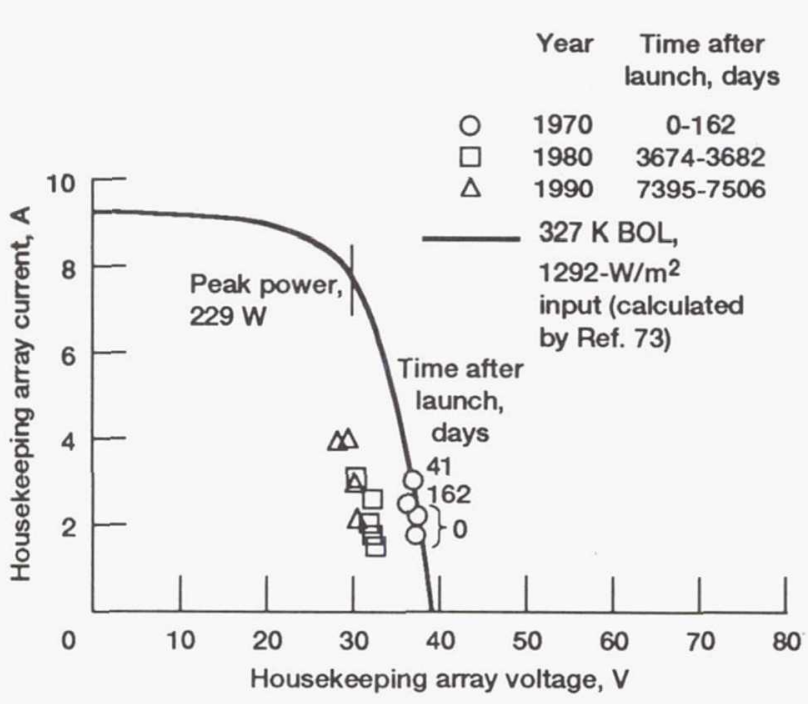

(b) Housekeeping array.

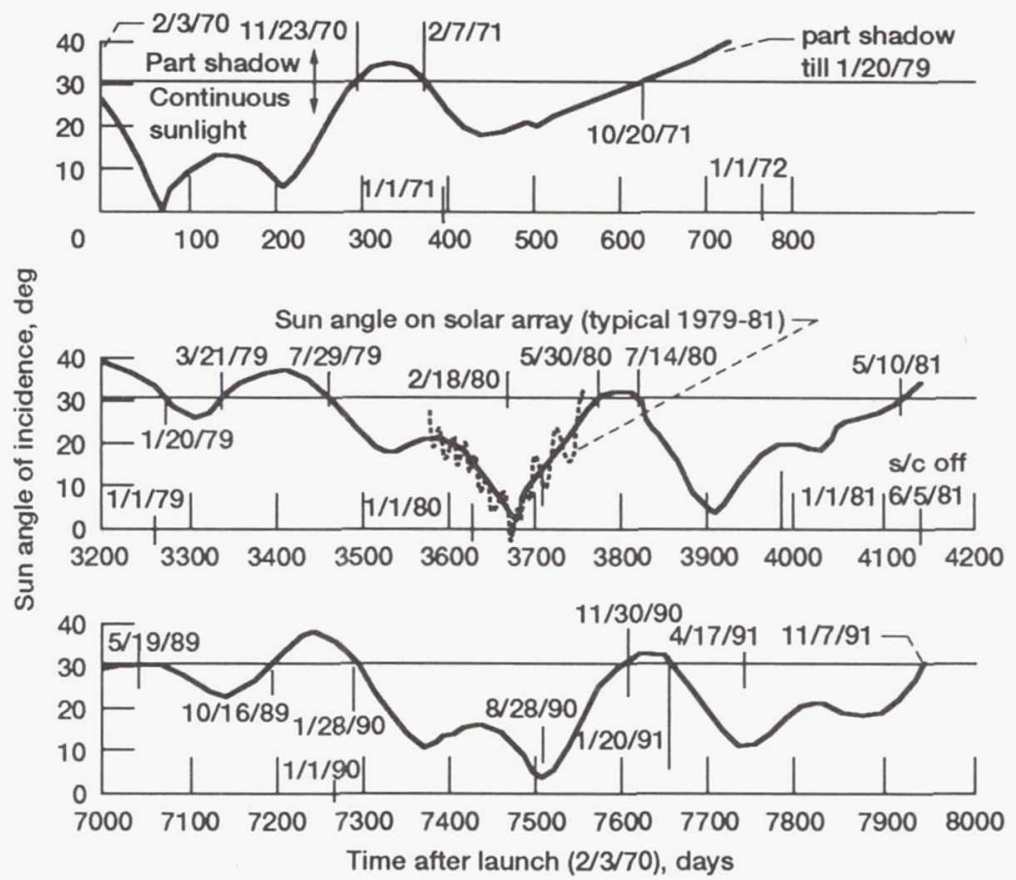

(c) Sun angle of incidence on orbital plane.

Figure 17.-SERT II solar array current-voltage data. (Data have been normalized to $327 \mathrm{~K}(0.3 \mathrm{~V} / \mathrm{K})$. See table XI(a) for actual data including other years.

in continuous sunlight. The voltage data shown in

Fig. 17(a) have been normalized to an array temperature of $327 \mathrm{~K}$ (typical array temperature for perpendicular Sun) by using a correction factor of $0.3 \mathrm{~V} / \mathrm{K}$ (array voltage decreases with increasing temperature). The uncorrected data of Fig. 17(a) plus other thruster array data are listed in Tables XII(a) and (c). The thruster solar array temperature was not constant but varied with the Sun angle of incidence, the location on the array, and the fraction of lighted Earth seen by the array. Three thermistors on each array half or wing were located at each end and in the middle to measure array temperature. ${ }^{45}$ The middle temperature reading for the left wing (Fig. 1(d)) is listed in Tables XII(a)and (c). The thermistor temperatures on the right wing were unavailable after 1971 when their telemetry subcommutator failed. The temperature at the array tip was typically $5 \mathrm{~K}$ cooler, and that at the array root (near the Agena) was $2 \mathrm{~K}$ warmer owing to thermal radiation from the Agena. The array temperature varied with time because of power load, Sun angle, and Earth radiation. Earth radiation caused an array orbital temperature variation of 5 to $14 \mathrm{~K}$ under different Earth surface conditions, such as, day/ night ratio, ocean/land ratio, or polar ice. The orbital temperature variation was not a concern in Table XII(a) data because the array temperature was measured at the same time as the current-voltage data. The middle temperature reading was assumed to represent the average temperature of the array. 
TABLE XII. - SERT II SOLAR ARRAY DATA

(a) Thruster (main) array with load

\begin{tabular}{|c|c|c|c|c|c|c|c|}
\hline \multirow[t]{2}{*}{ Date } & \multirow{2}{*}{$\begin{array}{c}\text { Time after } \\
\text { launch, } \\
\text { days }\end{array}$} & \multirow{2}{*}{$\begin{array}{c}\text { Sun angle of } \\
\text { incidence, } \\
\Theta_{\mathrm{SA}}, \\
\text { deg }\end{array}$} & \multicolumn{4}{|c|}{ Thruster array } & \multirow[t]{2}{*}{ Load } \\
\hline & & & $\begin{array}{c}\text { Temperature, } \\
\text { K }\end{array}$ & $\begin{array}{c}\text { Current, } \\
\text { A }\end{array}$ & $\begin{array}{c}\text { Voltage, } \\
\text { V }\end{array}$ & $\begin{array}{c}\text { Power, } \\
\text { W }\end{array}$ & \\
\hline $02 / 11 / 70$ & 8 & 25 & 325 & 7.4 & 68.5 & 507 & $88 \mathrm{~mA}$, beam 2 \\
\hline $02 / 11 / 70$ & 8 & 25 & 324 & 13.9 & 64.9 & 904 & $203 \mathrm{~mA}$, beam 2 \\
\hline $02 / 12 / 70$ & 9 & 24 & 327 & 17.2 & 61.3 & 1055 & $253 \mathrm{~mA}$, beam 2 \\
\hline $07 / 15 / 70$ & 162 & 14 & 326 & 16.4 & 59.5 & 976 & $253 \mathrm{~mA}$, beam 2 \\
\hline $09 / 11 / 74$ & 1874 & 23 & 328 & 2.5 & 63.0 & 158 & Preheater 2 \\
\hline $09 / 10 / 74$ & 1873 & 23 & 339 & 7.4 & 59.5 & 440 & $83 \mathrm{~mA}$, beam 2 \\
\hline $09 / 11 / 74$ & 1874 & 23 & 337 & 13.9 & 52.3 & 680 & $198 \mathrm{~mA}$, beam 2 \\
\hline $12 / 04 / 75$ & 2130 & 32 & 313 & 2.5 & 64.8 & 162 & Preheater 2 \\
\hline $12 / 04 / 75$ & 2130 & 32 & 337 & 13.1 & 50.4 & ${ }^{a} 660$ & $200 \mathrm{~mA}$, beam 2 \\
\hline $02 / 25 / 80$ & 3679 & 9 & 331 & 2.0 & 59.4 & 119 & Preheater 2 \\
\hline $02 / 25 / 80$ & 3679 & 9 & 332 & 3.3 & 59.4 & 196 & Discharge 2 \\
\hline $02 / 25 / 80$ & 3679 & 9 & 332 & 5.7 & 57.6 & 328 & Low mode 2 \\
\hline $02 / 26 / 80$ & 3680 & 8 & 332 & 7.4 & 55.8 & 413 & $83 \mathrm{~mA}$, beam 2 \\
\hline $02 / 26 / 80$ & 3680 & 8 & 331 & 13.9 & 52.2 & 726 & $200 \mathrm{~mA}$, beam 2 \\
\hline $02 / 26 / 80$ & 3680 & 8 & 330 & 16.4 & 50.4 & a827 & $255 \mathrm{~mA}$, beam 2 \\
\hline $05 / 11 / 90$ & 7397 & 13 & 327 & 4.9 & 57.7 & 283 & Prehcaters 1 and 2 \\
\hline 06/01/90 & 7418 & 15 & 329 & 4.9 & & 283 & Preheaters 1 and 2 \\
\hline $08 / 27 / 90$ & 7505 & 3 & 327 & 4.1 & & 237 & PPU heaters \\
\hline $08 / 29 / 90$ & 7507 & 3 & 324 & 4.9 & $\downarrow$ & 283 & Preheaters 1 and 2 \\
\hline $10 / 30 / 90$ & 7569 & 23 & 325 & 2.5 & 59.5 & 149 & Preheater 1 \\
\hline $04 / 17 / 91$ & 7738 & 9 & 327 & 4.9 & 57.7 & 283 & Preheaters 1 and 2 \\
\hline $11 / 06 / 91$ & 7943 & 30 & 318 & 4.9 & 59.5 & 291 & Preheaters 1 and 2 \\
\hline \multicolumn{3}{|c|}{ One data count equals } & $0.9 \mathrm{~K}$ & $0.8 \mathrm{~A}$ & $1.8 \mathrm{~V}$ & & \\
\hline
\end{tabular}

${ }^{a}$ Close to maximum array power.

TABLE XII.-Continued.

(b) Thruster (main) array, open-circuit voltage

\begin{tabular}{|c|c|c|c|c|c|}
\hline Date & \begin{tabular}{|c|} 
Time after \\
launch, \\
days
\end{tabular} & $\begin{array}{c}\text { Sun angle of } \\
\text { incidence, } \\
\Theta_{\mathrm{SA}}, \\
\text { deg }\end{array}$ & $\begin{array}{c}\text { Array } \\
\text { voltage, } \\
\text { V }\end{array}$ & \begin{tabular}{|c|} 
Array \\
temperature, \\
$\mathrm{K}$ \\
\end{tabular} & $\begin{array}{c}\text { Array voltage } \\
\text { corrected } \\
\text { to } 327 \mathrm{~K} \\
(0.3 \mathrm{~V} / \mathrm{K}) \\
\mathrm{V}\end{array}$ \\
\hline $02 / 04 / 70$ & 1 & 27 & 72.0 & 322 & 70.5 \\
\hline $02 / 04 / 70$ & 7 & 25 & 72.0 & 323 & 70.8 \\
\hline $03 / 07 / 70$ & 32 & 16 & 70.3 & 328 & 70.0 \\
\hline $03 / 25 / 70$ & 50 & 8 & & 331 & 69.1 \\
\hline $05 / 21 / 70$ & 107 & 11 & & 332 & 68.8 \\
\hline $07 / 07 / 70$ & 154 & 14 & $\downarrow$ & 329 & 70.9 \\
\hline $11 / 23 / 70$ & 293 & 26 & 68.5 & 326 & 68.2 \\
\hline $10 / 27 / 71$ & 631 & 31 & 72.0 & 314 & 68.8 \\
\hline $05 / 24 / 73$ & 1270 & 59 & 73.9 & $<310$ & $<68.8$ \\
\hline $09 / 11 / 74$ & 1874 & 23 & 72.0 & 311 & 67.2 \\
\hline $04 / 22 / 76$ & 2268 & 41 & 64.9 & 324 & 63.7 \\
\hline $01 / 22 / 79$ & 3273 & 20 & 64.9 & 322 & 63.7 \\
\hline $02 / 22 / 80$ & 3676 & 12 & 63.0 & 331 & 64.2 \\
\hline $05 / 27 / 90$ & 7413 & 15 & 61.3 & 327 & 61.3 \\
\hline $11 / 28 / 90$ & 7598 & 31 & 61.3 & 324 & 60.4 \\
\hline $11 / 28 / 90$ & 7598 & 31 & 63.0 & 320 & 61.0 \\
\hline $12 / 04 / 90$ & 7604 & 32 & 64.9 & 315 & 61.1 \\
\hline $12 / 04 / 90$ & 7607 & 32 & 68.0 & 310 & 62.9 \\
\hline $05 / 23 / 91$ & 7774 & 15 & 61.3 & 326 & 61.0 \\
\hline $11 / 07 / 91$ & 7944 & 30 & 64.9 & 318 & 62.2 \\
\hline \multicolumn{3}{|c|}{ One data count equals } & $0.9 \mathrm{~V}$ & $0.9 \mathrm{~K}$ & \\
\hline
\end{tabular}


TABLE XII. - Concluded.

(c) Housekeeping array with load

\begin{tabular}{|c|c|c|c|c|c|c|}
\hline Date & Time after & $\begin{array}{c}\text { Sun angle of } \\
\text { launch, } \\
\text { incidence, } \\
\Theta_{\text {SA }} \\
\text { degs }\end{array}$ & $\begin{array}{c}\text { Temperature, } \\
\text { K }\end{array}$ & $\begin{array}{c}\text { Current, } \\
\text { A }\end{array}$ & $\begin{array}{c}\text { Voltage, } \\
\text { V }\end{array}$ & $\begin{array}{c}\text { Power, } \\
\text { W }\end{array}$ \\
\hline $02 / 03 / 70$ & 0 & 27 & 327 & 1.6 & 37.0 & 59 \\
$02 / 03 / 70$ & 0 & 27 & 329 & 2.0 & 37.0 & 74 \\
$03 / 16 / 70$ & 41 & 13 & 333 & 2.8 & 35.2 & 99 \\
$07 / 15 / 70$ & 162 & 13 & 330 & 2.3 & 35.2 & 81 \\
$02 / 20 / 80$ & 3674 & 4 & 331 & 1.3 & 31.5 & 41 \\
$02 / 26 / 80$ & 3680 & 10 & 332 & 1.6 & 30.6 & 49 \\
$02 / 23 / 80$ & 3677 & 5 & 332 & 1.9 & 30.6 & 58 \\
$02 / 23 / 80$ & 3677 & 5 & 333 & 2.4 & 30.6 & 73 \\
$02 / 28 / 80$ & 3682 & 14 & 329 & 2.9 & 29.8 & 86 \\
$05 / 09 / 90$ & 7395 & 13 & 329 & 2.8 & 29.8 & 83 \\
$05 / 26 / 90$ & 7412 & 15 & 329 & 3.9 & 28.9 & 113 \\
$06 / 30 / 90$ & 7447 & 15 & 324 & 3.8 & 29.8 & 113 \\
$07 / 27 / 90$ & 7474 & 11 & 328 & 2.0 & 30.7 & 61 \\
$08 / 28 / 90$ & 7506 & 3 & 329 & 2.0 & 29.8 & 60 \\
$04 / 17 / 91$ & 7738 & 9 & 327 & 2.5 & 29.8 & 73 \\
$11 / 06 / 91$ & 7943 & 30 & 318 & 3.4 & 29.8 & 102 \\
\hline \multicolumn{2}{|l|}{ One data count equals } & $0.9 \mathrm{~K}$ & $0.4 \mathrm{~A}$ & $0.9 \mathrm{~V}$ & \\
\hline
\end{tabular}

The solid curve of Fig. 17(a) was calculated by the array manufacturer using ground measurements from panels of the flight array. The dashed curve of Fig. 17(a) is an estimated curve for the actual solar flux, $1233 \mathrm{~W} / \mathrm{m}^{2}$, initially on the solar array when it was deployed in orbit at $322 \mathrm{~K}$. The early 1970 thruster array data fall close to these calculated curves. After 9 and 162 days in space, small but measurable radiation degradation had occurred. After 3690 days (10 years) in space the thruster array showed increased degradation. By 7500 days ( 20 years) only a small additional degradation occurred. Unfortunately, there was no way to load the thruster array beyond $4.9 \mathrm{~A}$ in 1990 . Each ion thruster was out of propellant and could not produce an ion beam, which was the principal load for the array.

Figure 17(b) shows data in a similar format for the housekeeping portion of the solar array. The 1970 data are very close to the manufacturer's predicted curve. Some radiation degradation was noted after 160 days in space. Marked but expected housekeeping array degradation was noted in 1980 after 10 years and in 1990 after 20 years in space. The voltage data of Fig. 17(b) have been normalized to $327 \mathrm{~K}(0.3 \mathrm{~V} / \mathrm{K})$ but are listed unnormalized in Table XII(c).

Figure 17(c) is a plot of the Sun angle of incidence $\Theta_{S}$ on the SERT II orbital plane. The plot shows three major time periods when the spacecraft was in continuous Sun (i.e., 1970-71, 1979-81, and 1989-91). When $\Theta_{\mathrm{S}}$ was greater than $31^{\circ}$, the spacecraft passed into the Earth's shadow for part of the orbit. When $\Theta_{\mathrm{S}}$ was less than $31^{\circ}$, the spacecraft was in continuous sunlight.

For the years 1970 to 1973 and 1989 to 1991 the spacecraft was gravity-gradient stabilized, and the solar array was coplanar with the orbital plane to $\pm 2^{\circ}\left(\Theta_{\mathrm{SA}}=\Theta_{\mathrm{S}} \pm 2^{\circ}\right.$, where $\Theta_{S A}$ is the Sun angle of incidence on the solar array). For the years 1974 to 1981 the spacecraft was slowly spinning to keep the solar array facing the Sun. A natural precession or coning of the spacecraft spin axis occurred while the spacecraft was spinning and caused the solar arrays to move out of the orbital plane by as much as $60^{\circ} .{ }^{14,15}$ The $\Theta_{\mathrm{SA}}$ values of Table XII have been corrected for the out-of-plane cone angles for 1974 to 1981 . For the years 1979 to 1981 the cone angle was $4^{\circ}$ to $6^{\circ}$ and only small corrections were needed for these years. Figure 17(c) shows a dotted line of actual Sun angle of incidence on the solar array (not the orbital plane) due to the spin cone angle. The cone angle and the precession rate are a function of the spacecraft spin rate, which was being changed by ion thrusting. ${ }^{21}$

Figure 18 is a plot of thruster array relative peak power as a function of time in orbit. The solid curve in Fig. 18(a) was predicted by the array manufacturer for the flight array in a $1000-\mathrm{km}$ circular polar orbit. There were only two measured points near peak power for the thruster array. These points were measured on December 4, 1975, and February 26, 1980, with the ion thruster at beam current for about $30 \mathrm{~s}$, followed by a rapid undervoltage shutdown as the power edged past the peak power point. A similar thruster undervoltage shutdown at peak power occurred in 1977 at 33 percent of full beam current, but there was a greater degree of uncertainty in the data because of the $54^{\circ}$ Sun angle of incidence at the time and they were not plotted. The other plotted peak power points (circular symbols) were estimated by using solar array data at less than peak power and extrapolating along an assumed $\mathrm{I}-\mathrm{V}$ curve to the peak power point. As can be seen in Fig. 18(a), the actual peak power was always better (higher) than the manufac- 


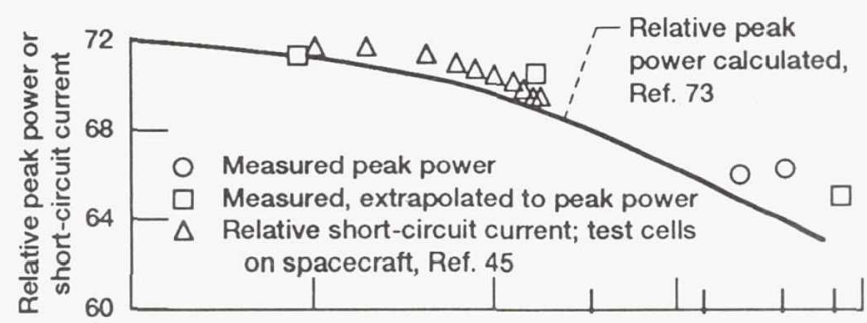

(a) Relative peak power.

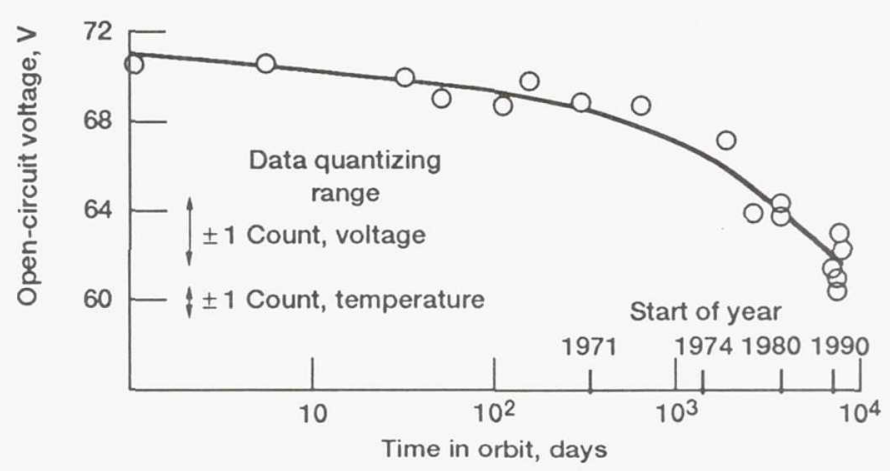

(b) Open-circuit voltage.

Figure 18.-Radiation degradation of SERT II thruster solar array.

turer's predicted curve. This indicates (1) that the solar array received less radiation damage than predicted and (2) that contamination from the ion thruster systems was minimal or zero.

Also shown in Fig. 18(a) is the relative short-circuit current measured for the first 162 days in orbit and reported in Ref. 45. The short-circuit current was measured by two test cells located on, but mechanically and electrically separate from, the solar array structure. Data beyond day $162(7 / 15 /$ 70) were not taken.

Figure 18(b) shows the open-circuit voltage for the thruster array. The open-circuit voltage has degraded from $71 \mathrm{~V}$ at launch in 1970 to $61 \mathrm{~V}$ in 1990 . The open-circuit voltages plotted in Fig. 18(b) have been normalized to $327 \mathrm{~K}$ by using the factor $0.3 \mathrm{~V} / \mathrm{K}$. The actual measured array current and voltage values used for Fig. 18(b) may be found in Table XII(b).

The housekeeping solar array (Fig. 17(b) and Table XII(c)) was never loaded to peak power intentionally, but the extrapolated peak power of 1990 was a ratio of 0.67 to that of the 1970 (day zero) predicted peak power of $230 \mathrm{~W}$. The 0.67 ratio compares closely with the 0.65 fraction for the relative peak power of the thruster array in the same year, 1990.

In September 1974 an interesting observation occurred. ${ }^{51}$ The spacecraft was spin stabilized with the solar array generally pointed toward the Sun. The spin axis, however, precessed with a 2- to 5-week period. During part of this precession period the solar array was facing away from the Sun. When this happened, the Earth albedo energy caused the solar array to put out enough power (about 15 percent of direct Sun power) that normal communications could be maintained with the spacecraft.

Thus, the solar array has been capable of supplying power to operate the spacecraft for 21 years in space without a problem. The fact that the array power degradation was always less than predicted indicated no significant contamination from ion thruster operation.

Thermal surfaces. An analytical thermal model for the spacecraft skins was validated by tests with the prototype spacecraft in a vacuum tank. ${ }^{49}$ Flight data showed (with one exception) no unexpected change in the temperatures of any thermal surface. ${ }^{37}$ Thermal surfaces were white Z-93 paint, black paint, or aluminum tape depending on the temperature control desired. ${ }^{38}$ The thermal design held the spacecraft within the desired temperature range for all conditions of Sun direction or thermal load from components. (References 33, 37, 38, and 49 give detailed information on the analytical model, the surface application, and the operating temperatures.) The one exception was to a Z-93 painted panel facing the Sun. It showed rapid degradation in the first week after launch, whereas neighboring Z-93 panels only experienced normal, slow degradation. Other authors concluded that some ground contamination had occurred on that panel during launch or launch pad procedures. ${ }^{37}$ All the other Z-93 panel temperatures were normal $(293 \mathrm{~K})$ and only changed their solar absorptance by 0.04 in $6000 \mathrm{hr}$ after launch. ${ }^{37}$ In 1990 , Z-93 panel temperatures were 293 to $298 \mathrm{~K}$. The variation was caused by a varying heat input from Earth. The black paint panels and the aluminum-surfaced panels continue to give expected temperatures after 21 years in space. 
The REX aluminum disk, which was closer to the ion thrusters than most spacecraft skins, showed little change in solar absorption. This also confirms that only the surfaces in a direct line of sight of the thruster accelerator grids were receiving atom deposition from the ion thrusters. (The direct-line-of-sight contamination experiment was discussed earlier in this paper.)

Backup attitude control system. The backup attitude control system was designed to be used to restore spacecraft attitude should any event cause it to be lost. As described earlier, it consisted of two sets of three gas nozzle jets and a central pressurized gas bottle. No emergency has arisen in the 21 years of spacecraft operation to date. The BACS system was used, however, to perform some mission operations that were not originally planned. In 1971 the BACS was turned on to confirm its design and to temporarily tip the spacecraft upside down to take RFI data with its antenna looking toward space instead of toward the Earth. In 1973 to 1978 the BACS was used five times to reorient the spacecraft to face the Sun and to spin up the spacecraft to maintain the new orientation. In 1979 to 1981 the BACS was used six times to despin the spacecraft when ion thruster operation had spun it to $5 \mathrm{rpm}$, which was considered too fast for mechanical integrity.

Direct observation of the spacecraft in July 1990 indicated that when it was captured by gravity-gradient forces sometime between 1981 and 1989, it was captured upside down. The ion thruster end was pointed away from the Earth. Because this direction caused some cooling and anomalous spacecraft telemetry output, the BACS system was used in August 1990 to rotate the spacecraft $180^{\circ}$ in order to return the ion thruster end to pointing Earthward. Because of a ground command error, gas to the nozzles was left on too long and an overspin with a period of $18 \mathrm{~min}$ resulted. In September 1990 another series of gas jet operations was executed to reduce the 18 -min spin. Unfortunately, a ground communication problem caused one nozzle to be left on $1 \mathrm{~min}$ too long and put the spacecraft into a slow (15-min period) tumble. After 4 weeks the damping force of the control-moment gyroscopes had reduced the tumble rate to a level where normal gravity-gradient forces stabilized the spacecraft in the normal gravity-gradient attitude. Throughout the 21-year spacecraft life, nozzle valves and pressure regulators all gave normal responses. The gas bottle still contains about one-half of its initial gas load.

Tape recorders. Two analog tape recorders (described earlier in the section "Data, Command, and Telemetry"), each capable of $144 \mathrm{~min}$ of data storage, were used in 1970 and in the early part of 1971 to give 100 percent coverage of the SERT II data. Later in 1971 to January 1972 the data coverage time was reduced to 80 percent. In January 1972 tape recorder 1 failed. The drive motor and on/off functions still worked, but no data were being recorded. Robert Zakrajsek of NASA Lewis proposed two possible failure mechanisms. One, the drive capstan may have been coated with silicon from the tape, permitting the tape to slip. Two, the 6.3-mm-wide tape may have broken or come off its track. Tape recorder 2 continues to function as of November 1991, the last time that it was used. As a sort of time capsule, one orbit of data was recorded on November 1, 1991, so that the tape may be played back at a future time to document the 1991 condition of the spacecraft.

Total recording use of tape recorder 1 at failure was $9900 \mathrm{hr}$ during a 23 -month period in space. Tape recorder 2 has logged over $10300 \mathrm{hr}$ of recording during the past 21 years in space.

Horizon scanners. The most remarkable feature of the horizon scanners was that their 1970 design life was $50 \mathrm{hr}$ and to date they have been operated for $2463 \mathrm{hr}$ over the past 21 years. It was recommended in 1970 that they only be used for $10 \mathrm{~min}$ at a time to conserve their operating life. But because they operated without problem, they were often operated for $2 \mathrm{hr}$ at a time, and several times they were intentionally left running for tens of hours and once for $1728 \mathrm{hr}$.

Normal horizon scanner output was received from 1970 through the middle of 1981 when the spacecraft was deactivated. At that time there were 690 operating hours and several hundred on-off cycles. When the spacecraft was reactivated in 1989 , both scanner heads spun when commanded on, but one scanner head failed to give electronic output. The other head had normal output and gave rollaxis position for 23 different orbits in 1989 to 1991 with $46 \mathrm{hr}$ of operation.

Control moment gyroscopes. The four CMG's are still operational after 21 years in space. Two CMG's were designed to operate as a pair, with the other pair as a backup. One pair of CMG's was always spinning from launch through January 1972. In May 1973 the CMG's were again turned on to support cathode restart tests until September 1973. From September 1973 to 1988 the spacecraft was spin stabilized and no CMG's were used. In June 1989 and through the present, one or two pair of CMG's have been spinning to help stabilize the spacecraft in order to obtain reflector erosion experiment and solar array data. REX data reduction was dependent on maintaining the REX surface in the orbital plane with a known Sun angle of incidence.

The total time of CMG operation in space over the past 21 years has been greater than $61000 \mathrm{hr}$ with more than $45000 \mathrm{hr}$ on the single CMG with the greatest number of operating hours.

Telemetry and command. The command system remains 100 percent functional after 21 years of in-space operation. The telemetry system still remains functional although one 
of four subcommutators failed in 1971. This failure resulted in the loss of 60 of the 1200 data channels. Many of the channels affected were redundant on other telemetry channels.

The operational hours logged to the end of 1991 operations (November 29, 1991) are as follows: command system, switching mode regulators, and command receivers, $100000 \mathrm{hr}$; data system, $72000 \mathrm{hr}$; transmitter 1 , $61000 \mathrm{hr}$; transmitter 2, $22000 \mathrm{hr}$; main inverter, $56000 \mathrm{hr}$; and standby inverter, $18000 \mathrm{hr}$. William Loftus of NASA Lewis has been the main person responsible for sending commands and receiving and displaying SERT II data for the last 11 years of the mission. Edward Petrik of NASA Lewis was responsible for the ground processing hardware and for writing new software programs as mission objectives changed from 1979 to 1991.

All spacecraft systems were turned off on November 29, 1991, with the spacecraft in a gravity-gradient stable position. Although no present plans call for reactivating the spacecraft, the spacecraft is capable of accepting turnon commands whenever solar array power is present.

Housekeeping backup battery. The spacecraft support unit (SSU) was originally specified and designed to operate without the aid of battery power. A battery was added as an enhancement early in the SSU development process. The fact that the power system was designed to function normally without battery power was especially beneficial to the extended mission operation of the SERT II spacecraft.

The 40-Ahr, silver oxide-zinc battery was not connected to the ion thruster subsystem bus but was only an emergency power source for spacecraft housekeeping loads. This battery remained on a float charge during normal spacecraft operation in 1970 . It automatically supplied power to the spacecraft housekeeping loads during four brief intervals in 1970 and 1971 when the spacecraft passed through the Moon's shadow. Significant battery cycling began to occur on November 23, 1970, when Sunsynchronous orbits ended and the spacecraft entered the Earth's shadow for a portion of each orbit. This sequence of 14 partial eclipse orbits per day continued for 75 days until Sun-synchronous orbits resumed on February 8, 1971. These partial eclipse orbits resulted in 1020 discharge cycles, with an average discharge time of 12 min each orbit, being accumulated on the battery.

The spacecraft did not enter the Earth's shadow again until November 15, 1971, when continuous eclipse orbits began (for the next several years). The battery was last observed functioning normally on July 14, 1972. It had accumulated 3277 discharge cycles, of an average $30 \mathrm{~min}$ each, during the November 15, 1971, to July 14, 1972, period. The battery was observed to have failed (shorted) during a spacecraft systems check on May 9, 1973. The 29 months of battery operation documented exceeded by about a factor of 2 the predicted battery life. The number of discharge cycles (well over 4000) significantly exceeded the battery design rating.

\section{Inactive Spacecraft Floating Potential}

The SERT II spacecraft contained probes that could sense the potential of the spacecraft as it orbited the Earth and interacted with the local space plasma. When the spacecraft ion thrusters were operating ("active" spacecraft), the spacecraft was surrounded by a plasma caused by the ion beam. This plasma, being more dense than the local space plasma, dominated the spacecraft potential. When the ion beam (or neutralizer discharge) was off, the now "inactive" spacecraft potential showed variation as a function of orbital position. A variation in spacecraft potential (a 5-V DC shift) also was measured when the ground connection of the solar array was switched from a center voltage ground $( \pm 30 \mathrm{~V})$ to a negative-end ground $(60 \mathrm{~V}$ to $0 \mathrm{~V})$. The following section will describe extensive (15 separate complete orbits of spacecraft potential) data taken during 1991 and compare it with data taken in $1970,{ }^{24} 1974,{ }^{15}$ and 1979. ${ }^{19}$

The spacecraft contained three hot-wire probes as described earlier. The spacecraft potential probe burned out in August 1970, and its data are shown only in Fig. 19(a). Each of two beam probes, which were made of heavier filament wire, continued to operate without failure. As Ref. 24 indicates, the beam probe potentials were very close (one telemetry count or $2.4 \mathrm{~V}$ ) to those measured by the spacecraft potential probe for an inactive spacecraft. The spacecraft probe, although on continuously, was sampled only once every $4 \mathrm{~min}$. The beam probes were sampled every $4 \mathrm{~s}$ but were designed to turn off after completing each 1-min sweep (about 15 data points) of the ion beam. In 1991, commands were sent to stop the sweep motor before probe turnoff at the end of a sweep, thus enabling continuous beam probe data. The data of Figs. 19(b), (c), and (e) were all taken with the beam probe of ion thruster 1 (probe 1 ). The data from probe 2 (ion thruster 2) tracked probe-1 data but were one telemetry count lower and are not presented in Fig. 19.

The data of Fig. 19(a), which were probably taken in March 1970, show the spacecraft driven negative to $-12 \mathrm{~V}$ when it passed over the equator southbound, or sunset. ${ }^{24}$ Northbound data, or sunrise, from the same report showed a steady spacecraft potential of $-7 \mathrm{~V}$ for all latitudes. The authors of Ref. 24 attempted to correlate data in terms of sunset or sunrise orbital position. As the Earth's plasma rotated with the Earth at $1000-\mathrm{km}$ altitude, the nighttime plasma took more than 44 min to reach the spacecraft, sufficient time for daytime plasma equilibrium. We believe that the sunset-sunrise differences in spacecraft potential were due to longitudinal positions of the spacecraft and not 


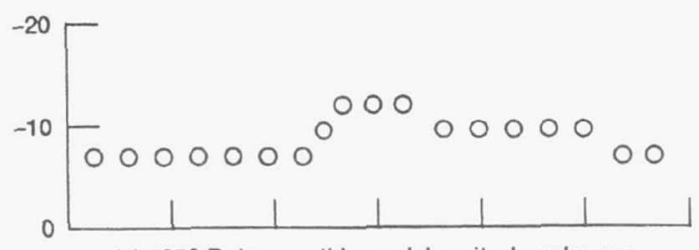

(a) 1970 Data: southbound; longitude unknown.

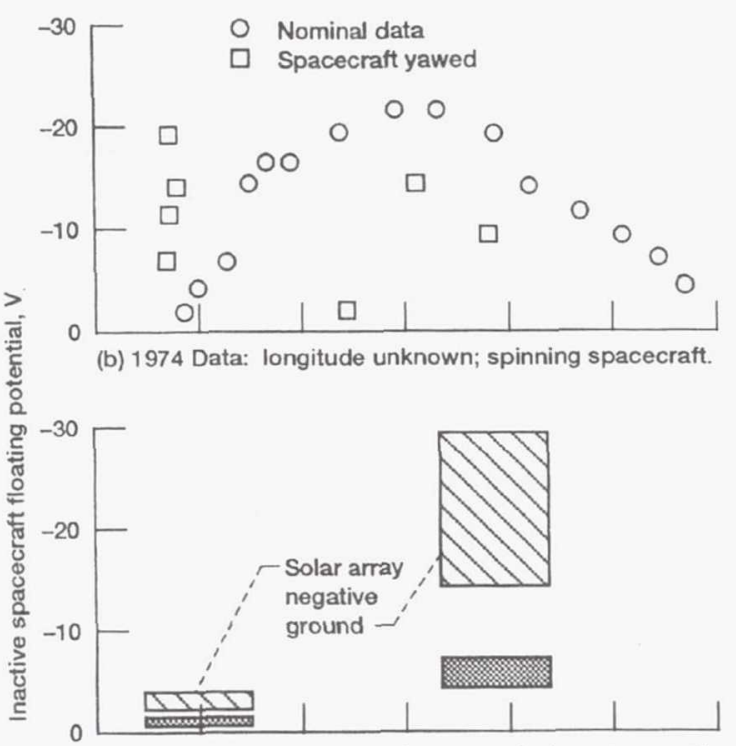

(c) 1979 Data: longitude unknown; spinning spacecraft.
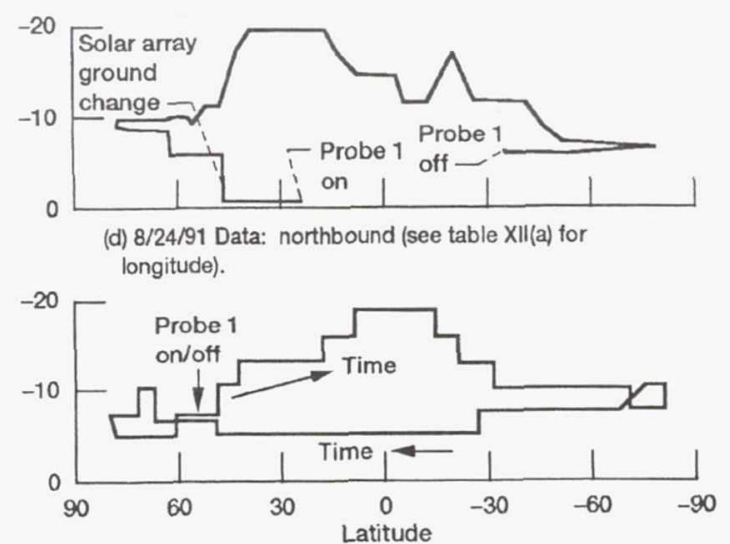

(e) 10/25/91 Data: southbound (see table XII(b) for longitude).

Figure 19.-Comparison of inactive spacecraft potentials at various mission years

nearness to the Earth's shadow. Unfortunately, no longitudinal data were reported for Fig. 19(a). ${ }^{24}$

The 1974 data of Fig. 19(b) were taken with a slowly spinning spacecraft, which was then necessary to maintain the solar arrays facing the Sun. The floating spacecraft potential again tended to be more negative at equatorial regions. ${ }^{15}$ However, the magnitude was larger and there was more data scatter. We believe that both the scatter and the larger magnitude were caused by the spinning spacecraft. The spin axis was not normal to the orbital plane and resulted in a yaw angle up to $50^{\circ}$ for the solar array panels to the spacecraft motion vector. The front side of the solar array contained $0.4 \mathrm{~m}^{2}$ of exposed metal cell-interconnect- ing tabs at potentials varying from $30 \mathrm{~V}$ to $-30 \mathrm{~V}$. Depending on the yaw angle, more ram ion current would be collected, making the spacecraft less negative; or more electrons would be collected by the positive interconnect tabs, which were now out of the spacecraft wake, thus causing a more negative spacecraft. Unfortunately, no records remain to tie the data of Fig. 19(b) to any specific yaw angles.

The 1979 data of Fig. $19(c){ }^{19}$ show even less detail on spacecraft position than Fig. 19(b) and also contain the yaw uncertainties noted for Fig. 19(b). The data of Fig. 19(c) show a step change in spacecraft potential with change of solar array ground connection. Some longitudinal informa- 
TABLE XIII. - SPACECRAFT VOLTAGE POTENTIAL DATA IN 1991

[Floating potential was constant between times listed.]

(a) $8 / 24 / 91$ data (northbound)

\begin{tabular}{|c|c|c|c|}
\hline Latitude & $\begin{array}{c}\text { West } \\
\text { longitude }\end{array}$ & GMT $^{\mathrm{a}}$ & $\begin{array}{c}\text { Floating } \\
\text { potential, } \\
\mathrm{V}\end{array}$ \\
\hline 25 & 68 & 0910 & -2.2 \\
\hline 45 & 73 & 0916 & -2.2 \\
\hline 49 & 78 & 0921 & -7.0 \\
\hline 62 & 80 & 0922 & -7.0 \\
\hline 65 & 89 & 0923 & -9.4 \\
\hline 81 & 91 & 0929 & -9.4 \\
\hline 55 & 180 & 0939 & -9.4 \\
\hline 52 & -118 & 0940 & -11.8 \\
\hline 49 & -115 & 0941 & -11.8 \\
\hline 45 & -113 & 0942 & -14.3 \\
\hline 42 & -112 & 0943 & -16.7 \\
\hline 39 & -111 & 0944 & -19.1 \\
\hline 19 & -105 & 0950 & -19.1 \\
\hline 15 & -104 & 0951 & -16.7 \\
\hline 9 & -102 & 0953 & -14.3 \\
\hline-1 & -100 & 0956 & -14.3 \\
\hline-5 & -99 & 0957 & -11.8 \\
\hline-15 & -97 & 1000 & -14.3 \\
\hline-19 & -96 & 1001 & -16.7 \\
\hline-22 & -95 & 1002 & -14.3 \\
\hline-25 & -94 & 1003 & -11.8 \\
\hline-41 & -89 & 1008 & -11.8 \\
\hline-45 & -88 & 1009 & -9.4 \\
\hline-51 & -85 & 1011 & -7.0 \\
\hline-81 & 0 & 1022 & -7.0 \\
\hline-32 & -84 & 1039 & -7.0 \\
\hline
\end{tabular}

${ }^{\mathrm{a}} \mathrm{GMT}=$ Grecnwich mean timc.

tion was noted in that more negative spacecraft potentials occurred over the South Atlantic Ocean.

When SERT II spacecraft extended operations were resumed in 1990 to 1991, only one ground station was available with the appropriate very-high-frequency (VHF) transmitting and receiving frequencies. That station was NASA Wallops Island in Virginia ( $37^{\circ} 50^{\prime} \mathrm{N}$ latitude, $76^{\circ}$ $30^{\prime} \mathrm{W}$ longitude). Probe data were received both in real time as the spacecraft passed overhead and by use of an onboard tape recorder that taped a full orbit. On the next pass over Wallops Island the taped data were transmitted to the ground. Fifteen such recorded orbits were obtained in 1991. Twelve of these orbits were northbound (see Fig. 19(d)) and three were southbound (see Fig. 19(e)). Although both northbound and southbound orbits passed over Wallops Island, each followed a different longitudinal path (as a function of latitude). The exact latitude, west longitude, Greenwich mean time (GMT), and spacecraft potential are listed in Tables XIII(a) and (b) for the northbound and southbound passes, respectively. The uncertainty in exact position was $\pm 1^{\circ}$ for latitude and $\pm 3^{\circ}$ for longitude at middle latitudes and $\pm 6^{\circ}$ at high $\left(<60^{\circ}\right)$ latitudes.

The data of Fig. 19(d) started at $25^{\circ}$ latitude and were flat for $6 \mathrm{~min}$. At $6 \mathrm{~min}$ a ground command was sent to switch (b) 10/25/91 data (southbound)

\begin{tabular}{|c|r|r|c|}
\hline Latitude & $\begin{array}{c}\text { West } \\
\text { longitude }\end{array}$ & GMT $^{d}$ & $\begin{array}{c}\text { Floating } \\
\text { potential, } \\
\mathrm{V}\end{array}$ \\
\hline 55 & 67 & 2130 & -9.4 \\
49 & 70 & 2132 & -11.8 \\
43 & 72 & 2134 & -14.3 \\
19 & 80 & 2141 & $-14.3 /-16.7$ \\
10 & 82 & 2144 & $-16.7 /-19.1$ \\
-14 & 88 & 2151 & $-19.1 /-16.7$ \\
-21 & 90 & 2153 & $-16.7 /-14.3$ \\
-31 & 92 & 2156 & $-14.3 /-11.8$ \\
-73 & 121 & 2209 & $-11.8 /-9.4$ \\
-81 & 180 & 2213 & -9.4 \\
-75 & -124 & 2217 & $-9.4 /-11.8$ \\
-72 & -117 & 2218 & $-11.8 /-9.4$ \\
-26 & -89 & 2232 & $-9.4 /-7.0$ \\
48 & -69 & 2354 & $-7.0 /-9.4$ \\
67 & -55 & 2300 & $-9.4 /-11.8$ \\
70 & -51 & 2301 & $-11.8 /-9.4$ \\
81 & 0 & 2306 & -9.4 \\
78 & -81 & 2312 & $-9.4 /-7.0$ \\
59 & -91 & 2315 & $-7.0 /-9.4$ \\
53 & -95 & 2317 & $-9.4 /-11.8$ \\
41 & -101 & 2321 & -11.8 \\
\hline
\end{tabular}

the solar array ground from center tap $( \pm 30 \mathrm{~V})$ to negative ground $(60 \mathrm{~V}, 0 \mathrm{~V})$ and the spacecraft potential was driven $5 \mathrm{~V}$ more negative. The potential change occurred in less than $4 \mathrm{~s}$ after the command was sent. Four seconds was the update time between probe data. The spacecraft potential was driven to a magnitude of $-19 \mathrm{~V}$ over eastern China. A smaller magnitude secondary peak of $-16.7 \mathrm{~V}$ was recorded over the Indian Ocean west of Australia. The spacecraft potential then dropped to $-7 \mathrm{~V}$, its base-level reading, until it was turned off. For the 12 northbound orbits recorded the peak magnitude and the secondary peak always occurred near the peak data of Fig. 19(d) within a range of $\pm 7^{\circ}$ latitude and $\pm 15^{\circ}$ longitude.

The southbound data of Fig. 19(e) show similar trends (i.e., a base level potential of $-7 \mathrm{~V}$, a peak of $-19 \mathrm{~V}$, and a somewhat smaller secondary peak of $-12 \mathrm{~V}$. However, the main peak now occurred over Ecuador and the secondary peak near Kazan, Russia. For the data of Fig. 19(e) the probe was on for a longer time than for Fig. 19(d) and a complete orbit was obtained. For all of the 1991 data the spacecraft was gravity-gradient stabilized (as in 1970), and the probable change in yaw axis was confined to $\pm 1^{\circ}$.

A rigorous analysis of the changes in floating spacecraft potential is beyond the scope of this report, but a brief discussion will be made. An explanation for the shift in space- 
craft potential with switching of the solar array ground position is as follows: Because the exposed solar connector tabs were at a more positive potential when the ground was $0 \mathrm{~V}$, they tended to collect a greater number of space plasma electrons. The spacecraft was driven to a more negative potential to reduce this collection and to maintain a charge balance. The exact quantitative potential change is difficult to model.

The changes in floating spacecraft potential with orbital position were possibly caused by the spacecraft charge balance being changed by a variation in space plasma electron temperature. Private analysis by Prof. Paul Wilbur of Colorado State University indicated that changes in space plasma density would not change the floating potential. Arrival rates of ions and electrons tend to balance, and density terms cancel out of, the charge balance equations. A higher plasma electron temperature, however, would tend to increase electron flow to the spacecraft, driving it to a greater negative magnitude. An analysis of the Earth's magnetic field on spacecraft charging has not been attempted, but magnetic field changes also may have changed the spacecraft potential.

The next three paragraphs will discuss the hot-wire probe accuracy of measuring spacecraft potential and details of the spacecraft surfaces that are important to charge balance. All three of the hot-wire probes were designed to the same philosophy (i.e., transformer heat a tantalum filament until it can emit several milliamperes). The filament was connected electrically to spacecraft ground through a $10-\mathrm{M} \Omega$ resistor. The current in the resistor was measured and converted into a telemetry signal. Typical probe emission currents were only $3 \mu \mathrm{A}$ or less, so that the probe filament potential was close $(<1 \mathrm{~V})$ to plasma potential and most of the potential $(<30 \mathrm{~V})$ between the space plasma and the spacecraft occurred across the $10-\mathrm{M} \Omega$ resistor. The probeto-space plasma potential difference was an electron sheath. The calculated sheath potential difference depended on probe emission current and plasma density, and varied between $0 \mathrm{~V}$ and $-1 \mathrm{~V}^{22}$ The probes were laboratory calibrated while immersed in a plasma and showed no detectable difference $( \pm 0.2 \mathrm{~V})$ with a $8 \times 10^{3} / \mathrm{cm}^{3}$ to $6 \times 10^{6} / \mathrm{cm}^{3}$ change in plasma density or with a range of emission currents up to $10 \mu \mathrm{A} .^{22}$ Because the spacecraft telemetry system discrimination (one count) was $2.4 \mathrm{~V}$ and typical probe readings were up to $21 \mathrm{~V}$, the effect of the probe sheath voltage drop was negligible.

The difference (one count, $2.4 \mathrm{~V}$ ) in spacecraft potential that was sensed by beam probes 1 and 2 either was experimental error in the telemetry system or was caused by the plasma wake effect due to the proximity of the beam probe mounting structures to the beam probe filament. The fixed, stationary beam probe position was very near that shown in Figs. 6 and 7. Wake effects on probe data for a nonspinning spacecraft (1970 and 1991) should be small because only the probe structure would produce a wake on the filaments. The characteristic size of this wake was smaller than the probable local plasma sheath length. Spacecraft-spinning probe data in $1979^{19}$ showed that the beam probe reading was one count lower in plasma potential when the probe was in the wake of the large $(1.5-\mathrm{m}$ diameter) spacecraft body. Depending on the spin axis angle and the yaw angle, the probe was not always in the wake of the spacecraft body.

Details on the spacecraft surfaces were as follows: (1) The ram area of the spacecraft (for zero yaw) was $10.4 \mathrm{~m}^{2}$ with a calculated ram ion current of $0.24 \mathrm{~mA}$ for the $1000-\mathrm{km}$ altitude of the spacecraft. If the yaw would go to $30^{\circ}$, as it did at times in 1974 and 1979 , the ram ion current would increase by 50 percent. (2) Photoemission areas were aluminum skin, $8.4 \mathrm{~m}^{2}$; Z-93 white paint, $2 \mathrm{~m}^{2}$; and quartz coverglass on solar cells, $17.4 \mathrm{~m}^{2}$. Photoemission should be constant because the spacecraft was always negative with approximately the same surfaces facing the Sun. The authors estimate the photoemission at $0.47 \mathrm{~mA}$ or less. (3) The solar cell interconnect tab area was uniformly proportioned from $30 \mathrm{~V}$ to $0 \mathrm{~V}$ for each panel. Figure 3(a) shows the arrangement of panels at $30 \mathrm{~V}$ to $0 \mathrm{~V}$ (positive panels) and at 0 to $-30 \mathrm{~V}$ (negative panels). The 18 solar array panels dedicated to the spacecraft housekeeping power needs were configured with their negative terminal hard wired to the spacecraft structure (ground).

In summary, the beam probe potential measurements indicated substantial and reproducible change (up to $12 \mathrm{~V}$ ) in spacecraft potential as a function of orbital position. Also, changing the solar array ground position caused a $5-\mathrm{V}$ step change in spacecraft potential. The probable error in the spacecraft potential data of Fig. 19 was zero to $2.4 \mathrm{~V}$ with a maximum error of $5 \mathrm{~V}$ (true spacecraft potential being more negative).

\section{Thruster-Spacecraft Interactions}

This section will summarize only the findings from the SERT II program on thruster-spacecraft interactions. The format of this section will follow that of Ref. 64 and organize the subject matter into five major areas. Some of these results have been presented in earlier sections but will be briefly given again. References will be noted that support or extend the results of the SERT II mission. To the authors' knowledge, no published results contradict any SERT Il "interactions" finding presented herein. Conducted electromagnetic interference (EMI) between the thruster and the power conditioner, or to the spacecraft, can be found in the prior section on thruster power conditioner development and will not be repeated here. The reference list contains a few of the many fine summaries in the literature on thruster-spacecraft interactions for other spacecraft. ${ }^{68,69,70,71}$ 


\section{Nonpropellant Particle Efflux}

The chief nonpropellant particles, as noted for the electron bombardment ion thruster, ${ }^{64,67}$ were molybdenum atoms that were sputtered from the thruster accelerator grid. The direction of these atoms was in the hemisphere downstream of the accelerator grid. The density distribution followed a cosine pattern with the thruster as a point source if viewed from the far field. ${ }^{74}$ Near-field (less than five thruster diameters) distribution would still be cosine, but with a disk source instead of a point source of molybdenum atoms. As noted in many places in the literature, $57,58,71$ less than 1 percent of these atoms were ionized by charge exchange with the primary ion beam. There was a low probability of any electric or magnetic field being able to direct molybdenum ions out of the rearward hemisphere back to a SERT II spacecraft surface in the forward hemisphere. As noted earlier, after 21 years there was no evidence of molybdenum deposition on any optical, thermal, or insulator surface in the forward hemisphere. The contamination cell experiment, which was placed to intercept sputtered molybdenum, did record a predicted amount of deposited molybdenum. ${ }^{25,26}$

Outgassing of the thruster system when first heated in space can also be a source of nonpropellant atoms. This problem was minimized on the SERT II spacecraft by (1) using materials of construction that had low outgassing; (2) after performing thruster system qualifying tests in vacuum, allowing the components to cool before backfilling the vacuum tank with dry nitrogen or dry air (water desorption was more difficult and may have adversely affected $\mathrm{BaO}$ on the cathode surfaces); and (3) when first in space, gently heating the thruster system components to permit them to outgas. Later outgassing was not required because insufficient gas molecules exist in space.

Another source of nonpropellant particle efflux that was unique to the SERT II spacecraft was the emissive beam probe $^{24}$ that was swept through the ion beam. The probe was traversed approximately 100 times on thruster 2 and 50 times on thruster 1 . The beam probe arm exposed $320 \mathrm{~mm}^{2}$ of tantalum and $710 \mathrm{~mm}^{2}$ of stainless steel to sputtering by the primary beam for $10 \mathrm{~s}$ per probe sweep. Table XIV lists the calculated total amount of sputtered material from the beam probe arm.

\section{TABLE XIV. - CALCULATED AMOUNT OF SPUTTERED MATERIAL FROM BEAM PROBE ARM}

\begin{tabular}{|c|c|c|}
\hline \multirow{2}{*}{$\begin{array}{c}\text { Thruster } \\
\text { beam probe }\end{array}$} & Tantalum & Stainless stecl \\
\cline { 2 - 3 } & Amount of sputtered material, g \\
\hline 1 & 0.008 & 0.013 \\
2 & .016 & .026 \\
\hline
\end{tabular}

The direction of the sputtered tantalum and stainless steel was from the flat bottom of the probe arm toward the thruster accelerator grid. Again the sputter flux density and distribution would follow a cosine law. Most of the sputter flux would condense on the thruster, with some going to space, to the top deck of the spacecraft, or to the lower part of the contamination cell experiment structure. Because no appropriate sensors were located on these surfaces, no condensation from the beam probe arm could be noted. Other surfaces of the spacecraft, such as the solar array and the horizon scanner lens, were shielded (line of sight) by the top deck. Because the beam probe was an experiment and would not be present in future ion thruster applications, it has no effect on the design of spacecraft that use ion thruster propulsion.

\section{Neutral Propellant Efflux}

The SERT II thruster at full thrust emitted $0.13 \mathrm{mg} / \mathrm{s}$ of neutral mercury atoms through the accelerator grid. These atoms possessed thermal ( 400 to $500 \mathrm{~K}$ ) velocities and were directed downstream with a cosine distribution. Most atoms traveled in a straight line to space because their mean free path was over $50 \mathrm{~m}$ for the densities present in the beam. Some atoms made charge ion encounters with beam ions. In these encounters the slow atoms became positively charged, and if formed near $(<10 \mathrm{~mm})$ the accelerator grid, were drawn to the accelerator grid. If they were formed $10 \mathrm{~mm}$ or more downstream of the accelerator grid, they were radially accelerated to tens of volts energy by the potential gradient in the beam plasma. The radial chargeexchange ions produced a dilute plasma at the beam edge (helpful for transporting neutralizer electrons) and then drifted radially into space. A few might strike surfaces on the top deck of the spacecraft but would do negligible sputtering damage owing to their low energy. The beam ion that lost its charge in the encounter would continue to travel in a straight line, roughly parallel with the other beam ions, but as an energetic neutral atom.

Most of the surfaces on the SERT II spacecraft were too warm to permit mercury condensation and showed no evidence of mercury propellant condensate. One exception was the cold surface of the contamination cell experiment, which was designed to sense mercury condensation. As mentioned earlier, this experiment location was poorly chosen and received enough molybdenum deposition to mask any mercury condensation. ${ }^{25}$ The contamination cell experiment is shown in Fig. 5 as a rectangular surface (behind each ion thruster) with two square solar cell surfaces recessed in the larger rectangle. The cold square was the smaller one and was radiatively cooled to $233 \mathrm{~K}$. The warm cell was designed to operate at $333 \mathrm{~K}$.

The neutralizer cathode emitted $0.05 \mathrm{mg} / \mathrm{s}$ of neutral mercury atoms in a cosine pattern directly into the primary 
ion beam and partly downstream. The amount of these atoms was one-third of those coming out of the thruster and added to the neutral density near the thruster, before drifting out to space or becoming charge exchanged.

\section{Ion Beam}

The primary ion beam consisted of a well-collimated $\left( \pm 15^{\circ}\right.$ half-angle) beam of $250 \mathrm{~mA}$ of mercury $(\mathrm{Hg}+)$ ions and a calculated 1 percent beam of charge-exchanged $\mathrm{Hg}$ atoms. An estimated 1 percent of the beam ions were in a zone between $15^{\circ}$ and $45^{\circ}$ half-angles with negligible beam ions beyond $45^{\circ}$. Enough electrons were trapped in the positive potential of the beam to produce a neutral plasma. The beam probe measured the width of the beam plasma potential and confirmed ground tests of the beam's $\pm 15^{\circ}$ edge divergence. Ground tests indicated that the average beam divergence was $8^{\circ}$ or about a 1 percent thrust loss. Ion beams of $200 \mathrm{~mA}$ and $85 \mathrm{~mA}$ of $\mathrm{Hg}+$ ions were also produced but were not well documented in $1970 .{ }^{24}$ Extensive probing of an $85-\mathrm{mA}$ beam was done in $1979 .{ }^{19}$ The 1979 beam probe results indicated a $\pm 15^{\circ}$ beam divergence at $85 \mathrm{~mA}$, but the beam plasma potential was 15 to $20 \mathrm{~V}$ lower owing to the lower value of beam current. Figure 20 shows the beam plasma potential of both 250 -mA and $85-\mathrm{mA}$ beams. The spacecraft potential (relative to space plasma) could be influenced by many things in addition to the current level of the ion beam. The higher beam level, $250 \mathrm{~mA}$, pushed the spacecraft potential about $12 \mathrm{~V}$ more negative than for the $85-\mathrm{mA}$ level. The spacecraft potential was maintained very close $(0$ to $-5 \mathrm{~V})$ to space potential by operating an ion thruster in the plasma mode ( no highvoltage grid ion extraction $)^{20}$ or just simply by operating a single plasma bridge neutralizer cathode. ${ }^{15}$

With no operating ion beam or plasma source the spacecraft potential was determined by an equilibrium between positive ram ion current, photoemission current, and space plasma electrons attracted to the exposed, positive, metal connectors in the solar array.

The equilibrium spacecraft potential (no ion beam or plasma source operating) was measured in 1970 at -4 to $-12 \mathrm{~V}$ with the variation being a function of the spacecraft latitude. In 1974, with the solar array center tap to ground (array voltage equal to $\pm 30 \mathrm{~V}$ instead of $60 \mathrm{~V}$ to $0 \mathrm{~V}$ ), the equilibrium potential was -2 to $-21 \mathrm{~V}$ and was again dependent on the spacecraft latitude. Reference 15 states that the potential variation may have been caused by differences in solar illumination or by local anomalies in space plasma. However, one orbital test in 1990 (and future 1991 tests) indicated nearly constant, $-5 \pm 2 \mathrm{~V}$, spacecraft potential over an entire orbit.

Figure 16 shows a cross section of the spacecraft and ion thrusters with plasma density estimates of the primary ion beam, the charge-exchange plasma, and the neutralizer plasma. Calculations of the primary ion beam density show it to be a good conductor to, or contactor with, space plasma. About $1 \mathrm{~km}$ of beam distance would enable thermal

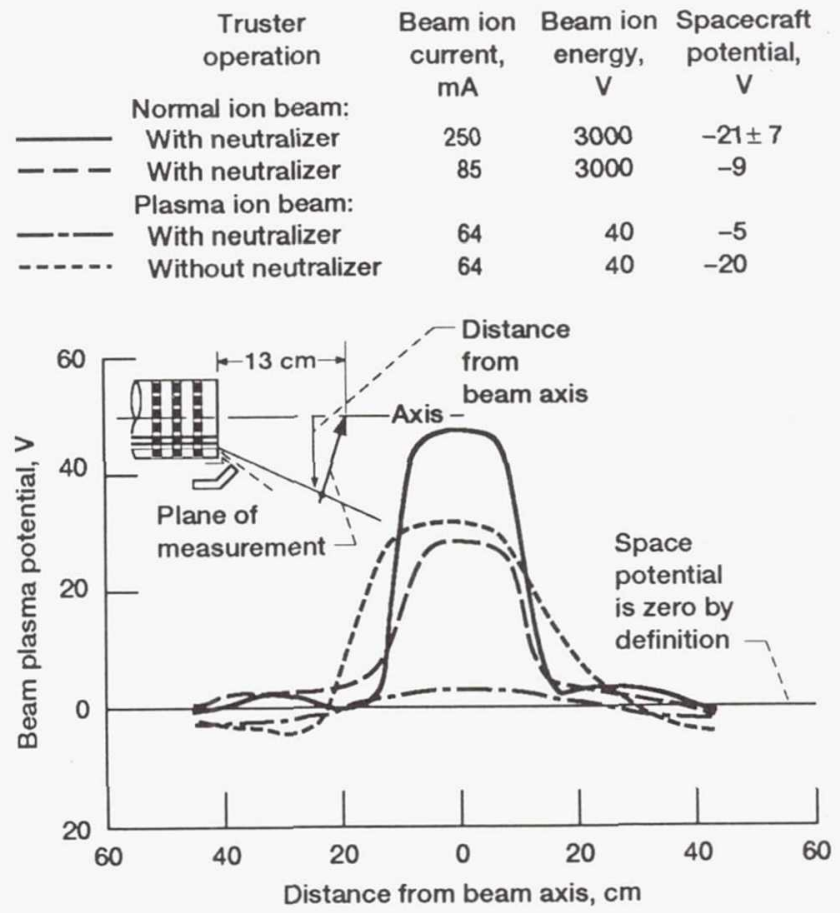

Figure 20.-Beam plasma potential profiles for various ion beam conditions. The 250-mA data were taken in 1970 . The $85-\mathrm{mA}$ data were taken in 1974 and 1979. The plasma beam mode data, $64 \mathrm{~mA}$, were taken in 1980. 
dispersion of the ions so that the beam density would be reduced to the ambient density at the SERT II altitude of $1000 \mathrm{~km}$, namely $10^{10}$ ions $/ \mathrm{m}^{3}$. The SERT II tests of $1979^{19}$ indicated that space electrons might be drawn into the ion beam any place along its length. The neutralizer on the spacecraft only needed to emit a few milliamperes of electrons into the beam to maintain beam neutrality. The balance of electrons (the full beam current) could be injected anywhere into the space plasma to maintain spacecraft neutrality. Results noted in the earlier section "Cross Neutralization Test, 1979" indicated that the balance of electrons could come from the neutralizer of the other thruster. Furthermore, the bias on either the near neutralizer or the distant neutralizer could control the spacecraft potential. ${ }^{19}$

\section{Low-Energy Plasma Efflux}

Most of the charge-exchange ions produced in the beam were accelerated $(0$ to $50 \mathrm{~V})$ radially outward and created most of the plasma that surrounded the ion beam and engulfed the nearby spacecraft. The results of Ref. 19 showed that the potential of the charge-exchange plasma outside the beam was always lower than the ion beam plasma potential but was strongly controlled by the neutralizer bias level. Negative bias could drive the charge-exchange plasma 10 to $30 \mathrm{~V}$ below the space plasma potential. A modeling of the charge-exchange plasma is presented in Ref. 65 and of its interaction with the solar array in Ref. 63.

Reference 19 gives results on the effect of spacecraft potential due to exposed solar array connector surfaces interacting with the charge-exchange plasma and with the space plasma for a "quiet" (ion thruster off) spacecraft. Two electrical configurations of the solar array were possible. For one, the solar array center tap was grounded to the spacecraft (with exposed connectors at $0 \pm 36 \mathrm{~V}$ ). The other was with the negative side of the solar array grounded (connectors at 0 to $72 \mathrm{~V}$ ). With quiet spacecraft operation the spacecraft potential was controlled by a balance of ram, attracted space electrons, and photoemission of electrons. For the center-tap solar array the spacecraft potential was $-7 \mathrm{~V}$, but with the negative end grounded, the spacecraft potential was driven to $-29 \mathrm{~V}$. If the low beam thruster or neutralizer was operating, the plasma thereby produced was a good electrical contactor to space plasma, and the spacecraft potential was the same, $-9 \mathrm{~V}$, for either electrical configuration of the solar array.

Another source of low-energy plasma efflux on the SERT II spacecraft was either thruster when operated in the plasma thrust mode (main discharge on, with no high voltage to accelerator grids). Details of the $40-\mathrm{V}$ plasma plume are presented in Refs. 19 and 20. The beam probe on thruster 2 was used to measure plasma potential variations downstream of thruster 2 with only the thruster 2 neutralizer on. ${ }^{15}$ The plasma potential was $\pm 5 \mathrm{~V}$ near the thruster beam axis and $-1 \mathrm{~V}$ on the wing (outside the beam (see
Fig. 20)). The operating neutralizer "locked" the spacecraft potential to near $(-4 \pm 4 \mathrm{~V})$ the space plasma potential. With no neutralizer plasma the spacecraft floated at -5 to $-22 \mathrm{~V}$ potential depending on orbital position. For negative biases of -23 and $-35 \mathrm{~V}$ on neutralizer 2 the on-axis plasma potential was near zero. The wing area plasma potential was -2 to $-10 \mathrm{~V}$ and -10 to $-15 \mathrm{~V}$ for neutralizer biases of -23 and $-35 \mathrm{~V}$, respectively. Positive neutralizer bias was not available because the V9 power supply design required a net neutralizer emission to generate a positive bias voltage. An earlier section of this report gives the thrust produced by this low-energy plasma.

\section{Electromagnetic Field Effluxes}

Each ion thruster contained eight permanent bar magnets located between soft iron pole pieces and produced a maximum magnetic field inside the ion thruster of $3.5 \mathrm{mT}$ $(35 \mathrm{G})$. The magnetic field outside the ion thruster was much weaker. Measurements made with a single ion thruster indicated that the external magnetic field was equivalent to a magnet dipole of $2.7 \mathrm{Am}^{2}$ having an axis collinear with the ion thruster thrust axis. ${ }^{48}$ Precise measurements of magnetic field integral values outside a SERT II ion thruster were made by Kaufman ${ }^{65}$ and are shown in Fig. 21. The typical shape of the external magnetic field is shown in Fig. 22.

The two flight ion thrusters had bar magnets sets that were aligned with opposite magnetic polarity between each ion thruster. This reduced the yaw-axis dipole magnetic

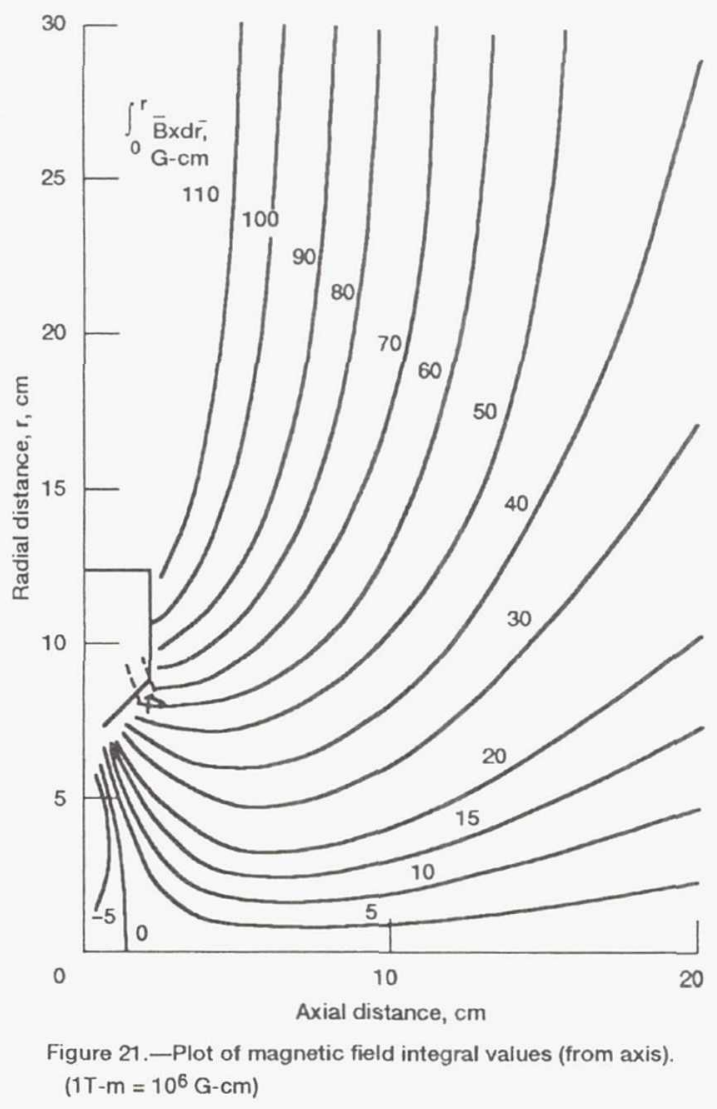




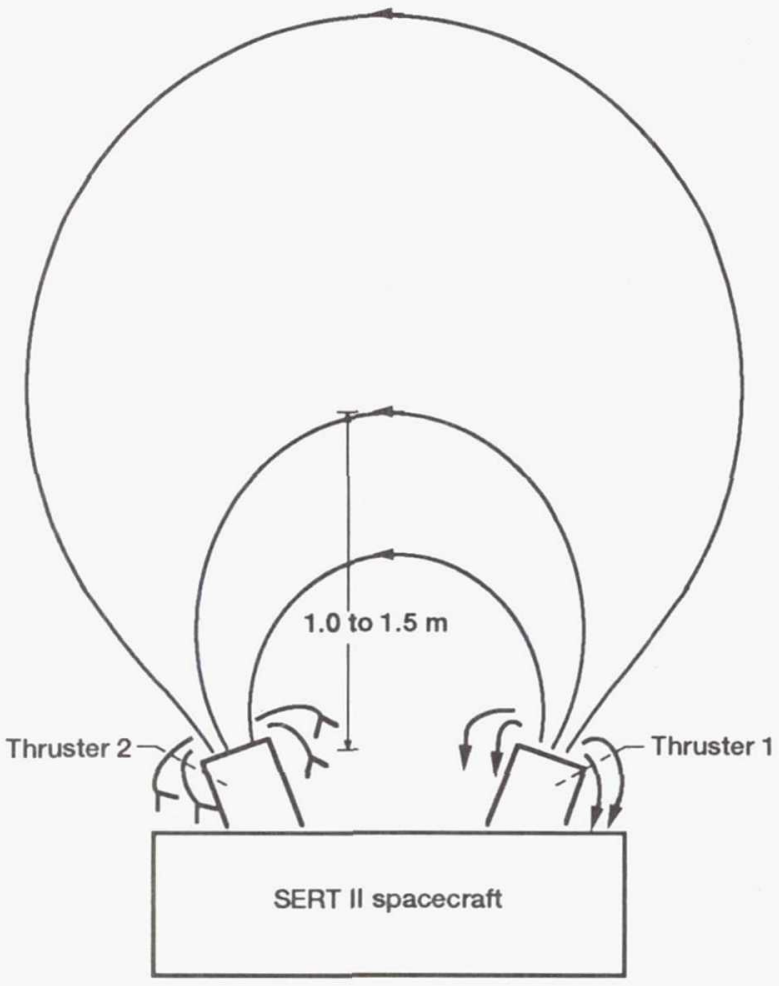

Figure 22. - Sketch of overall external magnetic field shape.

component to zero. (See Fig. 2 for axis illustration. The yaw axis was pointed toward Earth; the roll axis was in the plane of the paper and pointed in the orbital velocity direction; the pitch axis was perpendicular to the paper; and all axes passed through the spacecraft center of mass.) The roll-axis magnetic dipole component was $7.6 \mathrm{Am}^{2}$. Two permanent magnets were attached to the spacecraft to reduce the spacecraft roll-axis dipole component that was caused by the ion thruster magnets.

The spacecraft and the spacecraft support unit were completely assembled (including two ion thrusters) to make the following measurements: Magnetic field measurements made in both powered and unpowered states determined the contribution of any uncompensated current loops to the overall magnetic dipole. The ion thruster dipole field dominated the measurements, which were 0 to 10 times larger than the magnetic dipole caused by current loops in the powered spacecraft. The permanent magnet dipoles for the assembled spacecraft were $-2.3,-1.1$, and $2.3 \mathrm{Am}^{2}$, respectively, for the roll, pitch, and yaw axes. Additional magnetic dipole fields were produced by the Agena vehicle and the solar array current loops. These dipole fields could not be measured and manufacturer's estimates were used to provide a worst-case dipole for the total spacecraft of $-9.8 \mathrm{Am}^{2}$ (roll), -8.2 $\mathrm{Am}^{2}$ (pitch), and $-9.8 \mathrm{Am}^{2}$ (yaw). The strength of a disturbing magnet torque is the vector crossproduct of the dipole strength with the Earth's local magnetic field. These disturbing torques were less than the gravity-gradient restoring torques of the spacecraft and were not a significant factor in spacecraft attitude control.
No conducted or radiated EMI tests were performed with the SERT II spacecraft. The only EMI specification was that all spacecraft components operate compatibly without EMI problems. Even when the overcurrent from the power conditioner high-voltage supplies cycled continuously for $2 \mathrm{hr}$ during a ground test, only one EMI problem developed. That problem was caused by conducted EMI reaching and disrupting the telemetry system. The solution was to add small filters in each telemetry line from the power conditioner. After these filters were added, no EMI problems were encountered in ground or space operation of either ion thruster system or any other spacecraft component. As mentioned earlier, a radiofrequency detector failed to measure any RF noise from the ion beam or any ion thruster discharge that was greater than the Earth background RF noise.

For all purchased electrical equipment the contractor was responsible that the equipment meet the following radiated EMI specifications: The design levels, interference control, test plans, and testing were in accordance with MIL-STD$461,-462,-463$, with the allowable characteristics in accordance with the environment category of an unnamed airborne system, such as missiles and orbiting satellites.

\section{Concluding Remarks}

It is extremely satisfying to report a genuine space success story. The SERT II mission, which was designed for a $11 / 2$-year life, is still functioning today, after more than 21 years in space. The ion thruster only operated 5 months in space during 1970 against a 6-month goal and the SERT II mission was thereby officially labeled "a failure." The failure, which could only have been discovered in the zero gravity of space, could easily be corrected by several means, once it was known. In fact, the failure was so marginal that gentle spinning of the spacecraft to control its attitude in 1973 dislodged the metal web fragment that caused the failure and restored one of the ion thrusters to normal operation.

The major results of the mission were the operation of two ion thruster systems in space for 3781 and $2011 \mathrm{hr}$, respectively; the measurement of ion thruster thrust and efficiency in space and its agreement with values predicted from ground tests; the lack of any negative effect on the spacecraft from the ion thruster fields or the emitted particles; the successful restart of the ion thruster discharges for 240 and 300 times (thrusters 1 and 2, respectively) during 1969 to 1981; the normal operation of the propellant feed systems until the propellant tanks became empty in 1980 and 1981 (the empty tanks prevented the accumulation of more ion thruster discharge restarts); the extended mission operation of the ion thruster power conditioning units to 1991 for 15000 and $17900 \mathrm{hr}$, respectively; the demonstration of space ion beam neutralization by an electron emitter located $1 \mathrm{~m}$ away from the ion beam; the 
21-year data accumulation from the reflector erosion experiment, which indicated low micrometeoroid flux in the $1000-\mathrm{km}$ orbit of the spacecraft; data on the space radiation degradation of $\mathrm{N}$-on-P silicon solar cells after 21 years; and the success of the spacecraft systems, which for 21 years maintained the command, attitude control, thermal management, and data telemetry of the spacecraft.

\section{$\underline{\text { References }}$}

\section{$\underline{\text { Ion Thruster System }}$}

1. Bechthel, R.T., "Discharge Chamber Optimization of the SERT II Thruster," AIAA Paper 67-668, Sept. 1967.

2. Kerslake, W.R., Byers, D.C., and Staggs, J.F., "SERT II Experimental Thruster System," AIAA Paper 67-700, Sept. 1967. (Sec also NASA TM X-52323, 1967.)

3. Bechtel, R.T, Csiky, G.A., and Byers, D.C., "Performance of a 15-Centimeter Diameter, Hollow-Cathode Kaufman Thruster," AIAA Paper 68-88, Jan. 1968. (See also NASA TM X-52376, 1968.)

4. Rawlin, V.K. and Kerslake, W.R., "SERT II: Durability of the Hollow Cathode and Future Applications of Hollow Cathodes," Journal of Spacecraft and Rockets, Vol. 7, Jan. 1970, pp. 14-20. (See also NASA TM X-52532, 1969.)

5. Hoffman, A.C., Bauer, S.F., Briggs, R.W., Swiderski, E.F., and Weger, R.M., "Power Conditioning Development for the SERT II Ion Thruster," Proceedings of the 4th Intersociety Energy Conversion Engineering Conference, American Institute of Chemical Engineers, 1969, pp. 975-986.

6. Kerslake, W.R., Byers, D.C., and Staggs, J.F., "SERT II: Mission and Expcriments," Journal of Spacecraft and Rockets, Vol. 7, Jan. 1970, pp. 4-6. (Also AIAA Paper 67-700, Jan. 1970.)

7. Kerslake, W.R., Byers, D.C., Rawlin, V.K., Jones, S.G., and Berkopec, F.D., "Flight and Ground Performance of the SERT II Thruster." AIAA Paper 70-1125, Aug. 1970. (See also NASA TM $\mathrm{X}-52848,1970$.)

8. McKinney, H.F., McDaniels, J.L., and Dutton, R.A., "8000-Hour Life Test of an Electron Bombardment Mercury Ion Thruster System for SERT II," NASA CR-72789, 1970.

9. Byers, D.C. and Staggs, J.F., "SERT II Thruster System Ground Testing," Journal of Spacecraft and Rockets, Vol. 7, Jan. 1970, pp. 7-14.

10. Bagwell, J.W., Hoffman, A.C., Leser, R.J., Reader, K.F., Stover, J.B., and Vasicek, R. W., "Review of SERT II Power Conditioning," NASA TM X-2085, 1971. (Also NASA TM X-52858, 1970.)

11. Bagwell, J.W., "SERT II: Power Conditioning," Journal of Spacecraft and Rockets, Vol. 8, Mar. 1971, pp. 225-230.

12. Kerslake, W.R., Goldman, R. G., and Nieberding, W.C., "SERT II: Mission, Thruster Performance, and In-Flight Measurements," Journal of Spacecraft and Rockets, Vol. 8, Mar. 1971, pp. 213-224.

13. Zavesky, R.J. and Hurst, E.B., "Mechanical Design of SERT II Thruster System," NASA TM X-2518, 1972.
14. Kerslake, W.R. and Finke, R.C., "SERT II Hollow Cathode Multiple Restarts in Space," NASA TM X-68292, 1973.

15. Kerslake, W.R. and Finke, R.C., "SERT II Spacecraft Thruster Restart 1974," Journal of Spacecraft and Rockets, Vol. 12, Dec. 1975, pp. 780-781. (See also NASA TM X-71651, 1975.)

16. Kerslake, W.R., "Status of SERT II Thrusters and Spacecraft - 1976," AlAA Paper 76-1061, Nov. 1976. (Sec also NASA TM X-73501, 1976.)

17. Kerslake, W.R. and Ignaczak, L.R., "Status of SERT II Spacecraft and Ion Thrusters - 1978," NASA TM-78827, 1978.

18. Kerslake, W.R. and Ignaczak, L.R., "SERT II 1979 Extended-Flight Thruster System Performance," AIAA Paper 79-2063, Oct. 1979. (See also NASA TM-79256, 1979.)

19. Kerslake, W.R. and Domitz, S., "Neutralization Tests on the SERT II Spacecraft," AIAA Paper 79-2064, Oct. 1979. (See also NASA TM-79271, 1979.)

20. Kerslake, W.R. and Ignaczak, L.R., "SERT II 1980 Extended-Flight Thruster Experiments," AlAA Paper 81-0665, Apr. 1981. (Sce also NASA TM-81685, 1981.)

21. Kerslake, W.R., "SERT II Thrusters - Still Ticking After Eleven Years," NASA TM X-81774, 1981.

\section{Auxiliary Spacecraft Experiments}

22. Vernon, R.H. and Daley, H.L., "Emissive Probes for Plasma Potential Measurements on the SERT II Spacecraft," AIAA Paper 69-272, Mar. 1969.

23. Nieberding, W.C., Lesco, D.J., and Berkopec, F.D., "Comparative In-Flight Thrust Measurements of the SERT II Ion Thruster," NASA TN D-6008, 1970. (Also NASA TM X-52839, 1970.)

24. Jones, S.G., Staskus, J.V., and Byers, D.C., "Preliminary Results of SERT II Spacecraft Potential Measurements Using Hot Wire Emissive Probes," AIAA Paper 70-1127, Aug. 1970. (See also NASA TM X-2083, 1970.)

25. Staskus, J.V. and Burns, R.J., "Deposition of Ion Thruster Effluents on SERT II Spacecraft Surfaces," NASA TM X-2084, 1970. (Also NASA TM X-52860, 1970.)

26. Richley, E.A. and Reynolds, T.W., "Condensation on Spacecraft Surfaces Downstream of a Kaufman Thruster," NASA TM X-52746, 1970.

27. Provencher, C.E., Renz, D.D., and Hurst, E.B., "Actuator Design for the SERT II Beam Probe," NASA TM X-2190, 1971.

28. Steven, J.N., "Determination of the Extent of Ion Thruster Efflux Deposition on Spacecraft Surfaces From the SERT II Flight Thermal Data," AIAA Paper 75-356, Mar. 1975. (See also NASA TM X-71642, 1975.)

29. Mirtich, M.J., Mark, H., and Kerslake, W.R., "The Effect of Eleven Years in Earth Orbit on a Mirror Surface," Journal of Spacecraft and Rockets, Vol. 27, May-Junc 1990, pp. 258-266.

30. Mirtich, M.J. and Kerslake, W.R., "The Effect of the Near Earth Micrometeoroid Environment on a Mirror Surface After 20 Years in Space," Materials Degradation in Low Earth Orbit (LEO), Minerals, Metals, and Materials Society, Warrendale, PA, 1990, pp. 107-122. 


\section{Spacecraft and Components}

31. Everson, C.T., "SERT II Solar Array," NASA CR-72706, 1968.

32. Hawersaat, W., "Development of the SERT II Spacecraft Support Unit, Summary Report" NASA CR-72466, 1970.

33. Stevens, N.J. and Smolak, G.R., "Design of the Passive Thermal Control System of the SERT II Satellite," Thermodynamics and Thermophysics of Space Flight. Lockheed Missiles and Space Co., Palo Alto, CA, 1970, pp. 101-120. (See also NASA TM X-52744, 1970.)

34. Rulis, R.J., "SERT II: Design Requirements for Integrating an Electric Propulsion System into a Spacecraft," Journal of Spacecraft and Rockets, Vol. 8, Mar. 1971, pp. 209-213. (See also NASA TM X-2082, 1970, and AlAA Paper 70-1123, Aug. 1970.)

35. Goldman, R.G. and Hawersaat, W.H., "Description of the SERT II Spacecraft and Mission," AIAA Paper 70-1124, Aug. 1970. (See also NASA TM X-2087, 1970.)

36. Renz, D.D., Zavesky, R.J., and Hurst, E.B., "Evaluation of Failure Modes and Redesign of SERT II Gimbal Pin Puller," NASA TM $\mathrm{X}-2128,1970$.

37. Stevens, N.J. and Smolak, G.R., "Report on the Flight Performance of the Z-93 White Paint Used in the SERT II Thermal Control System," AIAA Paper 71-455, Apr. 1971. (See also NASA TM X-52970, 1971.)

38. Stevens, N.J., "Application of SERT II Thermal Control Coatings," NASA TM X-2155, 1971.

39. Conroy, M.J., "STADAN-NASCOM Support for the SERT II Mission," NASA TM X-2178, 1971.

40. Zakrajsek, R.J. and Domino, E.J., "SERT II Communications System Design," NASA TM X-2189, 1971.

41. DePauw, J.F. and Ignaczak, L.R., "Qualification and Testing of an Electrically Propelled Spacecraft-SERT II," NASA TM X-2199, 1971.

42. Wozencraft, J.G., "SERT II Control Center," NASA TM X-2217, 1971.

43. Cake, J.E. and Regetz, J.D., "Effect of Low Thrust and Earth Oblateness Orbit Perturbations on the Determination of the Launch Window for the SERT II Mission," NASA TM X-2233, 1971.

44. Krawczyk, R.J., "SERT II Spacecraft Electrical Power System," NASA TM X-2234, 1971.

45. Siegert, C.E., "Development History and Flight Performance of SERT 11 Solar Array," NASA TM X-2246, 1971.

46. "Thorad-Agena Ascent and Agena Orbital Performance Evaluation for Space Electric Rocket Test II (SERT II) Mission,” NASA TM $\mathrm{X}-2188,1971$.

47. Sharp, G.R., "Design of SERT Il Spacecraft Structures," NASA TM X-2301, 1971.

48. LeRoy, B.E., Regetz, J.D., and Lovell, R.R., "SERT II Spacecraft Attitude Response," NASA TM X-2324, 1971.
49. Smolak, G.R. and Stevens, N.J., "Validation of SERT II Thermal Analytical Techniques by Thermal Vacuum Testing of the Prototype Satellite," NASA TN D-6421, 1971.

50. Zavesky, R.J. and Hurst, E.B., "SERT II Gimbal System," NASA TM X-2427, 1971.

51. Ignaczak, L.R., Stevens, N.J., and LeRoy, B.E., "Performance of the SERT II Spacecraft After 4 1/2 Years in Space," NASA TM X-71632, 1974.

\section{Supporting References}

52. Cybulski, R.J., Shellhammer, D.M., Lovell, R.R., Domino, E.J., and Kotnik, J.T., "Results from SERT I Ion Rocket Flight Test," NASA TN D-2718, 1965.

53. Gold, H., Rulis, R.J., Maruna, F.A., and Hawersaat, W.H., "Description and Operation of Spacecraft SERT I Ion Thruster Flight Test," NASA TM X-1077, 1965.

54. Finke, R.C., Holmes, A.D., and Keller, T.A., "Space Environment Facility for Electric Propulsion System Research," NASA TN D-2774, 1965.

55. Nieberding, W.C. and Lovell, R. R., "Thrust Measurement of SERT I Ion Thrusters,” NASA TN D-3407, 1966.

56. Mark, H., Sommers, R.D., and Mirtich, M.J., "Effect on Surface Thermal Properties of Calibrated Exposure to Micrometeoroid Environment," AIAA Journal, Vol. 4, Oct. 1966, pp. 1811-1817. (See also NASA TM X-52056, 1965.)

57. Sellen, J.M., Jr. and Kemp, R.F., "Research on Ion Beam Diagnostics,” NASA CR-54692, 1966.

58. Staggs, J.F., Gula, W.P., and Kerslake, W.R., "Distribution of Neutral Atoms and Charge-Exchange lons Downstream of an Ion Thruster," Journal of Spacecraft and Rockets, Vol. 5, Feb. 1968, pp. 159-164. (See also NASA TM X-52259, 1967.)

59. Rawlin, V.K. and Pawlik, E.V.: "A Mercury Plasma-Bridge Neutralizer," Journal of Spacecraft and Rockets, Vol. 5, July 1968, pp. 814-820.

60. Bechtel, R.T., "Effect of Neutralizer Position on Accelerator Wear for a 30-Centimeter Diameter lon Bombardment Thruster," NASA TM X-67926, 1971.

61. Kerslake, W.R., "Design and Test of Porous-Tungsten Mercury Vaporizers," AIAA Paper 72-484, Apr. 1972. (See also NASA TN D-6782, 1972.)

62. Bechtel, R.T., "Performance of a Neutralizer for Electron Bombardment Thruster," AIAA Paper 72-207, Jan. 1972. (See also NASA TM X-67964, 1971.)

63. Kaufman, H.R., "Interaction of a Solar Array With an Ion Thruster Due to the Charge-Exchange Plasma," NASA CR-135099, 1976.

64. Byers, D.C., "Electron Bombardment Thruster Field and Particle Interfaces," Journal of Spacecraft and Rockets, Vol. 16, Sept.Oct. 1979 , pp. 289-301.

65. Kaufman H.R., "Plasma Physics Analysis of SERT II Operation," NASA CR-159814, 1980. 
66. Power, J.L., "Ground Correlation Investigation of Thruster/Spacecraft Interactions to be Measured on the IAPS Flights Test," Proceedings of the International Electric Propulsion Conference, Japan Society for Aeronautical and Space Sciences, 1984, pp. 266-285. (See also NASA TM-83598, 1984.)

67. Deininger, W.D., "Electric Propulsion Produced Environments and Possible Interactions With the SP-100 Power System," AIAA Paper 85-2046, Sept. 1985

68. Sovey, J.S., Carney, L.M., and Knowles, S.C., "Electromagnetic Emission Experiences Using Electric Propulsion Systems," Journal of Propulsion and Power, Vol. 5, Sept.-Oct. 1989, pp. 534-547.

69. Sovey, J., "NASA Experiences in Flight and Ground Testing of Ion Propulsion Systems," Intelsat Ion Propulsion Symposium for Communications Satellites, Monterey, CA, July 13, 1989, Session 2, Paper 3.
70. Fearn, D.G., "The UK-10 Ion Propulsion System Status and Applications," Intelsat Ion Propulsion Symposium for Communications Satellites, Monterey, CA, July 13, 1989, Session 1, Paper 3.

71. Kaufman, H., "Analysis of Charge-Exchange Ion Ficld Near Thruster," Intelsat Ion Propulsion Symposium for Communications Satcllites, Monterey, CA, July 13, 1989, Pancl 1, Paper 1.

72. Shaw, G.A.D. and Falconer, J.D., "SERT II: Solar Array Power System," Journal of Spacecraft and Rockets, Vol. 8, Mar. 1971, pp. 231-233.

73. Banks, B.A., Rawlin, V.K., Weigand, A.J., and Walker, J.C., Direct Thrust Measurement of a 30-cm Ion Thruster, AIAA Paper 75-340, Mar. 1975. (See also NASA TM X-71646, 1975.)

74. Maissed, C.J., and Glang, R., "Handbook of Thin Film Technology," McGraw-Hill, New York, 1970. 


\section{REPORT DOCUMENTATION PAGE}

Public reporting burden for this collection of information is estimated to average 1 hour per response, including the time for reviewing instructions, searching existing data sources, gathering and maintaining the data needed, and completing and reviewing the collection of information. Send comments regarding this burden estimate or any other aspect of this collection of information, including suggestions for reducing this burden, to Washington Headquarters Services, Directorate for information Operations and Reports, 1215 Jefferson Davis Highway, Suite 1204, Arlington, VA 22202-4302, and to the Office of Management and Budget, Paperwork Reduction Project (0704-0188), Washington, DC 20503.

\begin{tabular}{|l|l|l} 
1. AGENCY USE ONLY (Leave blank) & $\begin{array}{r}\text { 2. REPORT DATE } \\
1992\end{array}$ & $\begin{array}{r}\text { 3. REPORT TYPE AND DATES COVERED } \\
\text { Technical Memorandum }\end{array}$
\end{tabular}

4. TITLE AND SUBTITLE

5. FUNDING NUMBERS

Development and Flight History of SERT II Spacecraft

6. AUTHOR(S)

WU-506-42-31

William R. Kerslake and Louis R. Ignaczak

\section{PERFORMING ORGANIZATION NAME(S) AND ADDRESS(ES)}

National Aeronautics and Space Administration

Lewis Research Center

Cleveland, Ohio 44135-3191
8. PERFORMING ORGANIZATION REPORT NUMBER

E-6839
9. SPONSORING/MONITORING AGENCY NAMES(S) AND ADDRESS(ES)

National Aeronautics and Space Administration

Washington, D.C. 20546-0001
10. SPONSORING/MONITORING AGENCY REPORT NUMBER

NASA TM-105636

AIAA-92-3516

Corrected Copy

\section{SUPPLEMENTARY NOTES}

Prepared for the 28th Joint Propulsion Conference and Exhibit cosponsored by AIAA, SAE, ASME, and ASEE, Nashville, Tennessee, July 6-8, 1992. William R. Kerslake, Sverdrup Technology, Inc., Lewis Research Center Group, 2001 Aerospace Parkway, Brook Park, Ohio 44142; Louis R. Ignaczak, NASA Lewis Research Center. Responsible person, James Sovey, (216) 977-7454.

12a. DISTRIBUTION/AVAILABILITY STATEMENT

12b. DISTRIBUTION CODE

Unclassified - Unlimited

Subject Category 20

13. ABSTRACT (Maximum 200 words)

A 25-year historical review of the Space Electric Rocket Test II (SERT II) mission is presented. The Agena launch vehicle; the SERT II spacecraft; and mission-peculiar spacecraft hardware, including two ion thruster systems, are described. The 3 1/2-year development period, from 1966 to 1970, that was needed to design, fabricate, and qualify the ion thruster system and the supporting spacecraft components, is documented. Major testing of two ion thruster systems and related auxiliary experiments that were conducted in space after the February 3, 1970, launch are reviewed. Extended ion thruster restarts from 1973 to 1981 are reported, in addition to cross-neutralization tests. Tests of a reflector erosion experiment were continued in 1989 to 1991. The continuing performance of spacecraft subsystems, including the solar arrays, over the 1970-1991 period is summarized. Finally, the knowledge of thruster-spacecraft interactions learned from SERT II is listed.

\section{SUBJECT TERMS}

Electric propulsion; Space propulsion; Plasma applications; Spacecraft

15. NUMBER OF PAGES 50

16. PRICE CODE

$\mathrm{AO3}$

17. SECURITY CLASSIFICATION OF REPORT

Unclassified

18. SECURITY CLASSIFICATION OF THIS PAGE

Unclassified
19. SECURITY CLASSIFICATION OF ABSTRACT

Unclassified 
National Aeronautics and Space Administration

Lewis Research Center

Cleveland, Ohio 44135

Official Business

Penalty for Private Use $\mathbf{8 3 0 0}$
FOURTH CLASS MAIL

ADDRESS CORRECTION REQUESTED
|||||

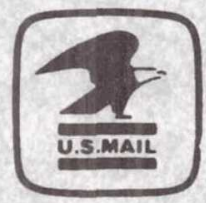

Postage and Fees Paid National Aeronautics and

Space Administration NASA. 451 